\title{
Active Consumerism: Measuring the Importance of Crowdfunding Factors on Backers' Decisions to Financially Support Kickstarter Campaigns
}

Kevin M. Duvall

West Virginia University

Follow this and additional works at: https://researchrepository.wvu.edu/etd

\section{Recommended Citation}

Duvall, Kevin M., "Active Consumerism: Measuring the Importance of Crowdfunding Factors on Backers' Decisions to Financially Support Kickstarter Campaigns" (2014). Graduate Theses, Dissertations, and Problem Reports. 293.

https://researchrepository.wvu.edu/etd/293

This Thesis is protected by copyright and/or related rights. It has been brought to you by the The Research Repository @ WVU with permission from the rights-holder(s). You are free to use this Thesis in any way that is permitted by the copyright and related rights legislation that applies to your use. For other uses you must obtain permission from the rights-holder(s) directly, unless additional rights are indicated by a Creative Commons license in the record and/ or on the work itself. This Thesis has been accepted for inclusion in WVU Graduate Theses, Dissertations, and Problem Reports collection by an authorized administrator of The Research Repository @ WVU. For more information, please contact researchrepository@mail.wvu.edu. 
Active Consumerism:

Measuring the Importance of Crowdfunding Factors on Backers' Decisions to Financially Support Kickstarter Campaigns

Kevin M. Duvall

\author{
Thesis Submitted to the \\ Reed College of Media \\ at West Virginia University \\ in partial fulfillment of the requirements \\ for the degree of \\ Master of Science \\ in \\ Journalism
}

Rita F. Colistra, Ph.D., Chair

Geah N. Pressgrove, Ph.D.

Steve Urbanski, Ph.D.

Elizabeth L. Cohen, Ph.D.

Department of Journalism

Morgantown, West Virginia

2014

Keywords: Kickstarter, crowdfunding, crowdsourcing, participatory culture, collaborative problem-solving

C) 2014

Kevin M. Duvall

ALL RIGHTS RESERVED 


\title{
ABSTRACT \\ Active Consumerism: \\ Measuring the Importance of Crowdfunding Factors on Backers' Decisions to Financially Support Kickstarter Campaigns
}

\author{
Kevin M. Duvall
}

The purpose of this research is to explore what factors of projects on Kickstarter, a popular crowdfunding website, are most influential in the decision to financially support a project. This study used triangulated research methods to explore these factors. An online survey of people who had financially contributed to one or more Kickstarter projects was conducted to better understand what aspects of projects backers found most important. A series of in-depth interviews with people who have financially supported one or more Kickstarter campaigns was also conducted to add perspective about the reasons people had for backing the campaigns. Findings suggest that Kickstarter has several distinct benefits for those who support its projects and offers them an experience that traditional channels of production cannot. Findings also suggest that Kickstarter backers feel involved in the process of creating the projects they support, and that backers are willing to take risks to see projects that are important to them come to fruition. The information gathered in this research will help to improve understanding of the attitudes that drive Kickstarter, which have implications for other crowdfunding platforms. This information will also help Kickstarter project creators know what aspects of their campaigns prospective supporters find most important. 


\section{TABLE OF CONTENTS}

1. Introduction 1

2. Literature Review 6

$\begin{array}{lr}\text { Crowdsourcing } & 6\end{array}$

Crowdfunding as a Nonprofit Effort 7

$\begin{array}{ll}\text { Crowdfunding as Business } & 10\end{array}$

The Role of Sharing Projects 13

$\begin{array}{ll}\text { Participatory Culture } & 15\end{array}$

Grunig and Hunt's Four Models of Public Relations 16

3. Research Questions 19

4. Methods 23

Survey Data-Gathering Process 23

Survey Implementation Procedures 25

Survey Instrument 26

About the Respondents 27

Operationalization of Variables 30

In-Depth Interview Data-Gathering Process 35

Interview Implementation Procedures $\quad 35$

Interview Guide 36

About the Participants 37

$\begin{array}{ll}\text { Interview Data Analysis } & 37\end{array}$

5. Results 39

Survey Results 39 
Localism

Involvement in the Creative Process

Likelihood of Sharing Projects

Rewards

Accountability

Influence of Education and Income

Most Common Reasons for Backing

Backers' Favorite Projects

$\begin{array}{ll}\text { Interview Results } & 51\end{array}$

$\begin{array}{ll}\text { Localism } & 51\end{array}$

Involvement in the Creative Process 52

Likelihood of Sharing Projects $\quad 54$

$\begin{array}{ll}\text { Rewards } & 56\end{array}$

$\begin{array}{ll}\text { Accountability } & 58\end{array}$

Most Common Reasons for Backing and Favorite Projects $\quad 61$

Summary of Key Findings 63

$\begin{array}{ll}\text { 6. Discussion } & 64\end{array}$

$\begin{array}{ll}\text { Localism } & 64\end{array}$

Creative Participation and Communication with Creators 66

$\begin{array}{ll}\text { The Importance of Sharing Projects } & 67\end{array}$

$\begin{array}{lr}\text { Participatory Culture } & 68\end{array}$

$\begin{array}{ll}\text { Rewards } & 69\end{array}$

$\begin{array}{ll}\text { Accountability } & 70\end{array}$ 
$\begin{array}{ll}\text { 7. References } & 77\end{array}$

8. Appendix A: Consent Form for Survey 81

9. Appendix B: Survey Instrument 82

10. Appendix C: Consent Form for Interview 88

11. Appendix D: Interview Guide 90

13. Appendix E: Sample Communications 93

14. Appendix F: Survey Demographic Information 96

15. Appendix G: Qualitative Survey Responses 103

16. Appendix H: Interview Transcripts 129 


\section{CHAPTER 1: INTRODUCTION}

As user-generated online content has grown, crowdfunding websites, such as Kickstarter, IndieGoGo, GoFundMe, and RocketHub, have become increasingly popular outlets for financing independent projects. Although the details of how crowdfunding platforms work vary from site to site, they typically consist of a project creator posting a pitch for a project (e.g., a film, a book, or a news story) on a crowdfunding website, containing an explanation (often with a video) of what he or she wants to do in creating the project and what the final product will be. Then, most of the time, creators offer their contributors (called "backers" on Kickstarter) rewards for different donation levels. For example, a backer who gives $\$ 20$ dollars to a film project might have his or her name in a special "thank you" section of the film's credits; a backer who gives $\$ 50$ might receive a DVD copy of the movie. Creators set a fundraising goal (a dollar amount) and start and end dates for their campaigns. They generally solicit contributions through their personal social networks and encourage their backers to share the projects with people they know. After the end date, no more funds can be contributed. Creators may only receive funds if their projects reach their goals, or they may be allowed to keep all money pledged, depending on the site. When creators complete the projects and rewards, they are sent to backers.

One of the most prominent crowdfunding sites is Kickstarter, which was launched in 2009. Kickstarter is a for-profit company that takes a 5\% fee from every successfully funded campaign (Kickstarter, 2013). Creators using Kickstarter do not receive any of the pledged funds if they do not reach their fundraising goal, and the funds pledged are never transferred from the backers to the creators. Kickstarter's biggest year to date was 2013, 
when projects on the site raised $\$ 480$ million in pledges, marking a 50\% increase over 2012 (Nicks, 2014).

Some Kickstarter projects have become successful in their respective industries and have been headed by prominent creators. For example, in April 2014, musician Neil Young raised \$6.2 million for a high-resolution portable digital music player called Pono (Gross, 2014). One year earlier, Rob Thomas, creator of the TV series Veronica Mars, raised 5.7 million to make a feature film continuing the show's story, which was ultimately released in March 2014 (John, 2014). Other Kickstarter-funded films have received attention from prestigious film festivals and award shows. At the 2012 Sundance Festival, for example, approximately $10 \%$ of the films shown were funded through Kickstarter, and one documentary, Detropia, was nominated for an Academy Award in 2013 (Blair, 2013). Kickstarter projects have also been financially successful after their release, such as musician Amanda Palmer's Kickstarter-funded 2012 album, Theatre of Evil, which debuted at number 10 on the Billboard 200 chart (Caulfield, 2012). In addition to being a viable outlet for creating widely popular media forms, Kickstarter has been a successful tool for producing more niche types of projects. For example, the 2013 Will Eisner Comic Industry Awards nominated “... at least two Kickstarter campaigns this year" (Blake, para. 7, 2013). These examples demonstrate that crowdfunded projects have the potential to achieve the same level of attention and acclaim as more established, traditional means of funding projects.

Despite crowdfunding's rising influence in creative industries, there are still issues over its uncertainties. A major concern is the lack of accountability on the part of crowdfunding sites to make creators finish their projects to the backers' liking, or at all. 
Amanda Palmer raised $\$ 1.2$ million (with a $\$ 100,000$ goal) for her new album. Though Palmer completed and released the album, critics raised questions about how she spent the money (e.g. spending more than necessary on the CDs and records that were sent to backers) (Jefferson, 2012). In a September 2012 interview with National Public Radio, Julie Uhrman, creator of the Kickstarter campaign for a video game system called Ouya that received $\$ 8.6$ million (with a $\$ 950,000$ goal), showed further confusion about the issue. When asked if she would return the funds if she were not able to complete the project, Uhrman said she did not know if Kickstarter required her to, but “... from a doing-the-right-thing perspective, we will treat our backers the best possible way" (Shahani, para. 15, 2012). The Ouya was ultimately released in June 2013. Continuing the issue of restitution, Rob Thomas offered backers who contributed $\$ 35$ or more (the pledge amount required to received a digital copy of the finished film) full or partial refunds to Veronica Mars backers who had issues with their digital copies of the movie, which backers could watch through the movie viewing website and mobile app Flixster. Some backers were dissatisfied with the quality of the video stream, and other were unable to access it; backers who informed Flixster's customer service that they had to purchase a digital copy through iTunes, Amazon, or other streaming services to see the movie were offered refunds as compensation for their expenditures (Grow, 2014).

In response to these concerns, Kickstarter representatives contended that taking chances on the success or failure of projects is necessary for encouraging creative projects that might be too risky for traditional companies, and said that the backers “... decide the validity and worthiness of a project by whether they decide to fund it" (Chen et al., para. 5, 2012). Company officials also explained that Kickstarter requires its 
creators to complete their projects and has provisions for backers to seek restitution. However, backers wanting restitution must seek action against the creators and not the site because the site is the intermediary of the transaction between the backer and the creator. In other words, Kickstarter transfers funds but does not possess them (Chen et al., 2012).

Past research about crowdfunding has shown a variety of reasons backers considered important in their decisions of whether they pledged money to a project. Some researchers found reasons that were important to many participants in their studies, such as feeling the projects were important to the backer or a larger society, (Aitamurto, 2011; Gobble, 2012; Ordanini et al., 2011). Researchers also found more controversial reasons, such as backers' desire to participate in the creative process (Aitamurto, 2011; Ordanini et al., 2011).

The purpose of this research is to measure backers' attitudes toward contributing to Kickstarter campaigns. Specifically, the goal is to determine what factors are most influential in people's decisions to give funds. Ultimately, the sustainability of the business model depends on creators' abilities to communicate with their potential backers. Therefore, this research could help influence future studies by showing more specific information about what backers want in choosing which campaigns to support. In determining what makes people want to support campaigns, this research can build upon the issues raised by past studies and suggest ways for creators to more effectively promote their campaigns and tell researchers more about the logic that motivates crowdsourcing. Beyond academic research, this study also has applied lessons. Kickstarter project creators could use the information in this study to learn more about 
what audiences want from Kickstarter campaigns. Prospective backers could learn about what makes contributing to Kickstarter projects a different kind of experience than buying a product or making a donation through a traditional production channel. 


\section{CHAPTER 2: LITERATURE REVIEW}

Because crowdfunding is a new, emerging platform, research on it is somewhat limited. At this point, researchers have examined crowdfunding largely in two ways: (1) as a fundraising tool for philanthropic efforts, and (2) as a business model for independent creators to finance projects that will, ideally, make money. Although the proposed research focuses on the business side of crowdfunding due to the commercial nature of Kickstarter, the philanthropic side also has value for analyzing how people respond to crowdfunding campaigns. The study of behaviors and attitudes toward crowdfunding can be grounded in the theories of participatory culture and bystander effects, as well as Grunig's Four Models of Public Relations. Each of these areas is discussed in the sections that follow.

\section{Crowdsourcing}

Crowdfunding is a type of crowdsourcing. In crowdsourcing efforts, companies or individuals assign tasks to wide audiences to accomplish a goal. Participants are rewarded in some way, from personal satisfaction to monetary gain. In using content analysis to form a definition of crowdsourcing, Estelles-Arolas and Gonzalez-Ladron-deGuevara (2012) found 40 different definitions of crowdsourcing and, based on the most frequently occurring words and concepts, formed a definition based on eight criteria: the crowd; the task at hand; what benefit the crowd obtains; the crowdsourcer (initiator of the crowdsourcing activity); what benefit the crowdsourcer obtains; the type of process (problem solving, production, etc.); the call to participate; and the medium used to crowdsource. Based on their findings, the authors concluded:

Crowdsourcing is a type of participative online activity in which an individual, an institution, a nonprofit organization, or company proposes to a group of 
individuals of varying knowledge, heterogeneity, and number, via a flexible open call, the voluntary undertaking of a task. The undertaking of the task, of variable complexity and modularity, and in which the crowd should participate bringing their work, money, knowledge and/or experience, always entails mutual benefit. The user will receive the satisfaction of a given type of need, be it economic, social recognition, self-esteem, or the development of individual skills, while the crowdsourcer will obtain and utilize to their advantage what the user has brought to the venture, whose form will depend on the type of activity undertaken. (Estelles-Arolas \& Gonzalez-Ladron-de-Guevara, 2012, p. 197).

As the Internet is the crowdsourcing medium, crowdsourcing has grown alongside the growth of Web 2.0. Gunes (2012) marks 2004 as the beginning of the Web 2.0 era, in which “... means and tools for interactive communication [have enabled] users to create user generated content and the passive browsers of the network [have] become the network itself' (p. 57). Gunes argues that the increase in user-generated content of Web 2.0 has turned consumers from passive to active, in that the participation of consumers in the production process gives consumers influence over the values used in creating content. Gunes (2012) further contends that crowdsourcing may yield better results than internal development within firms because a wider audience has a wider diversity of views and more effective ways to filter ideas from crowds. Like Estelles-Arolas and Gonzalez-Ladron-de-Guevara (2012), Gunes emphasizes the ability of crowdsourcing to provide mutual benefits between parties. As crowdfunding scholars have said, the success of crowdsourcing models depends on the willingness of the audience to participate, so the audience cannot work for the producers and get nothing in return (Ordanini et al., 2011;

Gobble, 2012; Balnaves, 2012).

\section{Crowdfunding as a Nonprofit Effort}

The role of the audience as participants in creating work can be seen in nonprofit crowdfunding projects. In nonprofit campaigns, financial contributors may or may not 
receive physical rewards for donations; they may have only the satisfaction of donating. For some donors, this satisfaction may be enough to compel them to donate. Aitamurto (2011) examined Spot.Us, a crowdfunding site devoted to journalism, as a case study. On Spot.Us, freelance journalists post pitches for stories they want to produce (print, radio, or TV) and seek donations to fund the stories. When a journalist finishes a story, he or she publishes the story independently or sells it to a publisher. Most donors contribute money, but they can also donate talents, such as editing or fact-checking.

In her interviews with journalists and donors, Aitamurto (2011) found an imbalance of opinion about the subject of active consumers. Journalists felt a strong sense of connection to donors and wanted donors to take a more active role in creating the stories, whereas donors did not feel connected to the journalists and did not think they had enough knowledge about the story topics to make valuable contributions to the story process. Donors even said they cared more about the act of funding journalism, which they felt was an important part of society, than the finished stories themselves; some said they did not even read the final products. Based on this finding, Aitamurto suggested that journalists promote their pitches as causes to best appeal to the aspect of the process that most interested donors.

Following Aitamurto's (2011) research, Carvajal, Garcia-Aviles, and Gonzalez (2012) said the link between journalists and donors put the audience in the role of the media gatekeeper; because audiences chose which stories to donate to, they determined what information was released to the public. Participation is crucial to this idea because the audience is given more power than in traditional media models, in which the media 
outlets control media content. ${ }^{1}$ The authors also point out that nonprofit news outlets have become more prominent in recent years, after seeing major news outlets like The New York Times and The Washington Post use them as sources. One nonprofit news outlet, ProPublica, received a Pulitzer Prize. Carvajal, Garcia-Aviles, and Gonzalez (2012) feel the crowdfunding model should be sustainable for nonprofit news, due to the direct relationship with the audience and the rising importance of nonprofit news sources, but suggest this success may depend on whether traditional media outlets adopt the crowdfunding model. Though independent journalists and nonprofit organizations are willing to relinquish some control over media content to audiences, it remains to be seen whether larger media companies will trade control for audience numbers.

Sorensen (2012) shows an example of how audiences act as media gatekeepers. She examined data from annual reports on TV documentary films in the UK and found that crowdfunding had gained popularity as a way to fund documentaries. One reason for this change was that public TV spending and TV advertising revenue had declined in the last decade, while online advertising revenue increased. In a departure from traditional media business models, the audience members have more gatekeeping power than advertisers, so the audience's values have more influence on media content than the influence of financial interests. Consequently, Sorensen found, certain types of documentaries tended to be funded more often. For documentaries about current events and political issues, crowdfunding campaigns were popular and successful. For more expensive documentaries, such as nature, historical, and undercover investigative films, crowdfunding could not provide enough money; these films required fully funded

\footnotetext{
${ }^{1}$ To some extent, it can be said that audiences always have control over media content, because their ratings and purchases determine media's success, but researchers make the distinction that audiences now have more direct control over content than in the past.
} 
commissions and backing from broadcasters to be made. When the audience determines what projects are funded, it gains editorial power. That is, audiences might be inclined to fund documentaries that support their views and opt not to fund those that present opposite views.

\section{Crowdfunding as Business}

In crowdfunding business models, the audience is also the primary influencer of content, but instead of editorial influence on information, the audience determines the value of products. Although most crowdfunding ventures are not investments, in that contributors do not receive money in exchange for their initial funds, many are designed to create a product to be sold for profit. Thus, the expectations of returns are inherently different from nonprofit ventures. However, audience attitudes toward crowdfunded business ventures share some characteristics with those of philanthropic efforts. Ordanini, Miceli, Pizzetti, and Parasuraman (2011) examined three crowdfunding platforms for aspiring venture capitalists: Germany-based Sellaband, for funding music projects; UKbased Trampoline, for investing in a business software program called SONAR; and Italy-based Kapipal, for any project creators seek to fund, akin to Kickstarter. In their interviews with these sites' founders and managers, the authors found that campaign backers for Kapipal were strongly motivated by the desire to fund projects they felt were important.

This sentiment echoes the donors interviewed in the Spot.Us study. Unlike the Spot.Us donors, who did not want to participate actively in creating news stories, the Sellaband contributors (who receive royalties for promoting artists) were primarily motivated by the chance to be involved in the creative process. The Trampoline backers 
received financial returns on their investments, so their main motivation was monetary gain.

Attitudes toward the backer protection in crowdfunding business models also varied. The Jumpstart Our Business Startups (JOBS) Act of 2012 contained a provision formally recognizing crowdfunding as a means of commerce (Weisman, 2012). The JOBS Act was intended to encourage Americans to start small businesses by simplifying the process of doing so; crowdfunding is part of this simplification. Gobble (2012) found proponents of the JOBS Act agreed that the law would help people launch new businesses. She points to Eric Migicovsky as an example. Migicovsky created the Pebble E-Paper Watch (a watch that connects to an iPhone or Android device), the most successful Kickstarter project in the site's history, raising \$8.3 million with a goal of $\$ 100,000$. Before 2012, Migicovsky would not have been allowed to raise venture capital without giving his backers equity in his company. Opponents of crowdfunding and the JOBS Act contend that the laws weaken investor protection, opening backers to too much potential for fraud.

Gobble (2012) argues against this claim, saying most project creators need to start funding through their personal social networks, which would likely catch on quickly to fraud attempts. One must acknowledge, though, that some financial scandals have included friends and family members of the people purporting the schemes (such as the Bernie Madoff ponzi scheme), which raises questions about Gobble's claim. Kitchens (2012) also argues against the position that crowdfunding sets backers up for fraud, holding that the Act's required disclosure of financial information to investors and the 
Securities and Exchange Commission would minimize individual economic losses on crowdfunding platforms, thereby allowing crowdfunding to grow.

Another important aspect of crowdfunding as a business model is that it changes traditional channels of business transactions. Balnaves (2012) looked at how crowdfunding (as well as the related area of crowd investing) challenged the power of traditional banking. He argued that by using crowdfunding sites as intermediaries instead of banks, financing can be easier, faster, and more efficient for people seeking small loans and investment opportunities. The same idea can be applied to transactions between creators and consumers (that are not investments). Through crowdfunding, an author no longer needs to sell a book to a publishing company for the book to be released; he or she can sell the product directly to the buyer. In this model, the owner of the means of production (a publisher or studio) does not control the creation of the thing being sold (a book, film, or video game), removing (or at least decreasing) the need for an intermediate production channel.

For example, video game developer InXile Entertainment used Kickstarter to venture into self-publishing in 2012 with its game Wasteland 2. The company's founder, Brian Fargo, wanted to make a sequel to a game he created in 1988, but publishers were not interested in the style of gameplay he wanted for the game, so the project never came to fruition (Lammle, 2012). Fargo and InXile decided to use Kickstarter to fund the development and publishing of the game, rather than shopping the idea to third-party publishers (Lammle, 2012). The campaign for Wasteland 2 raised $\$ 2.9$ million (InXile Entertainment, 2012). InXile returned to Kickstarter to fund a second game, Torment: Tides Numenera, in 2013; the campaign raised nearly \$4.2 million (InXile Entertainment, 
2013). In addition, it took only six hours to reach its $\$ 900,000$ funding goal despite not having any in-game footage available to show potential backers (BBC News, 2013). The continued success of InXile's Kickstarter-funded games suggests that it has strengthened its brand name and business practice to such a degree it does not need a more famous and widely recognized publisher to bring buyers to its games. These successful Kickstarter campaigns allowed InXile to release its games not only to backers, but also for anyone to purchase.

\section{The Role of Sharing Projects}

Research has shown that it is important for project backers to share information about the campaigns they backed with others. Kuppuswamy and Bayus (2013) examined crowdfunding contributions through the social psychology theory of the bystander effect (Darley and Latane, 1968). This theory explains that an individual is less likely to help when others are present because he or she believes the others will provide the needed assistance. Based on this theory, Kuppswamy and Bayus (2013) found that crowdfunding projects were more likely to be backed near the end of the campaign time frame because potential backers saw that their funds were needed. Creators tended to receive contributions from their friends and family near the beginning of the campaign and from strangers as the end approached, with a period of slower donation growth in the middle of the time period. The authors also found that projects tended to be funded by large numbers of backers, each contributing small amounts of money, rather than by a few donors giving large sums.

Ordanini et al. (2011) observed similar tendencies. They called the beginning stage of crowdfunding campaigns the "friend-funding" phase, in which project creators 
depended on the people in their close social circles for funding (p. 457). Next, campaigns enter the "getting the crowd phase," in which creators must promote the project more heavily through social media and rely on the social networks of the initial backers for further visibility and contributions (p. 458). Many projects never leave this phase and accumulate funds slowly. After gathering a crowd, some projects go through an "engagement moment," in which the creator sees rapid growth in contributions (p. 458). Usually, people who contribute during this phase did not have any prior connection to the creator or the social networks of the original backers, but they became interested in the project when they read about it online. The final phase is the "race to be in" stage; as the project nears its end, contributions increase because backers know they do not have much time left to be a part of the project (p. 458).

These findings show the importance of timing in crowdfunding campaigns. It is essential for creators to gain a solid foundation of friends and family as backers in the early stage, not only for the funding itself but also for the project to appear viable to other potential backers who might pledge during the subsequent stages of the campaign. Promotion through social media is imperative because of its potential for reach and for its value as a crowdsourcing tool; a creator can promote a campaign through social media on his or her own, while encouraging backers to do the same on their own social media pages to create a snowball promotional effect. Creators need to promote their projects more heavily during the ending stage, and they need to emphasize in their communications that the new backers are necessary for the project to be completed and that the chance to be part of a unique project is expiring soon. 


\section{Participatory Culture}

The theoretical framework of participatory culture provides a basis for examining crowdfunding and the relationship between creator and consumer. Jenkins (2006) defines a participatory culture as one that has all of the following characteristics:

1. Relatively low barriers to artistic expression and civic engagement;

2. Strong support for creating and sharing one's creations with others;

3. Some type of informal mentorship, whereby what is known by the most experienced is passed along to novices;

4. An environment in which members believe that their contributions matter;

5. An environment in which members feel some degree of social connection with one another (in other words, members care what other people think about the works they have created). (p. 9)

Jenkins further explains that participatory culture shifts focus from individual expression to community involvement. Crowdfunding revolves around community involvement, as crowds determine the value of projects, and fulfills Jenkins's criteria. Business intermediaries are not needed (relatively low barriers to artistic expression and civic engagement). The community shows support through funding and other contributions to projects (strong support for creating and sharing one's creation with others). Crowdfunding sites have memberships (users have to register to post campaigns) and can look to past campaign creators for assistance (some type of informal mentorship). The previously discussed studies showed that project backers felt their contributions are important to the success of the project (an environment in which members feel their contributions matter), and in some cases, the backers felt a connection with the creators or a feeling of community with each other (an environment in which members feel some degree of social connection with one another). In addition to meeting these criteria, crowdfunding is an example of collaborative problem-solving, which Jenkins (2006) defines as “... working together in teams, formal and informal, to complete tasks and 
develop new knowledge" (p. 8). Although Jenkins's examples of collaborative problemsolving (e.g., Wikipedia and fan communities) center on gathering and spreading information, crowdfunding essentially works the same way. Participants in crowdfunding efforts work together to decide the merit of new products or information in the way participants in collaborative problem-solving teams work together to cultivate information related to filling a gap in knowledge.

In a related article, Jenkins and Deuze (2008) discuss convergence culture, in which audiences have a direct impact on corporate-controlled media because usergenerated media content has converged with traditional content. In other words, the audience is put into an active, rather than passive, role of co-creating content. The authors further argue that the "grassroots" channels of the Internet allow even more audience participation due to the ease of communication with media providers. Crowdfunding reflects the themes of convergence. Backers are actively involved in the production process through fundraising, and they can have direct influence over content through their decisions over which projects to fund. Additionally, crowdfunding sites have limited barriers to entry in allowing anyone to create a campaign, so an audience member with his or her own idea can easily become a creator. ${ }^{2}$

\section{Grunig's Four Models of Public Relations}

At its core, crowdfunding is a type of fundraising, whether the funds are being raised for a charitable cause or a business venture. Therefore, fundraising literature can help measure creators' and backers' attitudes toward crowdfunding. In a study of how nonprofit organizations communicate with audiences, Kelly (1994) applied Grunig and

\footnotetext{
${ }^{2}$ Crowdfunding sites have various degrees of quality control measures to ensure the legitimacy of campaigns, based on the site and the nature of the project, but compared to traditional means of production, these sites make it easier for an everyday citizen to start a charity or business venture.
} 
Hunt's Four Models of Public Relations to the organizations' fundraising communications. Grunig and Hunt (1984) outlined their four models as follows: (1) press agentry, in which public relations practitioners try to get their organization's name to the public through mass media; (2) public information, in which the public relations team's goal is to disseminate information about the organization through publicly released media such as press releases, brochures, and websites; (3) two-way asymmetrical, in which an organization seeks input from its publics through research, with the goal of getting the publics to agree with the company's desired image; and (4) two-way symmetrical, in which organizations communicate with publics, with the goal of mutual understanding between the two parties rather than persuasion. Kelly (1994) found that press agentry was the most common form of communication, and two-way symmetrical was the least. Kelly proposed that the industry would benefit from a shift toward two-way symmetrical communication.

In 2010, Kelly, Laskin, and Rosenstein conducted a study of two-way symmetrical communication in investor relations. Unlike Kelly’s 1994 study and other past studies (Grunig \& Grunig, 1992, as cited in Kelly, Laskin, \& Rosenstein, 2010), this study found that two-way symmetrical was the most common form of communication, followed by two-way asymmetrical. The authors' findings show important changes in the public relations industry that apply to new "investor" models like crowdfunding. Some past researchers thought of the two-way symmetrical model as an ideal rather than a real practice, but it now appears that companies - even large corporations - prefer the transparent investor relations method to the one-way promotion popular in earlier times. In today's public relations world, where publics want to interact with companies and not 
just listen to controlled information through the press, audience participation is crucial. Crowdfunding and other crowdsourcing efforts show two-way symmetrical communication in action. By relying on the audience for the startup costs and tasks, project creators are directly involving their publics in the production process. For example, developers at InXile Entertainment asked backers of Torment: Tides of Numenara for input about the game's production. Backers were asked to vote on what type of combat system they wanted to see in the game on a backer-exclusive online forum (Sykes, 2013). This kind of backer participation is an example of how Kickstarter allows a creator and audience to reach a mutual understanding about the content being created (Grunig and Hunt, 1984). This increased involvement gives backers an increase in power because they determine the project's success, which affects the potential for future projects and business startups. 


\section{CHAPTER 3: RESEARCH QUESTIONS}

As previously discussed, research on crowdfunding has focused primarily on defining the term (and related terms), testing the viability of crowdfunding platforms from a practical and legal perspective, and thinking about the implications of crowdfunding on traditional and emerging media. In trying to understand what crowdfunding is and how it works, researchers have found some conflicting information about what made backers want to contribute to campaigns. Some researchers have mentioned local interests as a reason why people might consider a campaign important. For example, Aitamurto (2011) found that people were most likely to donate to journalistic projects that affected them, or their friends and family members, on a personal level. Participants in that study said they were drawn to stories that were happening in the cities where they lived and worked. Ordanini et al. (2011) and Gobble (2012) emphasized the importance of project creators using personal social networks at the beginning of campaigns. In this stage, backers are likely to contribute simply because

they are close to the creator; localism may lead to a similar feeling of closeness. Based on these findings, a research question was posed:

RQ1: How does localism influence a person's decision to financially contribute to a Kickstarter campaign, if at all?

Kickstarter has the potential to be a used as a platform for participatory culture (Jenkins, 2006), but research is conflicted on the extent to which audience members feel like participants in creating the media they consume. Although Jenkins (2006) and Kelly, Laskin, and Rosenstein (2010) have found increased uses of audience participation and two-way communication and developed strong theoretical foundations, studies about crowdfunding have found more mixed results. Aitamurto's (2011) backers were not 
interested in participation. Ordanini et al. (2012) found participation was an important factor, but the participants in that study were platform owners; those studies did not include interviews with backers of the sites, so the researchers did not have backers' input on whether they wanted to be a part of the creative process. The rise of participatory culture and two-way communication between producers and stakeholders (Jenkins, 2006; Kelly, Laskin, and Rosenstein, 2010) indicates that these changes were brought about by audience characteristics. Audiences wanted more direct communication and input, so industries adjusted accordingly. Following this thinking, audience members (in this case, Kickstarter backers), would likely want to be involved in the creative process and therefore would be more satisfied with the outcomes of projects because they were able to do so. To examine the role of participatory culture in crowdfunding, a research question and hypothesis were posed:

RQ2: To what extent did Kickstarter backers feel like they were part of the creative process, if at all? How important is it for backers to be able to communicate with project creators, if at all?

H1: Backers who feel more involved in the creative process will be more satisfied with the results of the projects they backed.

Researchers have emphasized the importance of project creators sharing their projects with people in their personal social networks, as well as the importance of shares from people who have backed projects (Ordanini et al. 2011; Kuppuswamy and Bayus 2013). However, research is limited with respect to whether different methods of sharing are more popular among backers. To further determine the role of sharing and different ways of sharing, a research question is posed:

RQ3: How likely are people who have backed Kickstarter campaigns to share information about the campaigns with others? What have backers done to promote Kickstarter campaigns? 
Some researchers found that participants were motivated by the rewards included with crowdfunding campaigns (Ordanini et al., 2011; Balnaves, 2012), but research on rewards included with Kickstarter projects is limited. Because Kickstarter is a for-profit company, most of its campaigns are carried out for business purposes; most people who back Kickstarter projects receive a product for their contribution. If incentives were not offered, people may not have any reason to support a business endeavor if they get nothing in return. In addition, many incentives and rewards are exclusive to Kickstarter backers, which raises their commodity value. This value might make the campaigns seem more special to backers because they can get a unique deal. To further explore the role of rewards, a research question was posed:

RQ4: How do exclusive rewards, given by the project creator, influence a person's decision to financially contribute to a Kickstarter campaign, if at all?

The issue of creator accountability also warrants further exploration. Researchers have found varying opinions on the controversy (Gunes, 2012), and the press has characterized it as a major concern in crowdfunding (Jefferson, 2012; Shahani, 2012), but little attention has been paid to whether the risks associated with crowdfunding's limited accountability have deterred backers from contributing. Further, these accountability concerns could affect the amount of money backers are willing to pledge. Backers who contribute higher amounts of money may care more about accountability because they have a greater investment in the project than those who contributed less money. To add insight to the issue of Kickstarter's accountability policy, a research question and a hypothesis were posed: 
RQ5: How does a person's attitudes toward Kickstarter's accountability policy for the completion of projects influence his or her decision to financially contribute to a Kickstarter campaign, if at all?

H2: Those who have contributed larger amounts of money to Kickstarter campaigns will be more concerned with the lack of accountability for the completion of projects than those who have donated smaller amounts.

Little attention has been paid to the relationship between backers' education and income levels and their likelihood of financially supporting a campaign. To explore these influences, a research question was posed:

RQ6: Are those with higher education and/or income level more likely to have donated to Kickstarter campaign than those with lower education and/or income levels?

Across nonprofit and business crowdfunding projects, researchers have found that many backers chose to contribute because they felt the creators needed the contributions for their projects to be fully realized (Aitamurto, 2011; Carvajal et al., 2011; Sorensen, 2012) or felt that the projects were important to the individual backer or to society as a whole (Aitamurto, 2011; Carvajal et al., 2012; Sorensen, 2012). Many researchers also agreed that the subject being covered or viewpoint being expressed was important; backers tended to support projects they could identify with personally (Aitamurto, 2011; Carvajal et al., 2011; Sorensen, 2012). To determine the role of these factors, as well as new factors that may emerge, two research questions were posed:

RQ7: What is the most frequently cited reason for financially contributing to a Kickstarter campaign?

RQ8: What were Kickstarter backers' favorite projects, and what factors were most important in their decisions to do so? 


\section{CHAPTER 4: METHODS}

The study utilized a survey and in-depth interviews to gain both broad and deep knowledge of backers' attitudes toward their Kickstarter experiences. This chapter provides a detailed explanation of the process of gathering survey data as well as the procedures used to conduct the survey. Next, the survey instrument is discussed, followed by a description of the respondents. Then, the variables are operationalized and data analysis procedures are discussed. Following the information about the survey is the details of the interview process, beginning with the process of gathering interview data and procedures used to conduct the interviews. The interview guide is detailed, and then the respondents are described. Discussion of data analysis procedures closes the chapter.

\section{Survey Data-Gathering Process}

The first component of this research was to conduct an online survey to gain insight into what factors of Kickstarter campaigns (based on the research questions) are most influential in getting people interested in funding them. In addition to obtaining a breadth of information from diverse audiences, an online survey was chosen because of the low cost of creating and hosting the questionnaire and the ease of exporting the data to a data analysis program. Although using multiple survey methods improves survey results (Luther, 2011), the time and cost constraints of this study do not allow for methods other than an online survey. However, this study revolved around an online platform, so an online survey is relevant to the respondents; they would likely prefer an online survey because they used the Internet to participate in the crowdfunding projects being studied. 
The study used a non-probability-based sample of people who have previously backed Kickstarter campaigns. Because the intention of the research was to study the factors that compelled people to participate in Kickstarter projects, a sample of people who have supported campaigns was necessary. It would not have been helpful to take a sample of any general population. Furthermore, Kickstarter is a relatively new platform, so general populations might have limited knowledge of it or the larger topic of crowdfunding.

Participants for the survey were found through a combination of convenience and snowball sampling. The primary investigator, co-investigator, and others sent the survey to people in their social networks via Facebook and Twitter. The posts encouraged readers to take the survey (if they have backed a Kickstarter project) and send it to people they know who have participated in Kickstarter. The Facebook posts were concise, as to increase the likelihood potential participants would read them. The tweets were inherently concise because of the platform's 140-character limit. The posts were made frequently to increase the likelihood people see them, but not excessively, to avoid annoying readers with a large number of messages. Posts made toward the end of the survey period mentioned that the survey period was closing soon, so participants were immediately needed.

After the several Facebook and Twitter posts sharing the survey had been made, the number of responses was still below the desired number of 150 respondents. Several outlets were used to try to gather additional responses. First, several project creators who had previously emailed the researcher about the launches of their campaigns shared the link with their backers. Then, the survey link was shared on some Kickstarter online 
communities, including the Kickstarter subreddit on the social news site Reddit. Still being slightly under the goal, the survey link and instructions were posted on Amazon Mechanical Turk, a site on which users are paid to complete designated tasks. Thirty MTurk users were given $\$ 1$ each to complete the survey; no other respondents were compensated. After these efforts yielded a number of responses above the goal, the survey was shared on Facebook and Twitter again, attracting some participants who had not yet completed it. The survey opened on March 7, 2014, and closed on April 3, 2014. See Appendix E for sample Facebook posts, sample Twitter posts, sample email communications, a sample forum post, and the Mechanical Turk message.

\section{Survey Implementation Procedures}

The Qualtrics Web-based survey software, provided by the Reed College of Media at West Virginia University, was used to implement the survey. This program allowed the responses to be downloaded directly to an SPSS data file to be analyzed. The survey did not require passwords or access codes, making it easier for participants to take the survey and thus likely leading to a larger number of responses. To ensure the results were not affected by multiple responses from the same individual, a software feature was used to prevent any one person from taking the survey more than once. Qualtrics also allowed the survey to contain a screening question, "Have you ever financially contributed to a Kickstarter campaign?" Respondents who answered "yes" were shown the rest of the questions, but those who answered "no" were taken to the end of the survey thanking them for participating.

Because Kickstarter is a relatively new platform and is not yet widely used, the number of backers who can be reached is limited. Further, a list of previous backers' 
email addresses could not be obtained, as Kickstarter does not share backer contact information with anyone except the creator of the project a person backed. These limitations made it unlikely that the survey could reach hundreds of people in one month. Taking these factors into consideration, the goal number of the participants was 150 . Participants were told they could skip any questions they did not want to answer, but respondents that did not answer at least $70 \%$ of the questions were deleted. The threshold of $70 \%$ was chosen because it is close to having three-fourths of the questions answered without having to reach the $75 \%$ mark exactly. Additionally, it could be seen in examining the raw survey data that a number of respondents stopped answering questions after the first few, so including these responses could skew the data by having some questions with many more answers than others. Respondents that answered "no" to the screening question were also deleted. Before filtering, the number of responses was 197. After discarding responses that met the criteria for removal, the final number of valid participants was 128 .

\section{Survey Instrument}

The survey contained 22 questions. Most of the questions regarding backers' attitudes toward campaigns used seven-point Likert-type scales, which allowed participants to give more thoughtful responses than simple "yes or no" questions would have permitted (Luther, 2011). The survey contained some open-ended questions to allow respondents to elaborate on their reasons for backing Kickstarter projects and what they liked about the projects they backed. The questions were ordered by topic (i.e., questions about rewards, then questions about localism, etc.) to maintain a logical flow (Luther, 2011). The questionnaire also included an introduction explaining the goals, purpose, and 
importance of the survey, informing participants that the questionnaire would take no more than 10 minutes of their time, that their responses would be kept confidential, and that they were allowed to quit taking the questionnaire at any time.

This study measured attitudes of people who have already contributed to Kickstarter, not a general audience's attitudes toward the platform, so the survey largely eschewed basic questions about participants' familiarity with Kickstarter and focused on specific reasons for contributing that backers may or may not hold important. As mentioned, the survey began with the screening question, "Have you ever financially backed a Kickstarter campaign?" Responses from participants who answer "yes" were analyzed. Responses from participants who answer "no" were deleted. Additionally, responses that failed to answer at least $70 \%$ of the questions were deleted. The questions were designed to find out why backers chose to contribute funds. In addition to questions about their Kickstarter experience, participants were also asked demographic questions. See Appendix A for the survey consent form and Appendix B for the survey instrument.

\section{About the Respondents}

Of the usable responses $(\mathrm{n}=128)$, survey participants represented 31 states and at least five countries. The three states that were most identified as the respondents' place of residence were West Virginia (17\% (22)), Pennsylvania (6\% (8)), and Ohio (5.5\% (7)), all areas regional to the location where the research was conducted. More respondents were male $(61.6 \%(77))$ than female $(37.6 \%(47))$. Nearly three-fourths, $73.6 \%(92)$ of respondents were between the ages of 25 and 44 . An additional 22\% (28) of respondents fell into the age ranges of 18-24 or 45-54 years old. Participants who were 55 years or older (3\% (4)) represented the smallest portion of the sample. A majority of respondents, 
$73 \%$ (91) had an annual household income of less than $\$ 100,000$, compared to $22.4 \%$ (29) who had $\$ 100,000$ or more. Slightly over half (53\% (66)) had a bachelor's or master's degree as their highest level of education completed. Approximately 17\% (21) had completed some college; this number includes students who are currently enrolled. Only 4\% (5) had not attended college at all.

More than half, 55.6\% (69), of the respondents had backed five Kickstarter campaigns or fewer. Among this portion, 26\% (32) said they had backed only one project, $12 \%$ (15) had backed two, and $8 \%(10)$ had backed three. The rest of answers given were in the single digits; however, a full breakdown of the number of projects backed can be found in Appendix F. As shown Figure 1, the most popular category was games, with $61 \%$ (78) of respondents saying they had backed a games project. Film/video followed with $35 \%$ (45). Other more popular categories included music (28\% (36)), publishing (26\% (33)), and art (23.4\% (30)).

Figure 1: Categories of Projects Backed

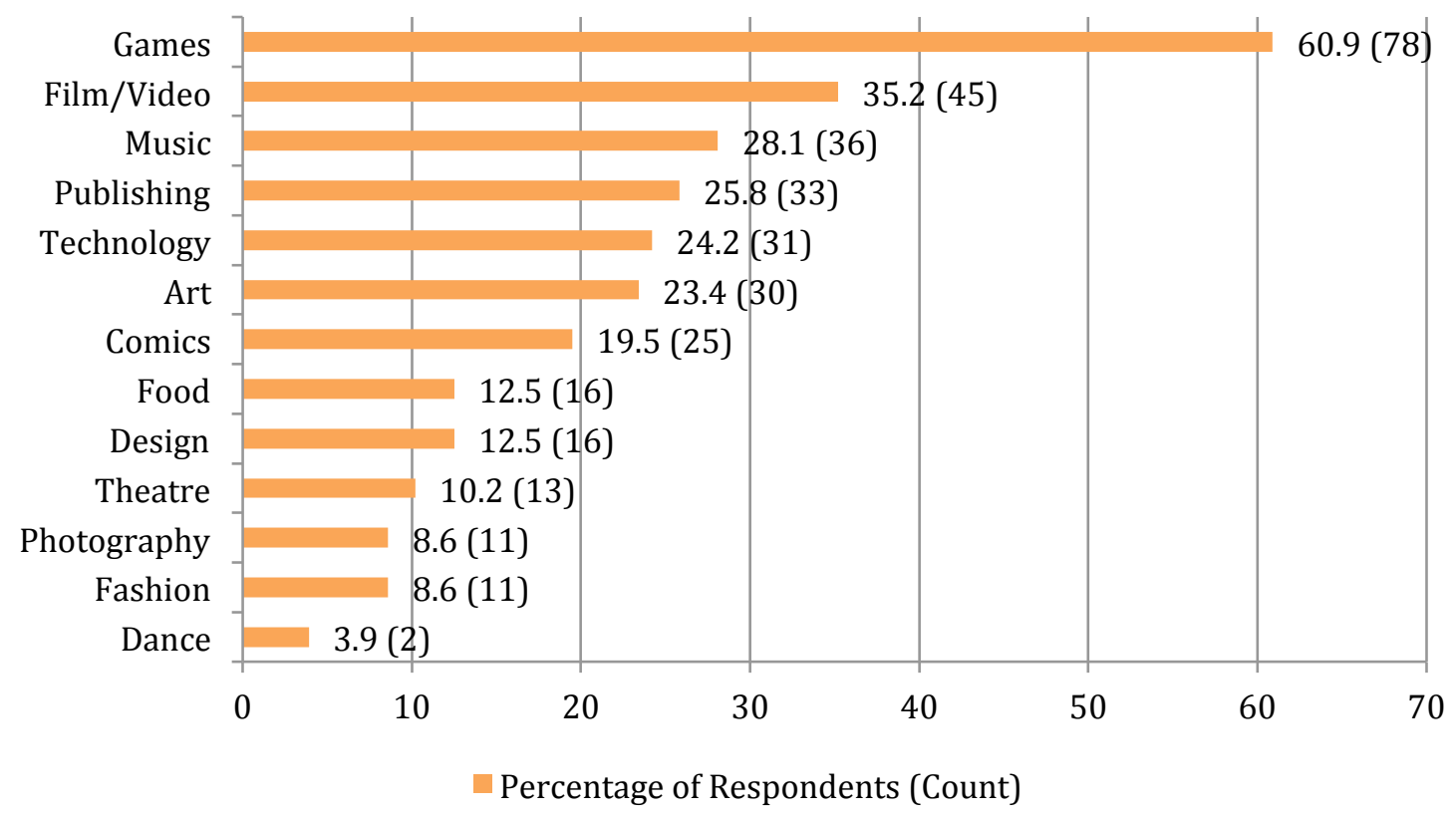


Figure 2 shows that $31 \%$ (40) of respondents first heard of Kickstarter through social media. Following closely, 28\% (30) said they first heard of the site from someone they know. Seventeen point two percent heard of Kickstarter because they knew a project creator. News media were the least frequently cited source of discovering Kickstarter, with only $11 \%$ (14) saying they first heard of the site from the news.

\section{Figure 2: How Participants First Learned About Kickstarter}

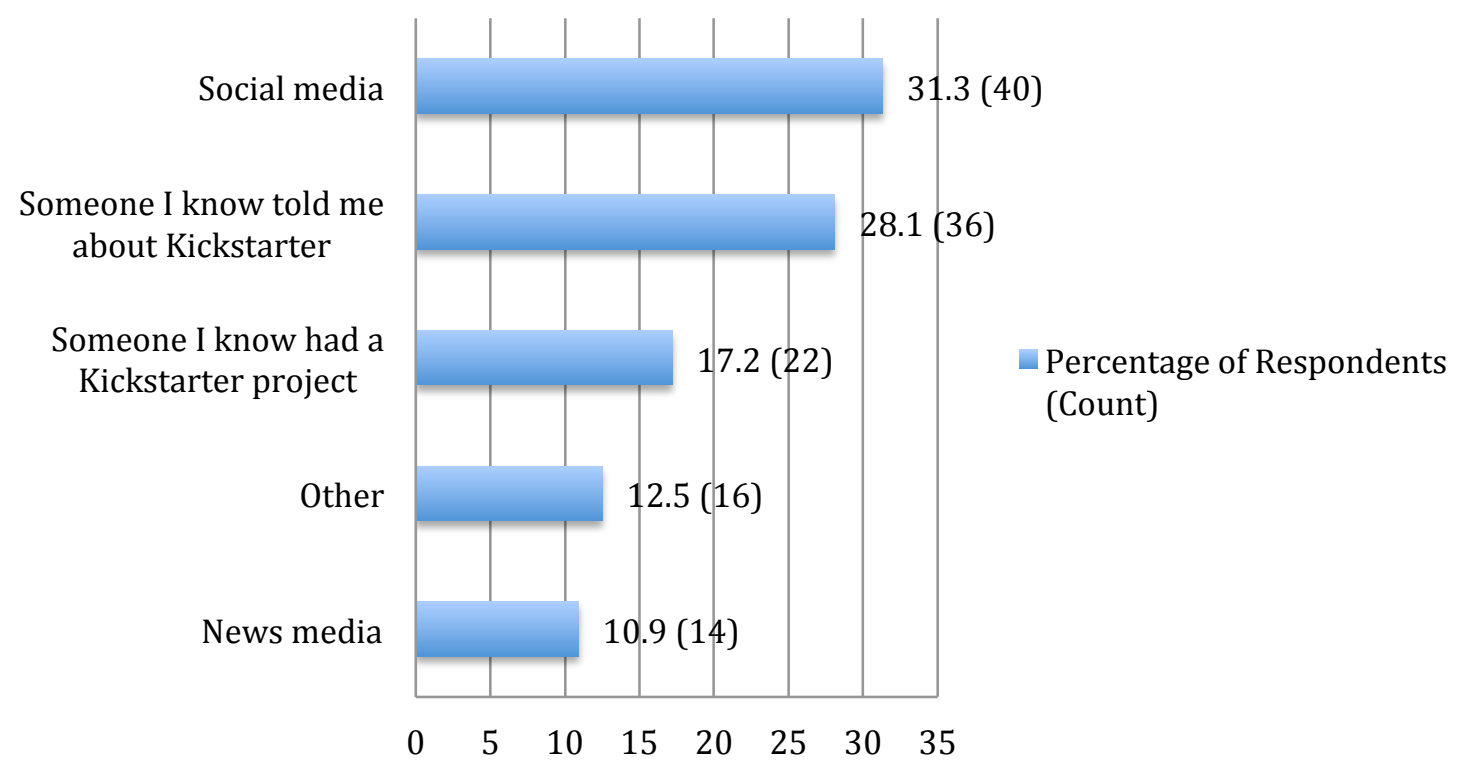

Most participants, $62 \%$ (72), said they first heard of Kickstarter between one and two years ago, and 16.4\% (19) said they first heard of it between two and three years ago. The rest of the answers given were in single digit percentiles. Twenty-nine percent (37) of the respondents said the largest amount they have contributed was $\$ 25$ or less, while $21 \%$ (27) said their largest contribution was $\$ 501$ or more. The rest of the results were scattered between the poles with no consistent pattern. The typical amount respondents pledged to projects was more consistent. Nearly $60 \%$ (76) said they have typically contributed $\$ 50$ or less, and an additional $24 \%$ (30) have typically contributed $\$ 51-\$ 100$ 
$(\bar{x}=\$ 50, S D=1.768)$. A full respondent breakdown of demographic information can be found in Appendix F: Survey Demographic Information.

\section{Operationalization of Variables}

Localism. To measure the variable of how localism influences backers' decision to pledge, RQ1 asked, How does localism influence a person's decision to donate to a Kickstarter campaign, if at all? Localism was defined as the extent to which participants are motivated by interest in projects that are being made in their communities and affecting people in those communities on a personal level. Localism is measured with one question asking respondents how important it is to them to support a local creator when choosing to back a Kickstarter campaign, using a seven-point Likert-type scale that ranged from "not at all important" to "extremely important."

Creative participation. To measure whether backers felt like they were part of the process of creating the projects they backed, RQ2 asked, To what extent did Kickstarter backers feel like they were part of the creative process, if at all? How important was it for backers to be able to communicate with project creators, if at all? Participation in the creative process was defined as the extent to which backers are influenced by two-way communication with creators and whether backers feel like they are part of the process of creating the project. Creative participation was measured with two question asking respondents the extent to which they agree or disagree with statements saying they placed importance on communicating with project creators and felt like they were part of the creative process. These questions used a seven-point Likert-type scale that ranged from "strongly disagree" to "strongly agree." 
In further exploring the role of the creative process, H1 posited, Backers who felt more involved in the creative process will be more satisfied with the results of the projects they backed. This hypothesis was tested using a correlation analysis of level of agreement that they feel involved in creating the project and level of satisfaction with the results of projects, as measured by a seven-point Likert-type scale ranging from "very unsatisfied" to "very satisfied."

Backers' likelihood of sharing projects. To determine how likely project backers are to spread information about the projects through personal communication or social media, RQ3 asked, How likely are people who have backed Kickstarter campaigns to share information about the campaigns with others? What have backers done to promote Kickstarter projects? This variable was measured with one seven-point Likert-type question asking participants to rate their likelihood of sharing projects, from "very unlikely" to "very likely," and one question asking participants to choose what they have done to support projects besides contributing funds. For this question, respondents could select all activities that apply (sharing in person, sharing through social media, trying to convince someone to back a project, noting other than contributing financially, or an "other" option, in which respondents were asked to write in a response). The nature of crowdfunding makes sharing information about projects crucial to the success of a project. Knowing the likelihood of sharing could give project creators a more accurate portrayal of what to expect from backers.

Rewards. To measure how much backers are motivated by the exclusive rewards offered in Kickstarter campaigns, RQ4 asked, How do exclusive rewards, given by the campaign starter, influence a person's decision to donate to a Kickstarter campaign, if at 
all? Rewards were defined as the items offered by creators in exchange for funds. These items were listed by creators on their project pages. This variable refers only to rewards expressly offered by the backer, so other intangible rewards such as feelings of personal satisfaction are not included. The influence of rewards was measured with one question asking respondents how important it is to them to have incentives and rewards when choosing to back a Kickstarter campaign. This question uses a seven-point Likert-type scale that ranged from "not at all important" to "extremely important."

Accountability concerns. To measure how much Kickstarter's limited accountability affects backers' decision to contribute, RQ5 asked, How does a person 's attitudes toward Kickstarter's accountability policy for the completion of projects influence his or her decision to financially contribute to a Kickstarter campaign, if at all? This variable was defined by how much the participants are influenced by the fact that Kickstarter cannot be held directly accountable for project creators that fail to complete their projects or fail to do so in a way that satisfies backers and cannot give backers restitution in these instances (Chen et al., 2012). The effect of Kickstarter's accountability concerns was measured with one question asking respondents how important the accountability policy is in their decision to back a Kickstarter campaign. This question used a seven-point Likert-type scale ranging from "I am very unlikely to back a campaign because of it" to "I am very likely to back a campaign despite it."

In addition to influencing whether a person chooses to support campaigns, this factor might affect how much money he or she willing to contribute or what campaigns he or she will support. Following this idea, H2 posited, Those who have contributed larger amounts of money to Kickstarter campaigns will be more concerned with the lack 
of accountability for the completion of projects than those who have donated smaller amounts. This hypothesis was tested with a correlation analysis between the typical amount contributed and the effect of the accountability policy on a person's decision to back. If a person pledges a small amount of money to a campaign, he or she will not likely feel much risk. A backer will feel much more risk when contributing a large amount of money, so the accountability issue becomes more important when a creator seeks a high dollar amount for project completion. People may be less likely to back these campaigns, as the risk of failure will have a great impact on their potential for loss.

The relationship between education and income levels and the likelihood of financial support. To determine whether there is a correlation between how much education, RQ6 asked, Are those with higher education and/or income level more likely to have donated to Kickstarter campaign than those with lower education and/or income levels? In this question, income level was defined as yearly household income (as opposed to personal income), and education level was defined by the highest level of education the participant has completed. This variable was measured with three survey questions. Two questions asked participants to choose their annual household income and highest level of education completed. One question asked participants to choose the number of Kickstarter campaigns they have backed. Correlation analysis between education level and number of projects backed and income level and number of projects backed was used to test the hypothesis. A strong correlation could give creators an idea of which audiences to appeal to primarily when pitching and promoting their projects.

The most common factor of donation. To determine which of the factors discussed are most common among Kickstarter backers, RQ7 asked, What is the most frequently 
cited reason for financially contributing to a Kickstarter campaign? This variable was measured with one survey question asking participants to choose the reasons they have ultimately chosen to pledge. Participants were allowed to check all the reasons that apply because they may have been motivated by different reasons for different projects. The reasons listed in the survey answer choices reflect the variables discussed in the previous research questions-localism and connection to the project creator, creative participation, incentives and rewards, and accountability concerns. Participants could also select an "other" answer, in which they were asked to write in a reason not listed. In examining which reasons appear most frequently in the results, the research can suggest which factors project creators should focus on when shaping their campaign pitches and communications with backers.

Backers'favorite projects. To explore the projects that backers held in the highest regard, RQ8 asked, What were Kickstarter backers' favorite projects they have backed, and what factors were most important in their decisions to do so? This variable was measured by one survey question with four parts: what the project was (respondents write in their answers), how much the participants contributed (respondents write in their answers), what category the project was placed in (respondents choose one option from the list of categories), and the respondents' most important reason for contributing to the projects (respondents write in a text box). This question gives insight into what kinds of projects backers had the most enthusiasm for and what factors most influenced their decision to contribute. Knowing what made backers excited about projects could help creators know what parts of campaigns to emphasize when promoting them. 
The survey data set was analyzed using SPSS v. 22. Frequencies were used to analyze all survey questions. Correlation analyses and descriptive statistics were used to answer one research question and test two hypotheses.

\section{In-Depth Interview Data-Gathering Process}

The second component of the research was to conduct intensive interviews. Conducting in-depth interviews helped gain greater insight into backers' thoughts about the themes discussed in the research questions and survey (Tuten, 2011). The interview format allowed participants to discuss aspects of campaigns they liked and disliked, with a particular focus on the importance of different parts of the campaigns on their decisions to contribute. Interviews added context to the survey responses, as they gave information that could help explain why survey respondents might have answered questions in the ways that they did. This aspect of interviews is particularly important because of the limited number of survey responses and exploratory nature of the study. Although indepth interviews do not provide the group interaction that focus groups would, they allow participants to share their thoughts without being influenced by the social setting of a group. Similarly, interviews keep participants from merely agreeing with others just to move the session along (Tuten, 2011).

\section{Implementation Procedures}

A total of eight interview sessions were conducted: four via Skype, three by phone, and one in person. In addition to time constraints, eight was chosen as the number of interviews because Aitamurto (2011) also interviewed eight crowdfunding participants. Each interview lasted 25-45 minutes. Participants were asked to choose which means of interviewing they preferred. All interviews were recorded and stored on a 
computer. The Skype interviews were recorded as video files using Call Recorder for Skype. The phone interviews were recorded using a basic digital voice recorder with earpiece and uploaded as audio files. The interview conducted in person was recorded as an audio file using Apple GarageBand. After interviews were conducted, they were transcribed to ensure accuracy and to use for later analysis.

Interview participants were found through the personal social networks of the researcher and thesis committee members. They were asked to be interviewed because they were known to have backed Kickstarter projects. The research did not require a large number of participants, as interviews only encompassed half of the research, so further sampling methods to recruit more participants were not necessary.

\section{In-Depth Interview Guide}

Prior to the interview sessions, participants were emailed a consent form. Each interview session began with an overview of the consent form, and participants had to verbally give their consent before starting the interview questions. The questions presented to the interview participants reflected the questions asked in the survey and expanded on its themes. The questions were open-ended to allow participants to talk about their experiences in as much depth as they desired, though some questions about basic information about participants' Kickstarter use, such as the number of projects participants had backed, did not warrant elaboration. The number of questions was not concrete, as some participants spoke in greater depth about certain aspects of projects, leading to greater numbers of follow-up and probing questions about those topics. At the end of every interview session, participants were given the opportunity to share any final 
thoughts they had about any of the topics discussed during the interview. See Appendix C for the interview consent form and Appendix D for the interviewer's guide.

\section{About the Participants}

The interview participants represented a variety of demographics. All participants currently resided in West Virginia, Ohio, or South Carolina, but they had lived in other areas, including Kentucky, New Jersey, Pennsylvania, Washington, D.C., and China. Five participants were male, and three were female. Most of the participants' ages were in the two most common age groups among the survey respondents (25-34 and 35-44). All were college graduates.

Participants' level of experience with Kickstarter varied as well. They had backed almost all of Kickstarter's project categories, including art, comics, dance, fashion, film $\&$ video, games, music, photography, publishing, technology, and theatre. Six of the eight participants had backed 13 projects or fewer; two had backed only one. One participant backed 21 projects, and one backed 48 . All had received the final products or seen the final results of at least one campaign they had backed, though some participants were still waiting on some projects to be completed and rewards to be sent. Most said social media was the way they first learned about Kickstarter and their primary means of finding and sharing new projects. Some found out about the site from news media, and others said they had shared projects through email.

\section{Data Analysis}

Transcripts were analyzed using a grounded theory approach (Glaser and Strauss, 1967). As the primary investigator reviewed them, natural themes emerged from the participants' answers. These themes were grouped into categories, which were used to 
organize participants' responses. The responses were then analyzed to see which categories were most prominent. The categories were compared to the data from the survey responses to determine whether the recurring themes of the interviews support the themes found in the survey. Ultimately, comparing the themes provided more valuable insight into the research questions than would be gained from using only one method. 


\section{CHAPTER 5: RESULTS}

The purpose of this study was to explore which factors of Kickstarter campaigns were most influential in backers' decisions to contribute to projects and understand the appeal of Kickstarter to people who have financially supported its projects. The findings also have implications about the appeal of Kickstarter to people who would potentially back Kickstarter campaigns. All quantitative analyses were conducted using SPSS v. 22.

\section{Survey Results}

\section{Localism}

The first research question asked, "How does localism influence a person's decision to donate to a Kickstarter campaign, if at all?" A seven-point Likert-type scale, ranging from "not at all important" to "extremely important," was used to measure how important respondents felt it was for Kickstarter project creators to be from their local areas. Survey participants largely rated localism as unimportant, as shown in Figure 3. More than one third of respondents $(36 \%(46))$ answered "not at all important" to the question of how important it was for a Kickstarter project creator to be from their local areas. Conversely, only $21 \%$ (27) chose one of the three positive answer choices (somewhat important, very important, or extremely important). 


\section{Figure 3: Importance of Localism}

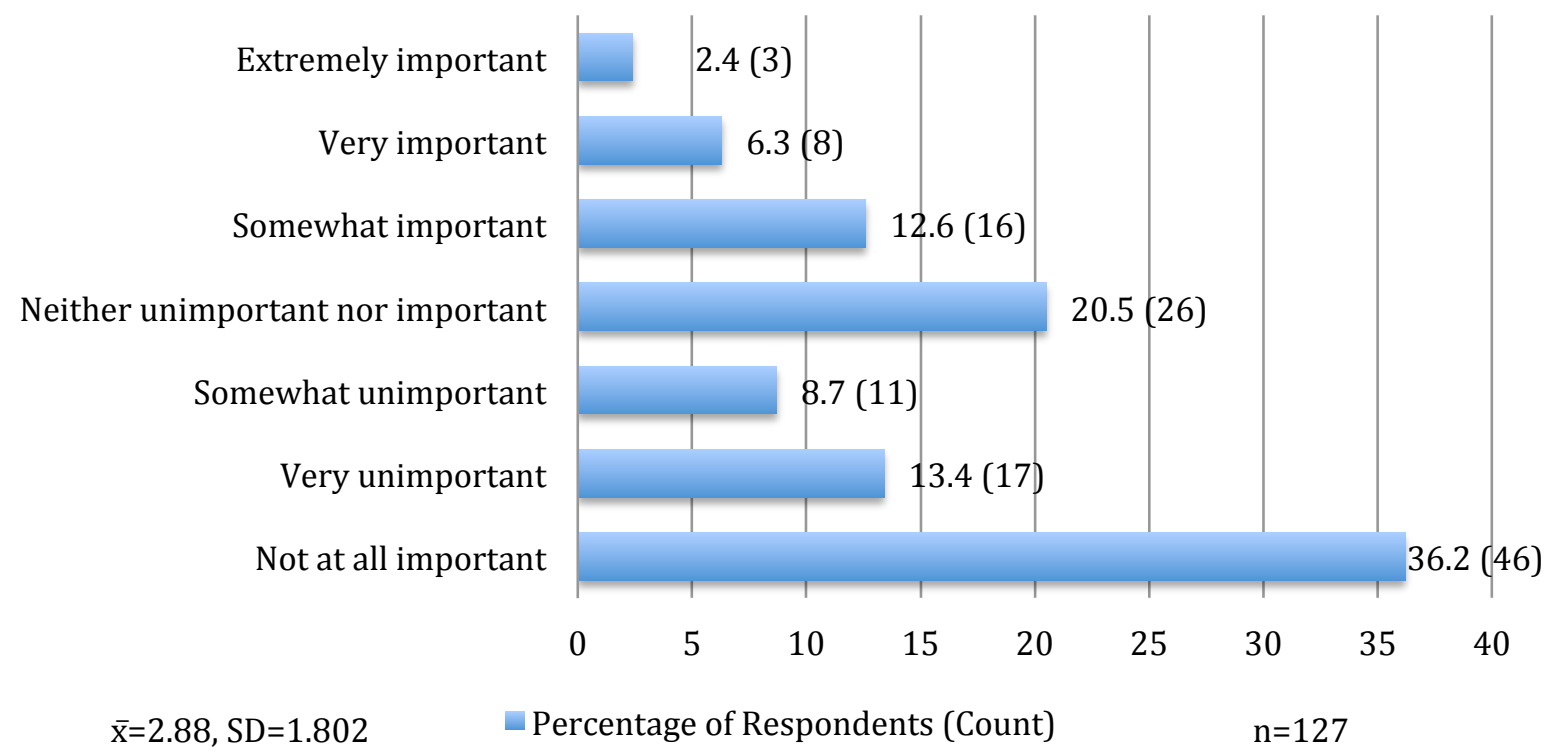

\section{Involvement in Creative Process}

The second research question asked, "To what extent did Kickstarter backers feel like they were part of the creative process, if at all? How important is it for backers to be able to communicate with project creators, if at all?" This question was explored by two variables: how important it was that respondents be able to communicate with project creators and how involved respondents felt in creating the projects they backed. A sevenpoint Likert-type scale, ranging from "strongly disagree" to "strongly agree," was used for both questions to measure the importance of these variables. Overall, respondents in the survey felt involved in the process of creating the projects they backed, as shown in Table 1. A majority of the respondents (72\% (89)) agreed with the statement that they were involved in the creative process when they backed a Kickstarter campaign.

More than two-thirds of participants (67\% (84)) said it was important, to some extent, that they are able to communicate with project creators when they have backed a project, compared to only $16 \%$ (20) who disagreed that communication between creators 
and themselves was important.

Table 1: Feelings of Creative Involvement and Communication

\begin{tabular}{|c|c|c|c|c|c|c|c|c|}
\hline & $\begin{array}{l}\text { Strongly } \\
\text { Disagree }\end{array}$ & Disagree & $\begin{array}{l}\text { Somewhat } \\
\text { Disagree }\end{array}$ & $\begin{array}{l}\text { Neither } \\
\text { Agree } \\
\text { Nor } \\
\text { Disagree }\end{array}$ & $\begin{array}{l}\text { Somewhat } \\
\text { Agree }\end{array}$ & Agree & $\begin{array}{l}\text { Strongly } \\
\text { Agree }\end{array}$ & $\begin{array}{l}\text { Mean \& } \\
\text { Standard } \\
\text { Deviation }\end{array}$ \\
\hline $\begin{array}{l}\text { It is important } \\
\text { that I } \\
\text { communicate } \\
\text { with the project } \\
\text { creator }\end{array}$ & $\begin{array}{l}1.6 \% \\
(2)\end{array}$ & $\begin{array}{l}8.8 \% \\
(11)\end{array}$ & $\begin{array}{l}5.6 \% \\
(7)\end{array}$ & $\begin{array}{l}16.8 \% \\
(21)\end{array}$ & $\begin{array}{l}19.2 \% \\
(24)\end{array}$ & $\begin{array}{l}32.0 \% \\
(40)\end{array}$ & $\begin{array}{l}16.0 \% \\
(20)\end{array}$ & $\begin{array}{l}\bar{x}=5.03 \\
S D=1.55\end{array}$ \\
\hline $\begin{array}{l}\text { I feel involved in } \\
\text { creating the } \\
\text { project }\end{array}$ & $\begin{array}{l}1.6 \% \\
(2)\end{array}$ & $\begin{array}{l}6.4 \% \\
(8)\end{array}$ & $\begin{array}{l}8.0 \% \\
(10)\end{array}$ & $\begin{array}{l}12.8 \% \\
(16)\end{array}$ & $\begin{array}{l}28.0 \% \\
(35)\end{array}$ & $\begin{array}{l}25.6 \% \\
(32)\end{array}$ & $\begin{array}{l}17.6 \% \\
(22)\end{array}$ & $\begin{array}{l}\bar{x}=5.06 \\
S D=1.5\end{array}$ \\
\hline
\end{tabular}

$\mathrm{n}=125$

Hypothesis one posited that backers who felt more involved in creating the projects they backed would be more satisfied with the results. The hypothesis was tested using a correlation analysis of respondents' level of agreement with the statement that they felt involved in creating projects and level of satisfaction with the results. The correlation was moderate, positive, and significant, $\mathrm{r}_{125}=.316, \mathrm{p}<.001$, thus supporting hypothesis one. This finding supports the idea that participation in the creative process is an important factor of Kickstarter campaigns.

\section{Likelihood of Sharing Projects}

Research question three asked, "How likely are people who have backed Kickstarter campaigns to share information about the campaigns with others? What have backers done to promote Kickstarter campaigns?” A seven-point Likert-type scale, ranging from "very unlikely" to "very likely," was used to measure respondents" likelihood of sharing projects via social media. Respondents were given five options for what they did to share projects, including an "other" option in which they could write in an answer. Respondents were instructed to select all methods of promoting projects they had used. As shown in Figure 4, survey respondents were interested in participating in the 
funding process by sharing projects with their friends or followers on social media sites. A majority of respondents $(69 \%(82))$ said they were likely to share projects via social media after backing them.

\section{Figure 4: Respondents' Likelihood of Sharing Projects on Social Media}

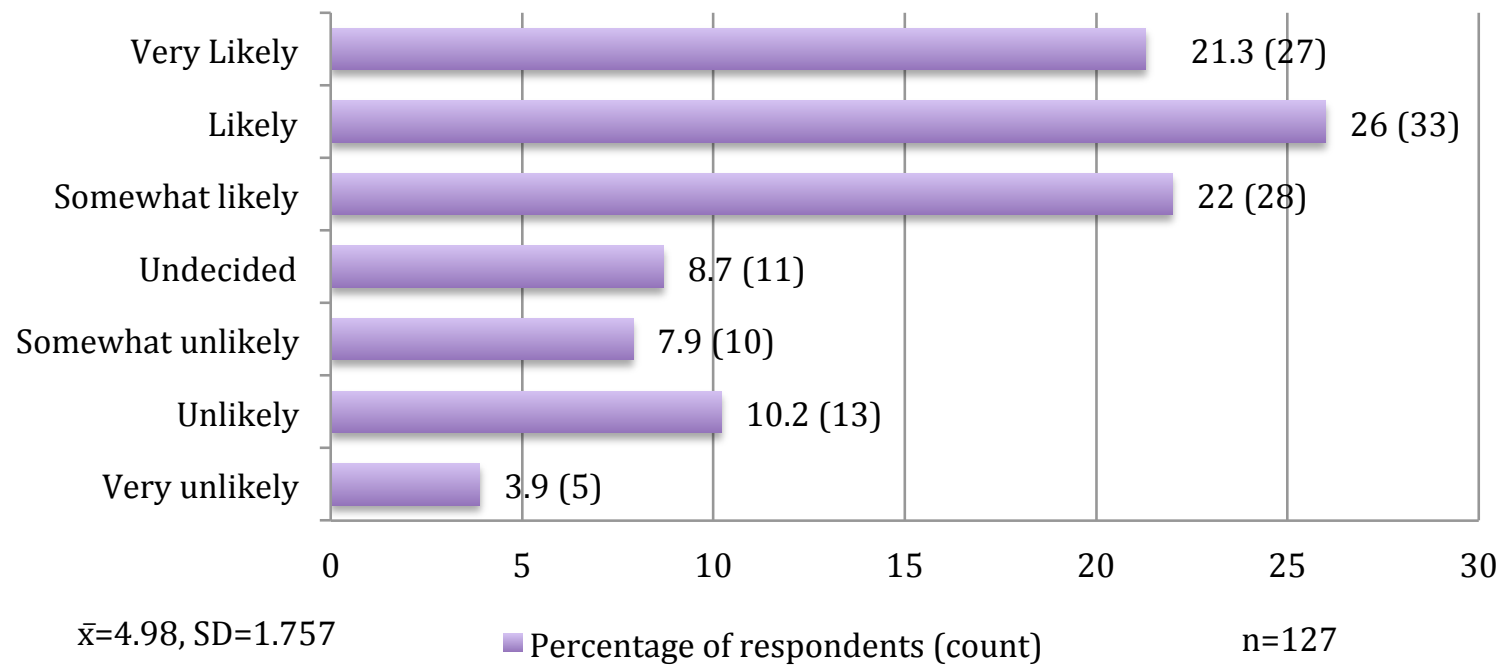

As shown in Figure 5, respondents were nearly equal in their use of person-toperson communication and social media as ways of sharing projects. Nearly three quarters of the respondents $(74 \%$ (95)) said they have told someone about the project in person. Almost as many (71\% (91)) said they have shared projects on their social media pages after backing them. These numbers suggest that although social media has great potential reach, backers of Kickstarter projects also place a high value on the more direct and personal communication that occurs between people. Respondents were not as likely to actively try to convince others to back projects, with approximately $48 \%$ (61) saying they had tried. The backers surveyed were likely more comfortable with simply sharing, rather than trying to convince. Very few backers said they had only contributed money or chose the "other" option. Those who chose "other" most commonly said they had shared 
projects on Internet forums, which they distinguished from social media.

Figure 5: What Respondents Did to Share Projects

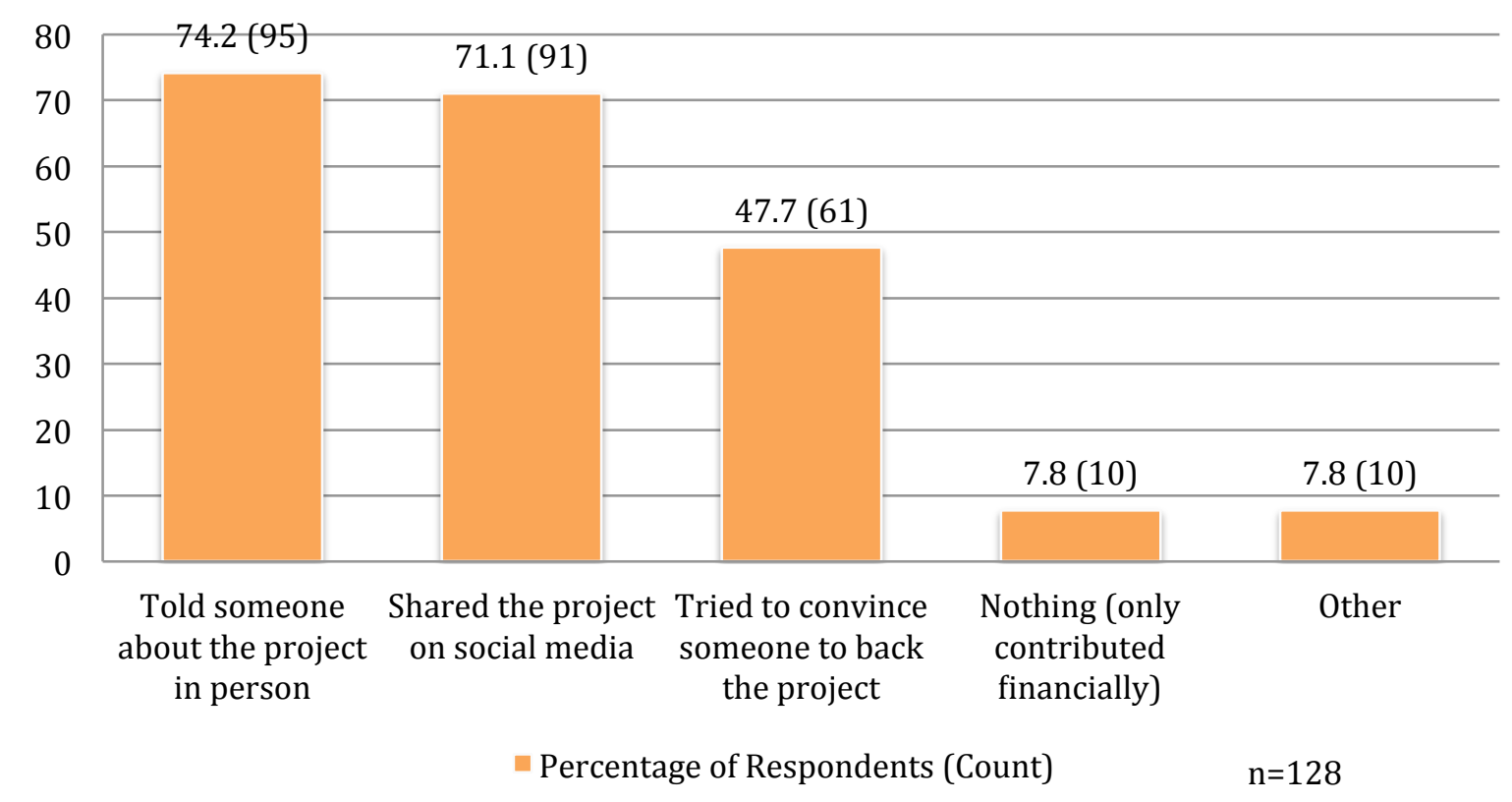

Rewards

Research question four asked, "How do exclusive rewards, given by the campaign starter, influence a person's decision to donate to a Kickstarter campaign, if at all?” A seven-point Likert-type scale, ranging from "not at all important" to "extremely important," was used to measure how important rewards were in respondents' decision to back Kickstarter projects. Participants rated the importance of the Kickstarter-exclusive rewards that creators usually include with their projects fairly high, as shown in Figure 6. Half $(50 \%(60))$ said rewards were either somewhat important or very important, while $39 \%$ (49) considered rewards unimportant. These data suggest that backers are attracted to the exclusive rewards that come with Kickstarter projects. 


\section{Figure 6: Importance of Rewards}

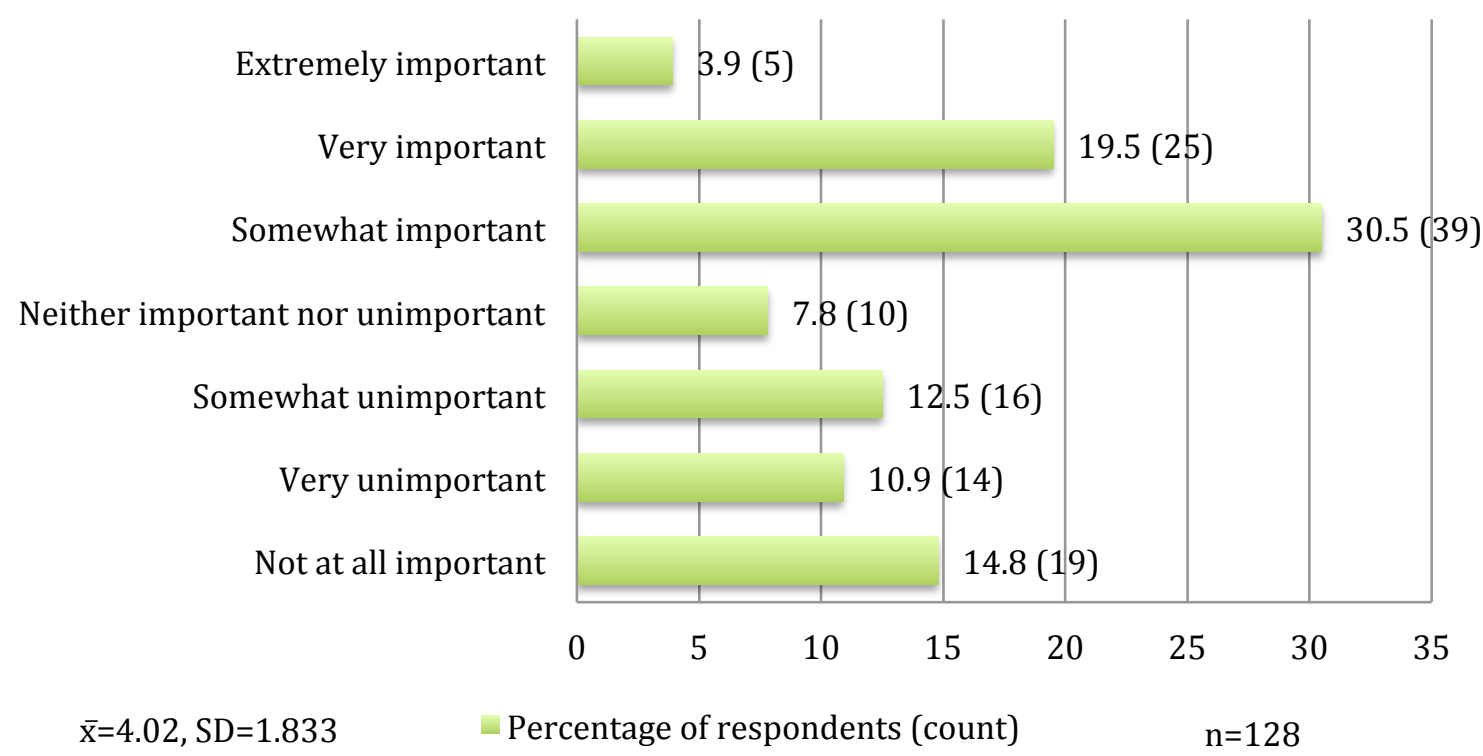

\section{Accountability Concerns}

The fifth research questions asked, "How does a person's attitudes toward Kickstarter's accountability policy for the completion of projects influence his or her decision to financially contribute to a Kickstarter campaign, if at all?" A seven-point Likert-type scale, ranging from "I am very unlikely to back a project because of the policy" to "I am very likely to back the project despite the policy," was used to measure the effect that the accountability policy had on respondents' decision to contribute. Figure 7 shows that participants were largely unaffected by Kickstarter's accountability policy in terms of whether it dissuaded them from backing a project. A majority $(61 \%(78))$ said they were likely, to some degree, to back a campaign despite the limited accountability Kickstarter has in seeing that projects get completed and that Kickstarter cannot give refunds or other restitution to backers when creators do not complete or only partially complete their projects. Only $24 \%$ (31) said they were either very unlikely, unlikely, or 
somewhat unlikely to back projects because of the policy. In other words, the accountability policy does not seem to matter to most backers.

Figure 7: How Kickstarter's Accountability Policy Influences Respondents

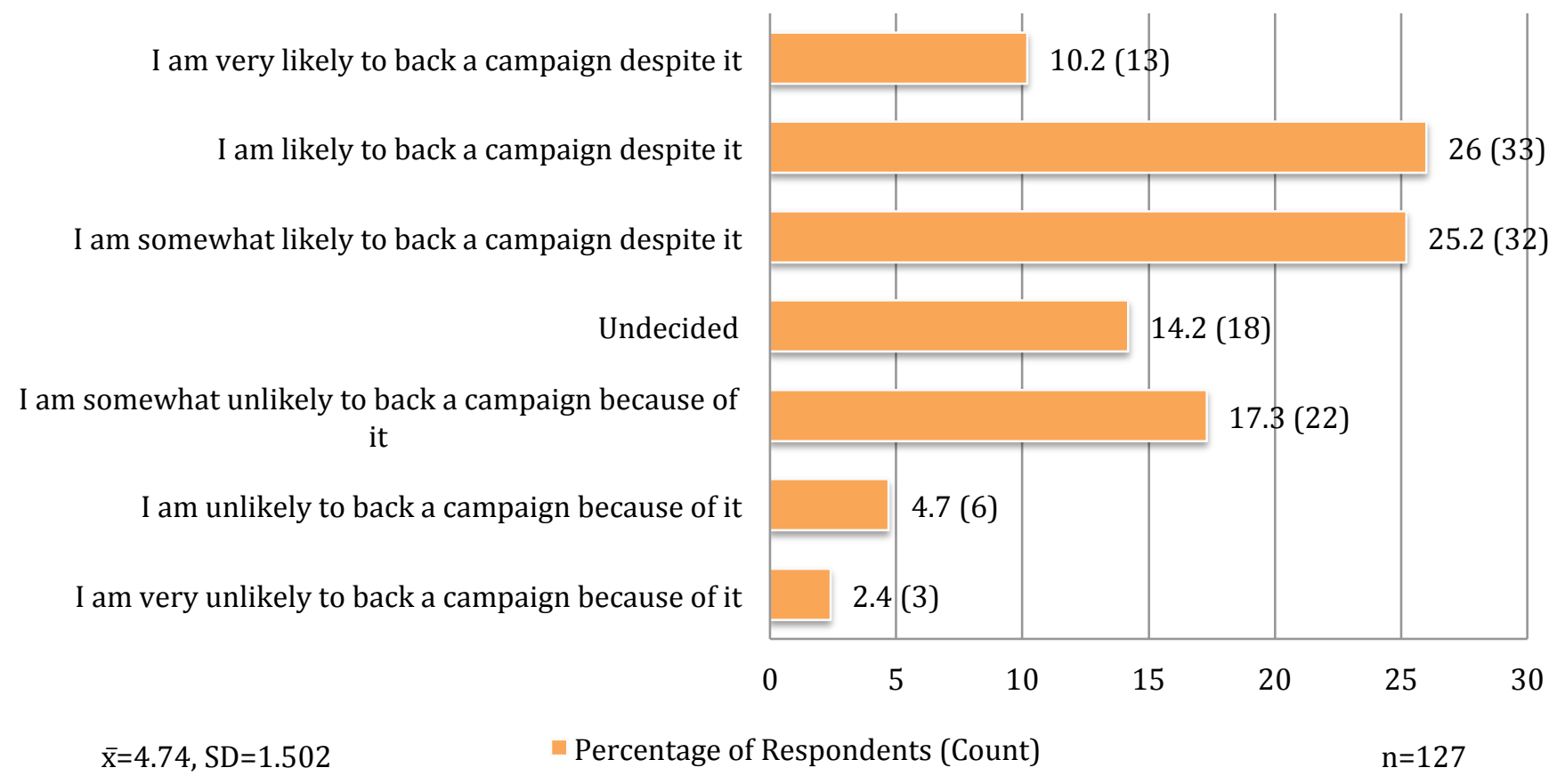

Further exploring the influence of accountability, hypothesis two posited that backers who typically contributed larger amounts of money to projects would be less likely to back projects because of the accountability policy, predicting an inverse relationship. The hypothesis was tested using a correlation analysis of typical amount of money pledged to projects and attitude toward Kickstarter's accountability policy. The results further demonstrate respondents were not dissuaded from backing projects due to the policy. Rather than being negatively influenced by the accountability policy, backers who typically contributed more money were more likely to say they were likely to back campaigns despite Kickstarter's limited accountability. The correlation between the two was weak but significant, $\mathrm{r}_{125}=.179, \mathrm{p}=.046$. This finding continues the theme of backers' 
willingness to support Kickstarter even though it carries risks in its accountability.

Because the hypothesis predicted an inverse relationship, $\mathrm{H} 2$ is rejected. However, these results should be interpreted with caution because the relationship was weak and the significance level approached the .05 cutoff.

\section{Education and Income Level and the Likelihood of Financial Contribution}

Research question six asked, "Are those with higher education and/or income level more likely to have donated to Kickstarter campaign than those with lower education and/or income levels?" These relationships were tested with two correlation analyses: one between education level completed and number of projects backed and the other between annual household income and number of projects backed. Neither education nor income level had a meaningful impact on how likely respondents were to financially contribute to Kickstarter projects. The correlation between education level completed and number of projects backed was weak and not statistically significant, $\mathrm{r}_{121} .150, \mathrm{p}=.102$. The correlation between annual household income and number of projects backed was similarly weak, $\mathrm{r}_{121}=.137, \mathrm{p}=.133$. These results suggest that education is not an integral part of what makes people aware of or interested in Kickstarter projects, and that income level is not a driving factor for contribution, which could be attributed to the fact that backers could frequently give small amounts to numerous projects without expending a great deal of their disposable income.

\section{Most Common Reasons for Backing}

Research question seven asked, "What is the most frequently cited reason for financially contributing to a Kickstarter campaign?" For this question, participants were asked to write their most important reason for backing one or more Kickstarter projects. 
Their responses were grouped into categories based on the answers that appeared most often. Responses that were generic or non-descript were placed into the "other" category, along with responses that were very uncommon. Respondents gave several answers that appeared most frequently. As shown in Figure 8, the most popular answers were that backers wanted the final product of a campaign $(25 \%(31))$ and that backers believed in the projects they were supporting $(23 \%(29))$. Several respondents said they were drawn to projects because they knew the creators $(12 \%(15))$ or were able to receive a discount on the final products compared to buying them in retail. A few cited fandom for a creator's previous work (5\% (6)) and enjoyment of the Kickstarter experience (5\% (6)) as important reasons. See Appendix G for a complete summary of respondents' answers to qualitative questions.

\section{Figure 8: Reason for Backing One or More Campaigns}

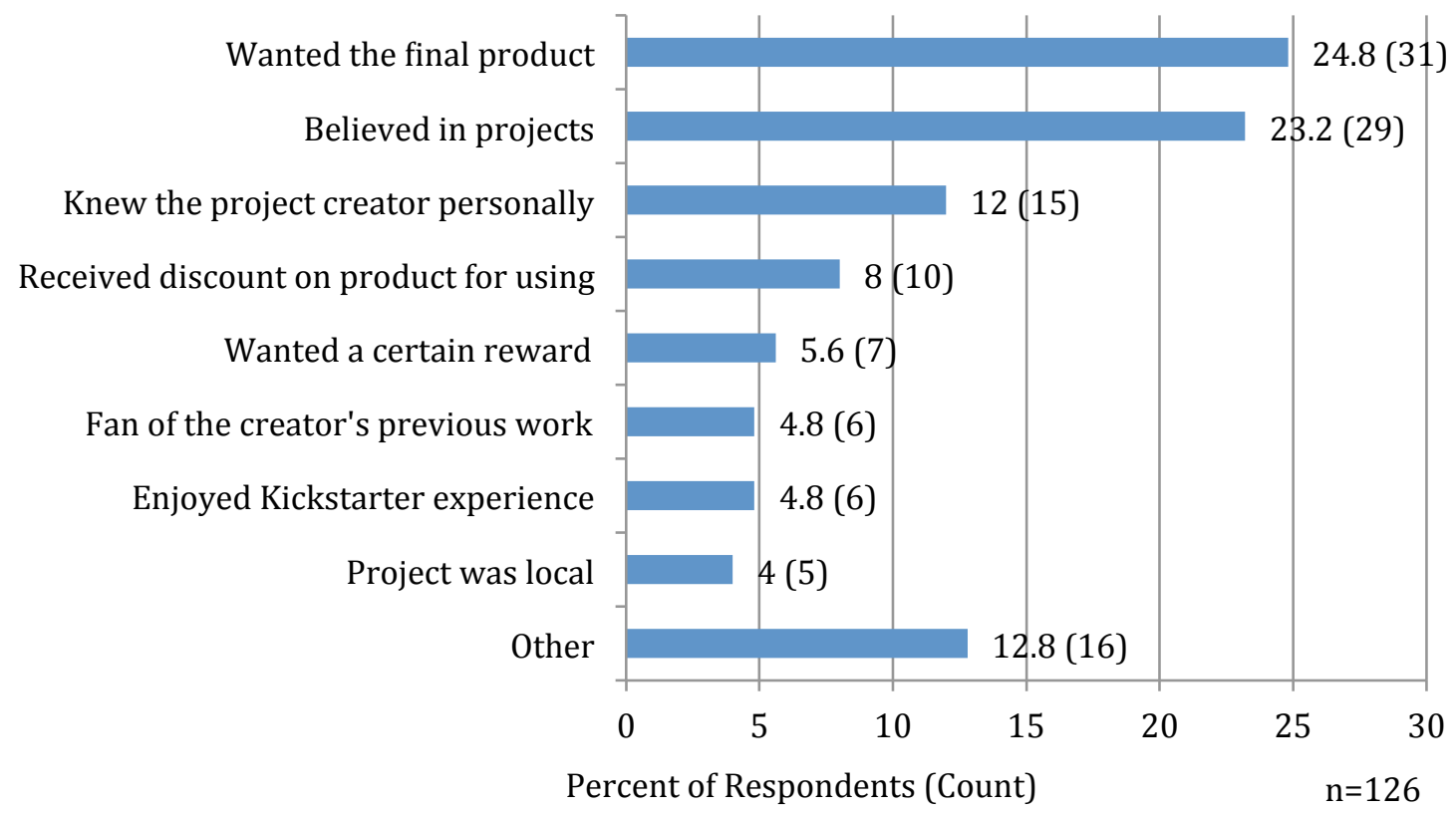




\section{Backers' Favorite Projects}

The final research question asked, "What were Kickstarter backers' favorite projects they have backed, and what factors were most important in their decisions to do so?" Respondents were asked to describe their reasons for backing in an open-ended format. As with the previous research question, responses were grouped into categories based on the responses. Respondents were also asked to choose the category of their favorite projects from a list of all 13 categories. Unlike the earlier question of which categories respondents had backed, respondents were only allowed to choose one category for this question.

Respondents' reasons for backing their favorite campaigns were similar to their reasons for supporting one or more campaigns, but their responses showed some notable differences. As shown in Figure 9, Fandom for the creators based on previous work was the most common answer given, with $38 \%$ (49) of the responses. Wanting the final product (19\% (24)) and knowing the project creator personally (17.4\% (22)) were also common answers. Around 10\% (13) said they received discounts on the final products by using Kickstarter. The reason of believing in the projects was much less common for this question, with only 7\% (9) citing it. 
Figure 9: Reason for Backing Favorite Project

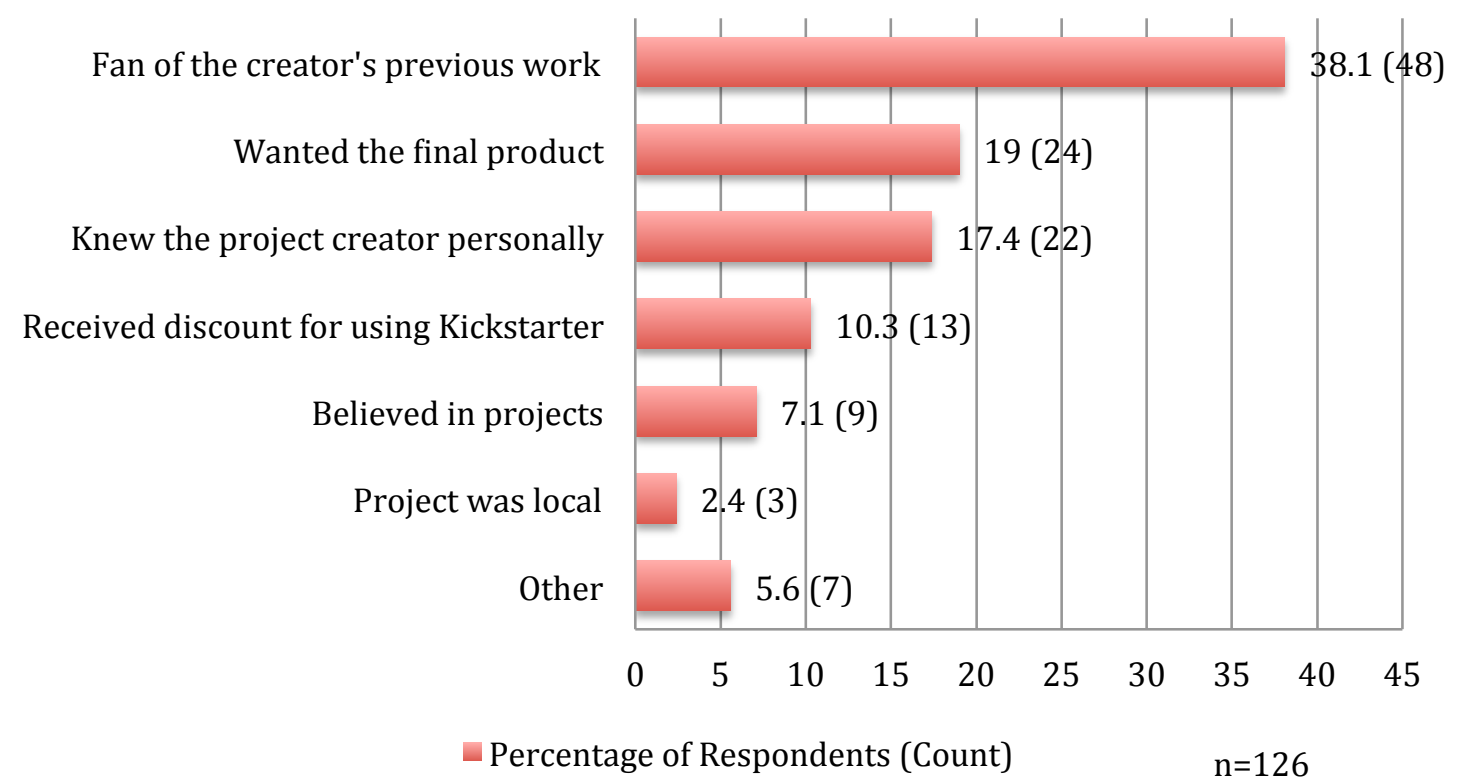

Figure 10 shows that nearly half of the respondents (49\% (62)) said their favorite project was in the games category. Games also received the most selections for the question of which categories the respondents had backed in all projects. The next two most commonly selected categories respondents had backed in all projects were the most commonly selected favorites, with music receiving $14 \%$ (18) of the votes for category of favorite project, and film/video receiving $11 \%$ (14). The less popular categories selected likely received less votes because not as many respondents had backed them at all. 
Figure 10: Category of Favorite Project

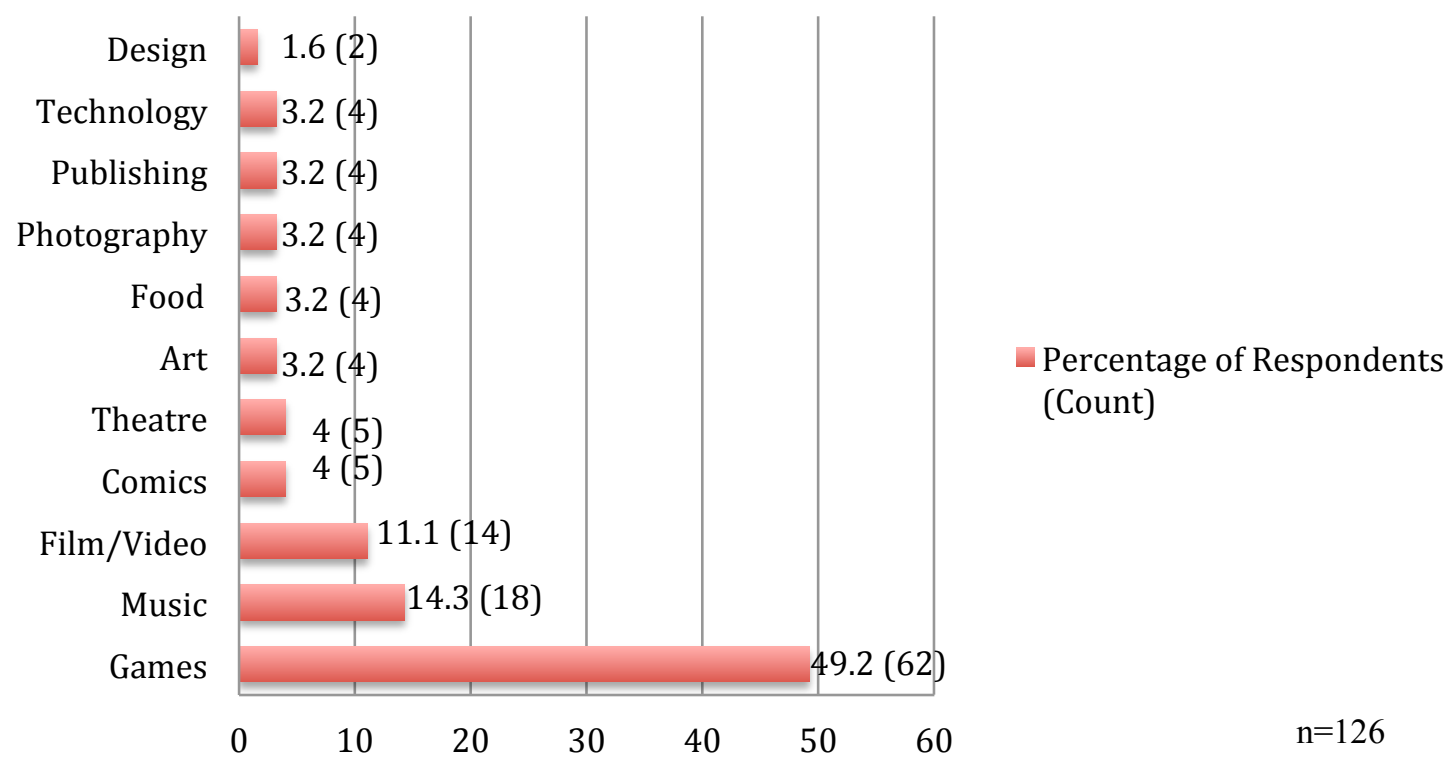




\section{Interview Results}

\section{Localism}

Interview participants were divided on the importance of supporting project creators from their local area. Some participants found it important to support projects that brought artistic work into their communities and may not have received funding without Kickstarter. A backer of 13 projects said, “...I'm from [Columbia] South Carolina and the arts aren't supported very well by our leadership and our government, so it's something that we have to do from the ground up." Another participant who backed one project echoed similar sentiments, saying:

The Columbia community has a lot of really good things going on, particularly for young professionals on the food scene and the art scene, etc., but it tends to circle around the same group of people who are starting projects or promoting initiatives, and a lot of them get city funding... It was also good that the same sponsors who are always tapped to support everything arts and cultural were not the sponsors of this, so it was sort of giving them a little bit of relief, and it was highlighting new artists in a genre that is not particularly thought of often.

Others, however, were motivated only by the type of project and their interest in it

or decided to back a project because they knew the creator (whether the creator was locally-based or not). One backer of nine projects said:

Local had nothing to do with it. I mean, because I knew them or knew their work, it was important... but just because somebody does a Kickstarter and they're local doesn't mean-you know, that's not a really huge weighing factor.

Among the participants who were not motivated by localism or had not backed projects based in their local areas, most said that the local factor could make them more inclined to contribute to a project if that project still fit within their interests. One 
participant who had backed 21 projects described the only locally based project he had backed:

It's called Travelling 219: The Seneca Trail. They wanted to go up this highway 219 in West Virginia, which goes all the way through the mountains, right into the panhandle of West Virginia, and they were just walking up and collecting stories. It was basically folklore, and I love West Virginia, number one, and number two, folklore; I just love folklore so much. And when my friend said, hey we're doing this stuff, collecting stories and oral histories from people around US 219, I was like, that sounds awesome, let's do it.

Project category was an important factor for how important a participant considered localism. Those who backed projects that generally had product-based outcomes, such as video games, board games, and music recordings, were not as likely to think the local aspect of a project was as important as those who more often backed categories like art, dance, and theatre, which more often had outcomes that were done only in one place, such as live performances and art exhibits. Overall, interview participants tended to hold localism as more important than survey respondents did. Survey responses mostly indicated localism was not very important, while the interview participants were more varied in their opinions.

\section{Involvement in the Creative Process}

Unlike the survey participants, who rated their feelings of creative involvement highly, the interview subjects were decidedly mixed on how involved they felt in the creative process when they backed projects. The backers who felt most strongly that they were part of creating the project had backed projects in which the creators directly asked backers for creative input. A backer of 11 projects described participating in the Torment project, in which the developer sought backer input about the gameplay (Sykes, 2013): 
They had two or three weeks where you could put all your arguments together on the forums - backer-only forums, so you had to have been a proven backer to participate - and then they said, "OK, once all your arguments have been fairly represented, we're going to hold a vote." They held the vote and then they made a decision. They took their own thoughts into account, but it ended up being that the fans voted for what they were leaning towards anyway...

Other backers felt like being part of the funding process for a project was not the same as being part of the creative process and that project creators had their project ideas ready to be made without further ideas from backers. These participants looked at Kickstarter as more of a funding tool than a platform for collective intelligence. A backer of one project said:

Yeah, my anticipation was that using Kickstarter was just in exchange, basically, for PayPal or something - some other way to make a donation. It was just - maybe it was the cool, new, hip way to get donors. It wasn't-I don't know what I'm trying to say - the business plan was thought out, it wasn't a think tank kind of thing, it wasn't a brainstorming or sharing of ideas. It was just a way to collect funds.

In between these two schools of thought is the idea that funding is a part of the creative process. Some participants felt like part of the creative process simply by funding, even though they were not asked for input regarding the project's outcome. A participant who had backed one project described such a feeling when describing whether her contribution made a difference to the final result (a movie):

Yes, I do, because it was such a small budget. I mean, the budgets movies get made on are, you know $\$ 100$ million plus these days, and this movie had a goal of just $\$ 2$ million. That's it. And whenever they hit the goal within just a few hours, they were making it clear via email and through, again, social media and whatnot, that the more money they got, the better the movie would be, because the bigger budget they would have. That was what encouraged me to donate even thought he goal had already been met, was that, "Hey, I'm just gonna help make it better." 
Interview participants were more similar to survey respondents in their views on communication with project creators. Although few engaged in direct communication with the creators, they appreciated the project updates because the updates let them know the project was being completed. One backer of 21 projects discussed the importance of updates when talking about a project that had a lack of communication from the creators:

I lived in Washington, D.C., when I Kickstarted that game. I went to-I lived in China for an entire year and came home, and it still wasn't here...They didn't tell us what was going on...They brought on a new Kickstarter halfway through the game they were planning for us and it was like, "What are you doing? You're not even done. You haven't shown us anything from the other game."

Through funding or active participation, backers generally felt involved in the process of creating the projects they supported. Not all creators sought information about details that backers wanted to see in the final products, but the level of communication throughout the process that backers usually received was greater than that of traditional media. To some extent, this increased level of communication was important, if not only for the fact that hearing from the creators on a regular basis lets backers know that the projects they've supported are being developed. Given the divergent views between survey respondents and interview participants, along with the weaker correlation effect size of the survey responses, future research is needed to further explore and define creative involvement.

\section{Likelihood of Sharing Projects}

The interview participants all said they were likely to share the campaigns they had backed with others through both social media and person-to-person communications, such as emails or simply telling another person about a project. Regarding social media's role in Kickstarter campaigns, a participants who had backed three projects said: 
I think, though, that for me-I'm in the newspaper business, so I have traveled extensively throughout the country. I've got friends in every major city in America-social is really the way I keep in touch with that community. So for me, just putting it out on social repeatedly, "Hey, we've got five days left and we're this close to the goal," I think that, for me, is even more impactful than telling my close circle of friends.

And I think that, again, if you look at the evolution of social as it relates to indie music, you know, I'm not inventing anything here, if you go back to the days of MySpace, these kids were putting their stuff out there long before an old guy like me with a checkbook realized that, "Hey, I've got 600 friends and, exponentially, I could get this in front of five or ten thousand people," they were doing it long before that.

Although social media's potential to reach large numbers of people is important for the success Kickstarter campaigns, interview participants also stressed the importance of more personal, one-to-one communication in communicating with an audience. One backer said:

I think it's beneficial on both sides. If it's somebody you have a personal relationship with, you can connect more directly and send them something more personal, you are more likely to get a donation or response out of a personal communication, like, "Dear [name redacted]," as opposed to something on Facebook. But on the same token, I saw it on Facebook. It would have been easy enough for me to share, because that whole "slacktivism" concept of people wanting to be activists or supporters of something, but they want to do it in the easiest way possible, and the easiest way possible is to hit "share."

Taken together, these ideas demonstrate that it is important for Kickstarter project creators to connect with their personal social networks to obtain initial funding (Kuppuswamy and Bayus, 2013), as well as to spread the project via social media and having backers spread the project through their social networks to reach enough of an audience to successfully fund the project. 
Rewards

Interview participants were not as motivated by rewards as survey respondents.

For most of the interview participants, rewards were not an important factor in their decision to back a project, but for some, the rewards were an incentive to contribute a higher dollar amount. For example, a backer of one project said:

Well, I was initially going to donate, I think, \$25 and just get the t-shirt, but when I figured out you would also get a digital copy of the movie, I thought, "Well, I would pay $\$ 25$ to buy the Blu-Ray anyway, so what's the point? I might as well get the digital copy." So then I upped it to $\$ 50$.

Another factor some participants liked about rewards was their exclusivity to

Kickstarter. Backers felt rewarded for their contributions when they received parts of the project that people who bought the product in retail (provided it was eventually sold in retail). One backer of 21 projects explained the appeal of exclusive rewards:

That Euphoria game that I Kickstarted, the one I was talking about a moment ago...there's a bunch of stuff that came with that game that you cannot get in the retail copy of it...It's such a cool thing, and he [the project creator] said, you know, you're going to be paying retail price for it, but you're going to get all this other great stuff. And when they kind of put it to me that way, I was like, "Wow. That's a, that's a cool way to do it."

On a similar note, a participant who had backed 48 projects saw the exclusive

status of some backer rewards as a reward for the risk of backing a Kickstarter project:

I really do like some type of exclusivity as a reward for being a financial backer. Just because there's no guarantee for delivery, so I feel like they have to offer something extra, whether that's a significant discount on the product or extra add-ons or exclusives not available elsewhere.

When asked about what kinds of rewards they might like to see in future campaigns, several participants replied that they wanted to see distinct items that would 
Kickstarter backers feel like they were invested in the projects. One backer of 11 projects gave an unusual example:

Actually, I saw a fairly awesome reward for a game I recently backed. It's called Deliverance: Kingdom Come. And they are actually having people forge legitimate swords as a backer reward...That kind of stuff was awesome - not necessarily the game itself, but it's almost like if Zelda were funded, you could get a copy of the Master Sword or the Hyrulean Shield. That would be awesome. That would definitely make me consider backing it more.

Though several participants were motivated to contribute or to contribute higher

amounts because of rewards, some saw rewards as inconsequential, even if they still liked the rewards they received from projects. In backing a campaign for a musician's new album, one participant who had backed three projects described the feeling that while he was satisfied with the project rewards, he was more concerned with supporting the arts with a donation than receiving products in exchange for money:

I got an 8 by 10 glossy, I got a t-shirt, I got a copy of the album, and then I've got bonus tracks in the studio itself, which I thought was pretty cool. But again, it's kind of like my donations to PBS. I don't do it for the rewards. The rewards are nice, but I do it for a different reason.

Based on the participants' thoughts, rewards do not hold exceptional importance for many Kickstarter backers, though for some, they provide incentives for many people to contribute to the projects and make backers feel like their contributions were special. Additionally, backers might enjoy the overall Kickstarter experience more because of the rewards. However, rewards on their own may not be enough to draw backers to project. Some backers need more intangible, goal-focused reasons to decide to fund projects. It should be noted, however, that in the one-on-one communication setting of an interview, participants may be less likely to say rewards are important because they do not want to seem self-serving than in an anonymous online survey. 


\section{Accountability Concerns}

On the whole, the interview participants were likely to continue using Kickstarter despite its limited accountability for projects that are not completed. These findings are consistent with the survey data, although some interview participants voiced concerns. A few backers said that the policy would not prevent them from using Kickstarter at all, but it would make them less likely to contribute large amounts of money to projects or make them more particular about what projects they would be willing to back. A backer of one project summarized this issue in an answer:

I suppose, as someone who is potentially going to fund future projects, that makes me think I'm really sure I'm not ever going to give money to someone I don't know, who I don't know who will finish a project, and I'm certainly never going to fund a tech gadget, because by the time that project is finished, it could be that a newer, greater, version has already come out. So it affects my desire to fund certain types of projects, but I don't know that I would expect Kickstarter to do anything to intervene on my behalf. And honestly, I'm not going to give a sizeable donation over Kickstarter anyway. It'll be maybe 50 bucks at the max of what I'd give.

Other participants said that despite these issues about Kickstarter, they trust

Kickstarter's name because of the successful and high profile projects that have been

funded through the site. When asked about his familiarity with the accountability policy, one backer of 11 projects said:

You know, honestly, when I got into it at least, I didn't really think twice about it because Kickstarter is a trusted name. I didn't realize until I read that that if they don't make the product then they're not liable. I'm like, well, I wouldn't back a project by someone I didn't trust anyway, so it's been moot for me, but I can see some issues with that policy.

He further added that he would be more likely to trust Kickstarter than other crowdfunding websites because of its reputation:

Yeah, because there are a couple [other crowdfunding sites]. I know, Zachary Levi, for instance is using a different website, and just because I 
trust his name, I'd probably feel comfortable that site, but in general, I'd probably stick with Kickstarter, and I would do some more research on other ones before then.

Perhaps more idealistically, one backer of three projects asserted that the reputation of an individual project creator or group of creators was a sufficient check for ensuring that a Kickstarter project was completed. When the policy was explained to him, he replied:

And, you know, I have to be really candid with you when I say this, I didn't know that, probably because two of the three projects that I funded were people that I knew or at least knew on some level...And I think that, yeah, at some point, you can probably make some money off this. You and I could set up a band, we'll and call it the [name redacted] and Kevin Band. We're gonna do this great album. We're gonna try to generate $\$ 5,000$, and we get our five grand and walk away. OK, you're gonna make five grand one time. I don't think that I would ever try to seek restitution for that. And at the same time, but I'm not investing tens of thousands of dollars either. I'm not looking at it from a commercial investment. I'm looking at it as more supporting local music or charitable contribution. I look at this the same way I do making a donation to PBS or the Red Cross.

Although backers saw the potential for problems with the accountability policy, they did not feel like the policy needed any significant changes, saying that limited accountability was necessary for Kickstarter to operate. In response to the question of whether he would like to see changes in the policy, a backer of 11 projects said:

Well, I think Kickstarter probably should have more accountability for that, but I think it would negatively impact what they're able to do, as far as giving people a space to promote their efforts. If they had to go to court every time someone didn't follow through, they might not be in existence.

A participant who had backed one project, echoed this idea, saying:

There's not really much that they can do. Would I like them to say, "Oh yeah, well, this didn't work, so here's your money back?" But, at the same time, there's not really much they can do. I know, as a consumer going into this, that I'm donating money. This doesn't guarantee that a project is going to go in, so I take responsibility for that. It's not Kickstarter's fault. 
So I wouldn't expect that as someone who funds a project. I know what I'm getting into.

Participants also placed the burden on prospective project backers to research the creators of a project and examine the details of it when deciding whether or not to contribute. Some felt that in most cases, Kickstarter users could tell how viable a project would be based on the information available through Kickstarter pages and further resources, such as a creator's website or past works. The backer of 21 projects whose worst Kickstarter experience was described above explained the need for research:

...you need to research it and check it out to make sure what you're investing in is actually worth it. Have these guys done anything? Do they deserve your money? Does it seem well put together? Someone could have the best idea in the world but have the most terribly run campaign. Should you give them money? Will they manage it well? The thing I always pay attention to is the very bottom of the Kickstarter page because it says "Risks and Rewards," and they say what the risks are...You really have to look at who you're giving your money to.

Though participants did not want Kickstarter to change its policy, some suggested that it would be helpful for backers to have easier access to information about the policy and what to do if a creator does not finish a project. A participant who had backed nine projects suggested:

From a personal standpoint of receiving rewards and things like that or completing the project, I would like Kickstarter to make these more readily accessible to those who are giving...I think somebody giving money would assume that this is set in stone, that the money's going to go to the project they're giving it to, so for the person who's contributing, I think the rules should be - even a general explanation — should be highlighted.

These interviews, along with the survey data, suggest that Kickstarter's continued success and growth is not contingent on implementing further accountability from project creators. Many backers know what to expect when choosing to support a project and 
recognize the risks and the need for diligent research about campaigns that interest them.

New issues could arise in the future regarding Kickstarter's accountability policy, but at present, the limited accountability of the policy is not often a deterrent for those interested in backing Kickstarter projects.

\section{Most Common Reasons For Backing and Backers' Favorite Projects}

Two major themes emerged from the interviews as to why participants chose to support Kickstarter projects. First, almost every participant said that an important reason—if not the most important reason—-for backing a Kickstarter project was that the project was important to its field. These were the projects that backers felt most passionate and enthusiastic about. Participants discussed the need for diverse, bold, and innovative projects in the industries they loved and wanted to support creators they knew were doing quality work. For example, one participant who had backed three projects explained why he thought it was important to back an album from Seth Walker, an independent blues musician:

With music, I think it's kind of a twofold process. I have to think that what the artist is doing is important. Again, if you take Seth Walker, which was by far my biggest backing - I think I gave $\$ 500$ or more to him, I can't remember what I gave - but to me, what Seth is doing from a blues standpoint - again, not commercially viable in the sense of, you know, he's not a John Legend. Hell, he's not even a Harry Connick, Jr., from a selling standpoint, but the work he's doing, in my opinion, is really, really important from the legacy of blues. And, in my opinion, what is being lost through commercialization of music is, again, you've got an A\&R guy, or you've got a label, that kind of looks at it says, "Well, I like it and I can make money off it," not "This is really good work that's really important, and it's following these five attributes of blues progressions."

Continuing this idea with a second theme, backers said they did not think the diverse projects they were backing would be made without funding of Kickstarter because they may be considered too risky for traditional means of funding, which can 
have limitations due to what could be profitable in its market. Publishers may be unwilling to take risks on ideas that might not be appealing to a wide audience. Further, creators may not have the means to for their work to reach people without the use of a platform like Kickstarter. One backer of 21 projects discussed Broken Age, a computer game that was funded by an independent game development company in 2012. $\mathrm{He}$ explained that the game would have likely struggled to find funding from publishers because it was not in a popular video game genre:

Well the guy, Tim Schaffer: he is a really famous video game creator. He made a lot of amazing old point-and-click adventures... and they decided to - they tried to go to publishers to try to make a new one and nobody would make it. Everyone's like, "No. That's too risky. No one will give us money because they don't think they'll get a return because they don't think people would want to play a point-and-click adventure in this day of Call of Duty and, you know, World of Warcraft or League of Legends." Like, it's just something that they thought would be too boring or something. And they created this game called Broken Age...Their goal was $\$ 400,000$ to make this game, and they ended up getting $\$ 3,336,000$.

Overall, the interview participants' reasons for backing projects reflected the reasons survey respondents gave for backing their favorite projects. However, some survey respondents said the reasons they backed one or more projects because they wanted to have the final product, whereas interview participants did not cite this reason as a contributing factor. The interviews show that there are audiences for more diverse things than what major production companies and publishers will usually release. Audience members are looking to Kickstarter as a place where the work that might not find its way to mainstream success can thrive and reach the people who will love it. Participants valued different aspects of Kickstarter projects, but they had common ground in feeling that the projects were important and deserving of an audience. This factor is the driving force behind Kickstarter. A summary of key findings can be found in Table 2 
Table 2: Summary of Key Findings

Key Findings

- Localism was not very important to backers when choosing whether to back a project.

- Backers felt like part of the creative process and wanted to be able to communicate with project creators.

- Backers who felt more involved in the creative process had greater satisfaction with project results

- Backers were likely to share projects in person and on social media.

- Kickstarter-exclusive rewards were important to backers, especially when choosing how much money to contribute.

- Kickstarter's accountability policy did not affect backers' interest in using the platform, regardless of the typical amount they pledged.

- Income and education levels did not affect backers' likelihood of contributing to projects.

- Knowing the project creator personally was important to many backers.

- Many backers said they contributed to Kickstarter projects because they felt the work being done was important to its field. 


\section{CHAPTER 6: DISCUSSION}

This study used an online survey $(n=128)$ and a series of in-depth interviews $(n=8)$ to explore factors of Kickstarter projects to determine which aspects were most important to backers' decisions to financially support projects. Participants in this study demonstrated that Kickstarter does not precisely fall into a category of being a charitable or a business platform. It is apparent from the survey and interview responses that backers have different fundamental views of what Kickstarter is for. Some see it as a way to support small or nonprofit efforts, such as performances for a local area, while others look to Kickstarter as a place to obtain products being made by businesses, such as video games. For some backers, the viewpoint may change depending on the type of project. It seems, then, that Kickstarter is a viable platform for nonprofit ventures or companies wanting to launch their products through crowdfunding. For any Kickstarter creator, be it a community arts promoter or a business startup, the data suggest some factors to consider when launching and carrying out a campaign.

\section{Localism}

Localism was not very important to backers in this study. This theme is contrary to previous research. Crowdfunding participants in Aitamurto's (2011) study, for example, were primarily motivated to contribute because they felt that the journalistic projects on Spot.Us were important to the cities in which they lived. In this instance, however, localism may have differing influence based on the type of project being backed. Spot.Us hosts solely journalistic projects, which might be, in some cases, inherently more important to the area in which a story is taking place. In this study, the most popular categories were games and film/video, in which it is less likely for location 
to matter. Most games projects are delivered digitally (for computer games) or via mail (for board or card games). Film/video projects are often distributed digitally or via mail as well, though some projects in this category are film festivals that only take place in one city. Even with festivals in mind, one can see why some project categories may lend themselves to local interest more than others, and backers who favor those kinds of projects may be less likely to view localism as important, though they could potentially be motivated by the local factor.

Although localism was not very important to backers in this study, local interests are part of the theme of community, which emerged from the survey and interview results. Backers were motivated by the feeling that projects were important to some kind of community to which they belonged, especially when backers discussed their favorite projects. For some, the community was a physical place, such as in Aitamurto's (2011) study of backers who wanted to support projects in the cities in which they lived or worked. For others, the community derived from mutual appreciation for the creator, subject, or type of project, and the work was accessible to anyone regardless of geographic location. Like the participants in Sorensen's (2012) study, in which crowdfunding backers tended to fund TV documentaries based on enthusiasm for a topic or issue, some participants in this study were brought together as project backers based on enthusiasm for a filmmaker, actor, musician, or game developer. For creators, this finding highlights the need to emphasize the communal aspects of projects, whether they are working to improve a geographic community or a creating something for a large fan following. 


\section{Creative Involvement and Communication with Project Creators}

Backers also wanted communication from the creators throughout the process. Following the findings of Kelly, Laskin, and Rosenstein (2010), backers' desire for twoway communication is reflected in their strong agreement that the ability to communicate with and receive updates from creators was an important part of their Kickstarter experience. Kickstarter is an example of how Grunig and Hunt's (1984) model of twoway symmetrical communication is useful for content creators and audiences to reach a mutual understanding about each other's interests. Creators receive the funds to make their projects, while backers can take an active role in telling creators what they want. In following campaigns from start to finish, participants in this study felt like they were part of the process of creating projects. Jenkins (2006) and Jenkins and Deuze (2008) view participation in the creative process as part of a participatory culture, in which content creators and audiences collaborate to reach a common goal. The results support this theory, as they demonstrate a desire for audiences to help create the things they want to experience and that many backers felt like they had some influence over how the final product turned out. Some participants differed, saying they did not feel they influenced the final result, but still felt like part of the creative process because without their funds, the project would not be completed.

Although some did not feel they were part of the creative process at all, the number who did is notable enough for creators to consider when shaping project communications. Another important consideration for creators is that the feeling of being part of the creative process had a positive impact on backers' satisfaction with the final results of projects, as shown by the moderate, positive correlation between level of 
feeling involved and satisfaction. The ability to involve backers in the creative process can be a unique selling benefit of Kickstarter over traditional platforms of distribution. Backers appreciate being able to talk to creators about a project's progression and specifications, and creators should offer such communication opportunities to cultivate the best relationship with backers that they can. Backers who were happy with one of a creator's projects could be more likely to return for future projects.

\section{The Importance of Sharing Projects}

In support of the findings of Ordanini et al. (2011) and Kuppuswamy and Bayus (2013), this study shows that it is crucial for project creators to use personal connections to start their funding. Many backers cited knowing creators as a strong motivating factor for contributing. Given the number of respondents who had also backed one to three campaigns, it is likely that a substantial portion of them only backed projects because they knew the creators. Creators who are very well known in their fields can likely reach their funding goals without a large group of personal connections as backers, but the vast majority of Kickstarter creators need the support of people they know to help reach their funding goals. Neil Young, for example, could fund his Pono Music Player without needing pledges from his friends because his fame led to press coverage for his project. A lesser known musician like Seth Walker is more likely to need contributions and sharing from his personal connections to reach his goal and help his project gain exposure when he does not have media coverage to get his name out to mass audiences.

In addition to needing personal connections to share projects and gain momentum in the funding process, project creators need to use multiple methods of sharing projects and encourage their backers to do the same. Because participants found individual 
communication to be about as important as sharing projects on social media, it is clear that the focused attention of one-on-one communication is as important as social media's ability for many people to read about a project. The two types of communication could also overlap. For example, several interview participants mentioned having contacted friends through Facebook messages to tell them about Kickstarter projects they had backed. Essentially, backers are using social media as a type of word of mouth.

\section{Participatory Culture}

In addition to feeling involved in the creative process, the influence of community demonstrates the role of participatory culture in crowdfunding. Many successful Kickstarter campaigns have been driven by fan communities, be they fans of a specific work, such as Veronica Mars, or fans of a broader category of things, such as the fans of independent video games that backed the Ouya console. Fan communities are part of a participatory culture because they encourage social interaction among members (Jenkins, 2006). Kickstarter allows fan communities to further expand because it enables fans to have social interaction with project creators. This way, fan groups can turn their topics of conversation into real results by conveying their ideas and desires to creators, which distinguishes Kickstarter from traditional ways of funding and purchasing products. Through its encouragement of social interaction between creators and backers, Kickstarter cultivates a community of funding and creating (Jenkins, 2006) that shows how two-way symmetrical communication benefits both sides (Grunig \& Hunt, 1984).

Participatory culture is further demonstrated by the importance of sharing projects. One of Jenkins's (2006) factors of a participatory culture is that it recognizes members for their contributions. For Kickstarter backers, sharing is an important 
contribution, and they will likely find greater recognition for their sharing than they would through traditional forms of financial support. For example, a backer would likely receive more recognition for a Kickstarter contribution than a donation to PBS or NPR. When people donate to those organizations, they might hear their name on a TV or radio broadcast, but they are not encouraged to call their friends and family members to tell them about their donations. On Kickstarter, however, backers are encouraged to share projects they have backed with their friends and followers on social media. Not only does this encouragement help creators spread knowledge of their projects, but it also allows backers to be recognized for their contributions, increasing the feelings that these contributions matter (Jenkins, 2006).

\section{Rewards}

Overall, the rewards that were included with projects were at least somewhat important to backers. Though rewards were not always a major factor in whether a person chose to back a campaign, they were appreciated. Further, rewards played a role in how much backers were willing to contribute, and some backers were drawn to campaigns specifically because of rewards. Rewards increased the overall satisfaction many participants had with their Kickstarter experiences due to being exclusive, cost-effective, or simply entertaining, and they had a degree of influence in drawing people to use Kickstarter. Like the ability to get involved in the creative process, rewards are a unique benefit that crowdfunding has compared to traditional means of productions. When shaping their pitches to prospective backers, project creators should emphasize the exclusivity of their project rewards as a distinct part of the Kickstarter experience. Along with supporting a project important to one's community and becoming a part of the 
creative process, tangible rewards make backers of Kickstarter projects happy and possibly more likely to come back to Kickstarter in the future.

\section{Accountability}

Backers' acceptance of Kickstarter's accountability policy is positive for creators, but it does not free them from the responsibility to deliver their campaign promises. It benefits Kickstarter and prospective creators because it makes the site accessible for those new to crowdfunding or to their fields by removing barriers to entry (for example, a band funding its first recording). Backers are willing to take risks by supporting Kickstarter projects, so the barriers to entry for creators are fairly low, and the viability for innovative and non-mainstream projects is high. However, accountability gives some backers reservations. Some are less likely to give high dollar amounts to campaigns, back certain types of projects, or support any projects made by people they do not know.

As shown in Kickstarter's history, controversies over the ways in which some campaigns were carried out and distributed have not kept projects from being successful (Jefferson, 2012; Grow, 2014), and uncertainties about backer protection have not kept projects from obtaining large amounts in pledges (Shahani, 2012). Large numbers of backers felt that these projects were worthy of their pledges, so it is apparent that people are willing to take financial risks on Kickstarter if they have enough interest in seeing an innovative project be made. To maintain the positive view most backers have of Kickstarter, however, creators need to make sure they know what they are getting into with their projects. Creators need a realistic view of what they want to do and how much money they need, as well as a project pitch that shows backers what the final result will be to let backers know they have a solid vision of how the project will be developed. 
Clear, consistent, and accurate communication with backers from the beginning of campaigns is essential for Kickstarter's continued growth as a creative platform.

\section{Most Common Reasons for Backing and Backers' Favorite Projects}

When discussing the reasons for supporting Kickstarter and their favorite projects, participants in this study reiterated the themes discussed above: community, creative participation, and rewards. Some wanted to support people who were close to them personally. Others wanted works they found important to their respective communities to be made for others to see. Some backers wanted rewards that came with certain pledge levels. Many felt they were an important part of creating the projects they backed, as the projects could not have been created and released without support from fans. This point, in particular, is important for the relationship between creators and backers. Two-way symmetrical communication (Grunig and Hunt, 1984) depends on the willingness of the

creators to open communication with backers. By being transparent about the progress of a project, creators strengthen Kickstarter's benefits for prospective backers. Through twoway communication and backer participation, Kickstarter can give backers an experience that other production channels cannot - a way to directly tell content creators what they want. For creators, Kickstarter offers a chance to find and grow an audience for their work and engage with that audience without the need for any intermediaries. It creates a more two-sided method of production than traditional means allow.

\section{Strengths}

The key strength of this study is that it used longstanding, well-defined methods of public relations and advertising research (survey and in-depth interview) to measure audience characteristics of a new business model. By the very nature of crowdfunding, 
audience contribution is essential to the sustainability of the emerging business platform. This research will help project creators (and the scholars who study their work) learn how to best shape their project pitches and communications in ways that will stimulate potential backers' interest and encourage current backers to spread the word about the campaign to others. These ways include what parts of the campaign to emphasize most strongly and what kinds of incentives and rewards to offer with the projects.

Another important strength is the triangulation of the research. By using a qualitative and a quantitative method, the study gains reliability. Because the data is based on participants' answers to questions, it may inherently contain respondent bias. Method triangulation helps correct respondent bias, as the two methods add support to each other. The survey helps shape the content of the interviews, while the interviews help explain the survey results. Using both methods gives a broader and deeper base of knowledge than could be provided by either method on its own.

A third strength is that the study had a diverse population of participants. Survey respondents represented 32 US states and five foreign countries, and interview participants lived or had lived in numerous states. The ages of the survey participants were diverse as well, and the ages of the interview subjects represented the age groups that were most common among the survey respondents. The income and education levels of participants varied, and no group was under- or overrepresented. The only disparity in the demographics was that there were 30 more men than women in the 128 valid survey responses. This issue could likely be corrected with a larger number of participants. 


\section{Limitations}

The study also has some limitations. First, it is limited by the fact that it is focused on successfully funded campaigns that reached their final results. The questions in both the survey and interview guide were written to explore participants' reasons for support and satisfaction with the campaign results. Although survey and interview participants may have backed campaigns that were unsuccessful or not yet finished, their responses indicate they had experience with success. Backers might view the campaigns differently in retrospect than those who funded successful projects. By examining what influences backers to contribute funds, this study intends to measure what makes a project succeed. On the other side of measuring backers' attitudes, future research could examine what makes a project fail.

Additionally, its results cannot be generalized to a larger population of Kickstarter backers. The survey results cannot be generalized because a non-probability sampling method was used. In accordance with its privacy policy, Kickstarter (2012) does not release backers' email addresses to third parties, so the only ways to send the survey to backers are to ask project creators to include the survey link in their communications with backers and encourage backers to send the survey to other backers they know. Therefore, a sampling frame of Kickstarter users is not available.

Further, the number of peopled surveyed and interviewed is fairly low, which could have affected the results. For example, a study with a greater number of respondents may find education and income levels to be more influential. Because Kickstarter is a relatively new website that uses an emerging business model, the number of people who have used it is small compared to more traditional forms of commerce. 
Despite the efforts of the primary investigator, faculty advisor, and others, the number of valid survey responses fell below the goal. Time constraints prohibited leaving the survey open for more time and conducting more than eight interviews. Larger numbers of participants in both parts of the study could have added further insight to the research questions.

The questions in this study regarding localism and creative participation may have led to some confusion about the ways that variables were operationalized. According to the operationalization of variables, localism meant that the local aspect of a project was interesting to backers, but some participants seemed to think localism meant that they would back a project solely because it was local. Some of the answers regarding localism may have been more positive if the intention of the definition were stated outright to participants. Similarly, participants had different definitions of what qualified as involvement in the creative process. Some considered funding to be part of the creative process, while others drew a distinction between funding and creative involvement.

\section{Future Research}

Because this study had a small sample size, replicating it with a larger sample size could change the results. Kickstarter is growing in popularity, so future researcher are more likely to obtain a larger sample than in this study. Eventually, researchers may be able to use a probability-based sampling method, such as a stratified sample, of Kickstarter backers. In addition to increasing the size of the sample, it may be beneficial for future studies to use a different sampling method to explore the potential effects of particular variables (e.g. education, income, past Kickstarter experience) on attitudes toward Kickstarter. 
Localism, in particular, warrants further exploration with another method of sampling. Localism was not very important to the backers in this study, but its limited importance may have been affected by the sampling method. Convenience/snowball sampling might have led to an unusually high number of respondents who had backed projects in games, film/video, and music, which are inherently less likely to be important to a specific location than performance-based categories like theatre and dance. In other words, a video game or a DVD of a movie can be enjoyed in the same way regardless of location, while a dance or theatrical performance could only be experienced locally. For example, one interview participant stressed the importance of funding arts projects to benefit the city she lived in, while others, who primarily backed games, considered localism unimportant. Therefore, a quota or stratified sample of survey respondents or a more purposive sample of interview participants could be used to measure the importance of localism across all project types.

The theory of the bystander effect, which was mentioned in this study as part of background research but not explored in depth, could be used as the theoretical foundation of a future study about the timing of project contributions. Kuppuswamy and Bayus (2013) and Ordanini et al. explored the role of timing in the process of running a crowdfunding campaign, but further exploration could be built on their findings.

Another avenue for future studies is changing or adding research questions in conjunctions with changes in Kickstarter. For example, Kickstarter's accountability policy has changed over the course of the site's existence, and it could change again in response to a major issue with backer protection. In addition, if more famous people turn 
to Kickstarter as a way of funding their projects, audiences could begin to view the site differently, warranting further exploration.

Finally, future research could examine the factors that have made Kickstarter projects unsuccessful, or the aspects of Kickstarter that might dissuade prospective backers from using it. This study could be redesigned to tailor the questions toward what did not work about Kickstarter projects rather than what did. Looking beyond a sample of people who have backed Kickstarter campaigns, future studies could survey or interview people who have not to test their interest in crowdfunding. Research may find that people would be open to using Kickstarter but have not found a project that they like, or it might uncover reasons that make people hesitant about supporting Kickstarter projects. 


\section{References}

Aitamurto, T. (2011). The impact of crowdfunding on journalism: Case study of Spot.Us, a platform for community-funded reporting. Journalism Practice, 5 (4), 429-445. doi: 10.1080/17512786.2010551018

Balnaves, M. (2012). The Australian finance sector and social media: Towards a history of the new banking. Media International Australia 143, pp. 132-145. Retrieved from http://web.ebscohost.com/ehost/pdfviewer/pdfviewer?sid=5debbbc3-079842b6-aca9-0b185e182f77\%40sessionmgr113\&vid=10\&hid=119

Blair, E. (2013, January 25). For would-be Sundancers, Kickstarter can fuel films. National Public Radio. Retrieved from http://www.npr.org/2013/01/25/170191605/for-would-be-sundancers-kickstartercan-fuel-films

Blake, C. (2013, April 17). Are the Eisners over superheroes? Robot 6 @ Comic Book Resources. Retrieved from http://robot6.comicbookresources.com/2013/04/arethe-eisners-over-superheroes/

Carvajal, M., Garcia-Aviles, J., \& Gonzalez, J. (2012). Crowdfunding and nonprofit media. Journalism Practice 6 (5/6), pp. 638-647. doi: $10.1080 / 17512786.2012 .667267$

Caulfield, K. (2012, September 19). Dave Matthews Band debuts at no. 1 on Billboard 200. Billboard. Retrieved from http://www.billboard.com/articles/news/475029/dave-matthews-band-debuts-atno-1-on-billboard-200

Chen, P., Strickler, Y., \& Adler, C. (2012, September 4). Accountability on Kickstarter. Kickstarter Blogs. Retrieved from http://www.kickstarter.com/blog/accountability-on-kickstarter

Classic video game Planescape gets Kickstarter reboot (2013, March 7). BBC News: Technology. Retrieved from http://www.bbc.co.uk/news/technology-21700329

Darley, J., \& Latané, B. (1968). Bystander intervention in emergencies: Diffusion of responsibility. Journal of Personality and Social Psychology. Retrieved from http://www.yangjing.gwball.com/generalpsychology/w2_r1.pdf

Estelles-Arolas, E., \& Gonzalez-Ladron-de-Guevara, F. (2012). Towards an integrated crowdsourcing definition. Journal of Information Science 38 (2), pp. 189-200. doi: $10.1177 / 0165551512437638$

Glaser, B. \& Strauss, A. (1967). The discovery of grounded theory: Strategies for qualitative research. Piscataway, New Jersey: Aldine Transaction. 
Gobble, M. (2012). Everyone is a venture capitalist: The new age of crowdfunding. Research Technology Management 55 (4), pp. 4-7. Retrieved from http://content.ebscohost.com.www.libproxy.wvu.edu/pdf27_28/pdf/2012/RTM/01 Jul12/77491064.pdf? $\mathrm{T}=\mathrm{P} \& \mathrm{P}=\mathrm{AN} \& \mathrm{~K}=77491064 \& \mathrm{~S}=\mathrm{R} \& \mathrm{D}=\mathrm{f5h} \& E b s c o C o n t e n t=$ dGJyMMv17ESep7Y4y9fwOLCmr0uepq9Sr6q4SbGWxWXS\&ContentCustomer =dGJyMPXs54rz5OeOuePfgeyx44Dt6fIA

Gunes, S. (2012). Wisdom of firms versus wisdom of crowds. International Journal of Business, Humanities \& Technology 2 (3), pp. 55-60. Retrieved from http://web.ebscohost.com.www.libproxy.wvu.edu/ehost/pdfviewer/pdfviewer?sid $=3 \mathrm{c} 074 \mathrm{da} 0-\mathrm{b} 410-4 \mathrm{e} 4 \mathrm{e}-815 \mathrm{e}-3 \mathrm{f} 45 \mathrm{~b} 8 \mathrm{~d} 3 \mathrm{c} 3 \mathrm{fa} \% 40$ sessionmgr $113 \& \mathrm{vid}=12 \& \mathrm{kid}=114$

Gross, D. (2014, April 15). Neil Young's Pono music player raises millions. CNN Tech. Retrieved from http://www.cnn.com/2014/04/15/tech/mobile/neil-young-ponokickstarter/

Grow, K. (2014, March 18). 'Veronica Mars' Kickstarter backers angry at rewards. Rolling Stone. Retrieved from http://www.rollingstone.com/movies/news/veronica-mars-kickstarter-backersangry-at-rewards-20140318

Grunig, J., \& Hunt, T. (1984). Managing public relations. New York: Holt, Rinehart and Winston.

InXile Entertainment (2012, March 13). Wasteland 2. Kickstarter. Retrieved from http://www.kickstarter.com/projects/inxile/wasteland-2

InXile Entertainment (2013, March 6). Torment: Tides of Numenera. Retrieved from http://www.kickstarter.com/projects/inxile/torment-tides-of-numenera

Jefferson, C. (2012, September 19). Amanda Palmer's million-dollar music project and Kickstarter's accountability problem. Gawker. Retrieved from http://gawker.com/5944050/amanda-palmers-million+dollar-music-project-andkickstarters-accountability-problem

Jenkins, H. (2006). MacArthur. Confronting the challenges of participatory culture: Media education for the 21 st century. Retrieved from https://ecampus.wvu.edu/webct/urw/tp0.lc5116001/cobaltMainFrame.dowebct

Jenkins, H., \& Deuze, M. (2008). Convergence culture. The International Journal of Research into New Media Technologies 14 (1), pp. 5-12. doi: $10.1177 / 1354856507084415$

John, E. (2014, March 13). Veronica Mars, the movie: 'Fans gave their money, there was all this pressure.' The Guardian. Retrieved from 
http://www.theguardian.com/film/2014/mar/13/veronica-mars-movie-fansmoney-pressure-return-kickstarter-funded-marshmallows

Kelly, K. (1994). Utilizing public relations theory to conceptualize and test models of fund raising. Journalism \& Mass Communication Quarterly 72 (1), pp. 106-127). Retrieved from http://web.ebscohost.com/ehost/pdfviewer/pdfviewer?sid=f7e65ccb-2ea5-4d068885-211f3df3f3f5\%40sessionmgr111\&vid=7\&hid $=117$

Kelly, K., Laskin, A., \& Rosenstein, G. (2010). Investor relations: Two-way symmetrical practice. Journal of Public Relations Research 22 (2), pp. 182-208. doi: 10.1080/10627261003601630

Kitchens, R., \& Torrence, B. (2012). The JOBS Act: Crowdfunding and beyond. Economic Development Journal 11 (4), pp. 42-47. Retrieved from http://web.ebscohost.com/ehost/pdfviewer/pdfviewer?sid=bdd7e046-db46-45fa9a62-e0e996f44c91\%40sessionmgr110\&vid=6\&hid=125

Kuppuswamy, V., \& Bayus, B. (2013, February 20). Crowdfunding creative ideas: The dynamics of project backers in Kickstarter. Retrieved from http://business.illinois.edu/ba/seminars/2013/Spring/bayus_paper.pdf

Lammle, R. (2012, April 15). Five retro games brought back from the dead by Kickstarter. Mashable. Retrieved from http://mashable.com/2012/04/15/retrogames-kickstarter/

Luther, C. (2011). Survey. In Zhou, S. \& Sloan, W. (Eds.), Research Methods in Communication (pp. 289-305). Northport, Alabama:University of Alabama Press

Nicks, D. (2014, January 8). Kickstarter projects raked in $\$ 480 \mathrm{M}$ in 2013 for biggest year ever. Time. Retrieved from http://business.time.com/2014/01/08/kickstarterprojects-raked-in-480m-in-2013-for-biggest-year-ever/

Ordanini, A., Miceli, L., Pizzetti, M., \& Parasuraman, A. (2011). Crowd-funding: Transforming customers into investors through innovative service platforms. Journal of Service Management 22 (4), pp. 443-470. doi: $10.1108 / 09564231111155079$

Privacy policy (2012, October). Kickstarter. Retrieved from http://www.kickstarter.com/privacy

Shahani, A. (2012, September 3). When a Kickstarter campaign fails, does anyone get their money back? National Public Radio. Retrieved from http://www.npr.org/blogs/alltechconsidered/2012/09/03/160505449/when-akickstarter-campaign-fails-does-anyone-get-their-money-back 
Sorensen, I. (2012). Crowdsourcing and outsourcing: The impact of online funding and distribution on the documentary film industry in the UK. Media, Culture, \& Society 34 (6), pp. 726-743. doi: 10.1177/0163443712449499

Sykes, T. (2013, November 24). InXile asking Kickstarter backers to vote over Torment's combat system. PC Gamer. Retrieved from http://www.pcgamer.com/2013/11/24/inxile-asking-kickstarter-backers-to-voteover-torments-combat-system/

Tuten, T. (2011). Interviews and intensive interviews. In Zhou, S. \& Sloan, W. (Eds.), Research Methods in Communication (pp. 289-305). Northport, Alabama: University of Alabama Press

Weisman, J. (2012, March 27). Final approval by House sends jobs bill to President for signature. The New York Times. Retrieved from http://www.nytimes.com/2012/03/28/us/politics/final-approval-by-house-sendsjobs-bill-to-president-for-signature.html? $\mathrm{r}=0$

What is Kickstarter? (2013). Kickstarter. Retrieved from http://www.kickstarter.com/hello?ref=nav 


\title{
APPENDIX A: CONSENT FOR WEB SURVEY
}

\author{
IRB Study \#TBD
}

By participating in this online survey, you agree to participate being conducted by a master's student at the Perley Isaac Reed School of Journalism at West Virginia University. Your participation is voluntary and you may quit at any time. All precautions have been taken so there are no risks to your participation, unless you feel uncomfortable answering questions about your use of Kickstarter and a few general questions about yourself. If you have any questions about this study, you may contact the principal investigator, Kevin Duvall, at kduvall1@mix.wvu.edu or (304) 545-0388. You may also contact the faculty advisor for the project, Dr. Rita F. Colistra, at Rita.Colistra@mail.wvu.edu or (304) 293-6793.

All research on human volunteers is reviewed by a committee that works to protect your rights and welfare. West Virginia University's Institutional Review Boards (IRB) has acknowledgement of this study on file. If you have questions or concerns about your rights as a research subject, you may contact, anonymously if you wish, you can contact the Institutional Review Board at (304) 293-7073. If you contact the IRB, please refer to study number [TBD].

What is the purpose of this study?

The purpose of this study is to explore the reasons Kickstarter backers have for contributing to projects. This research will help future project creators know what aspects of their campaigns are most influential for backers.

\section{How long will your part in this survey last?}

The questionnaire takes approximately 15 minutes to complete.

How many people will participate?

The goal for the number of participants is 150 .

\section{How will your privacy be protected?}

Every effort will be made to ensure that your privacy and confidentiality will be protected. Your name and contact information will only be used to track who has or has not responded so reminders may be posted. Your name will not be used in any of the information obtained from this study or in any of the research reports. No information will be attributed to any individual participant. Results of each question will be compiled electronically by the Web survey program, and only I, Kevin Duvall, and my thesis chair, Dr. Rita F. Colistra, will have access to these data. I will avoid deductive disclosure by limiting my analysis to the overall data collected by respondents.

Thank you very much for taking this questionnaire. Your input is valuable to the future of Kickstarter. Please click on the arrow in the right-hand corner below to begin the survey. 


\section{APPENDIX B: SURVEY INSTRUMENT}

1. Have you ever financially backed a Kickstarter project?

A. Yes

B. No

(If No, the respondent will be taken to a Thank You for Participating page.)

The following questions will ask you about your Kickstarter use.

2. How many Kickstarter campaigns have you backed?

Enter Number

3. What types of Kickstarter campaigns (projects) have you financially backed? (Check all that apply.)
A. Art
H. Comics
B. Dance
I. Design
C. Fashion
J. Film/Video
D. Food
K. Games
E. Music
L. Photography
F. Publishing M. Theatre
G. Technology

4. Think about your favorite Kickstarter campaign that you financially backed, and please answer the following questions about it.

4a. What type of project was it? (Choose only one.)
A. Art
H. Comics
B. Dance
I. Design
C. Fashion
J. $\quad$ Film/Video
D. Food
K. Games
E. Music
L. Photography
F. Publishing M. Theatre
G. Technology

4b. Approximately how much did you contribute?

Enter Dollar Amount

4c. Why did you decide to support this campaign? Please enter your response in the space provided below. 
4d. How do you feel about the final results of the project? Briefly describe in the space provided below.

5. Approximately how long ago did you first learn of Kickstarter?

Enter Number of Months and/or Years

6. How did you learn of the site?
A. Someone I know told me about Kickstarter
B. Someone I know created a Kickstarter campaign
C. News Media
D. Social Media
E. Other (please specify)

7. What is the largest amount of money you have pledged to a Kickstarter campaign?
A. $\$ 25$ or less
B. $\$ 26-\$ 50$
C. $\$ 51-\$ 75$
D. $\$ 76-\$ 100$
E. $\$ 101-\$ 200$
F. $\$ 201-\$ 300$
G. $\$ 301-\$ 400$
H. $\$ 401-\$ 500$
I. $\$ 501$ or more

8. What is the typical amount of money you have pledged to a Kickstarter campaign?
A. $\$ 25$ or less
B. $\$ 26-\$ 50$
C. $\$ 51-\$ 75$
D. $\$ 76-\$ 100$
E. $\$ 101-\$ 200$
F. $\quad \$ 201-\$ 300$
G. $\$ 301-\$ 400$
H. \$401-\$500 
I. $\$ 501$ or more

9. Besides contributing money, what else (if anything) have you done to support Kickstarter campaigns? (Check all that apply.)
A. Told other people about the project in person
B. Shared the project with friends or followers on social media
C. Tried to convince others, either in person or via social media, that they should also financially back the project.
D. Nothing. I have only contributed financially.
E. Other (Please specify.)

10. Why did you ultimately decide to contribute to one or more Kickstarter campaigns? (Please write your answer in the space below.) 
The following questions will ask you about the reasons you chose to back campaigns and your satisfaction with the campaigns you have backed.

11. How important are the Kickstarter-exclusive rewards offered by creators in your decision to back a Kickstarter campaign?

Not at all important $\quad 1 \quad 2 \quad \begin{array}{lllllll} & 4 & 4 & 5 & 6 & 7 & \text { Extremely important }\end{array}$

12. When choosing a Kickstarter campaign to back, how important is it that the project creator is from your local area?

Not at all important $\quad 1 \quad \begin{array}{llllllll} & 2 & 3 & 5 & 6 & 7 & \text { Extremely important }\end{array}$

13. After you have backed a Kickstarter campaign, how likely are you to share information about the campaign on social media sites (Facebook, Twitter, etc.)?

$\begin{array}{llllllllll}\text { Very unlikely } & 1 & 2 & 3 & 4 & 5 & 6 & 7 & \text { Very likely }\end{array}$

14. On average, how satisfied were you with the results of the Kickstarter campaigns you have backed?

Very unsatisfied $1 \begin{array}{llllllll}1 & 2 & 3 & 4 & 5 & 6 & 7 \text { Very satisfied }\end{array}$

15. Kickstarter cannot give refunds to backers when creators do not complete their funded projects. How does this policy affect your decision to back a campaign, if at all?

I am very unlikely to back a campaign because of it

$$
\begin{array}{lllllll}
1 & 2 & 3 & 4 & 5 & 6 & 7
\end{array}
$$

I am very likely to back a campaign despite it 
The following questions will ask you to agree or disagree with statements about your feelings on working with project creators.

16. When I back a Kickstarter campaign, it is important that I am able to communicate with the project creator.

$\begin{array}{llllllllll}\text { Strongly disagree } & 1 & 2 & 3 & 4 & 5 & 6 & 7 & \text { Strongly agree }\end{array}$

17. When I back a Kickstarter campaign, I feel like I am involved in creating the project.

$\begin{array}{llllllllll}\text { Strongly disagree } & 1 & 2 & 3 & 4 & 5 & 6 & 7 & \text { Strongly agree }\end{array}$

The questionnaire is almost finished. The last few questions will as you about demographic information.

18. What is your gender?
A. Male
B. Female
C. I prefer not to answer

19. What is your age?
A. $\quad 18-24$
B. $25-34$
C. $\quad 35-44$
D. $\quad 45-54$
E. $55+$
F. I prefer not to answer

20. What is your approximate yearly household income?
A. Under $\$ 25,000$
B. $\$ 25,000-\$ 49,999$
C. $\$ 50,000-\$ 74,999$
D. $\$ 75,000-\$ 99,999$
E. $\$ 100,000-\$ 124,999$
F. $\quad \$ 125,000-\$ 149,999$
G. $\$ 150,000$ or more
H. I prefer not to answer 
21. What is the highest level of education you have completed?
A. Less than a high school degree
B. High school degree to GED
C. Some college (no degree; may be currently enrolled)
D. Vocational certificate or associate's degree
E. College graduate (bachelor's degree)
F. $\quad$ Some graduate work (no degree)
G. Master's or other graduate professional degree
H. Doctoral degree

22. In what state do you currently live?

[participants must write in their answer] 


\title{
APPENDIX C: CONSENT FORM FOR INTERVIEW
}

\author{
IRB Study \#TBD
}

By participating in this interview, you agree to participate being conducted by a master's student at the Perley Isaac Reed School of Journalism at West Virginia University. Your participation is voluntary and you may quit at any time. All precautions have been taken so there are no risks to your participation, unless you feel uncomfortable answering questions about your use of Kickstarter. If you have any questions about this study, you may contact the principal investigator, Kevin Duvall, at kduvall1@mix.wvu.edu or (304) 545-0388. You may also contact the faculty advisor for the project, Dr. Rita F. Colistra, at Rita.Colistra@mail.wvu.edu or (304) 293-6793.

All research on human volunteers is reviewed by a committee that works to protect your rights and welfare. West Virginia University's Institutional Review Boards (IRB) has acknowledgement of this study on file. If you have questions or concerns about your rights as a research subject, you may contact, anonymously if you wish, you can contact the Institutional Review Board at (304) 293-7073. If you contact the IRB, please refer to study number [TBD].

I volunteer to participate in a research project conducted by Kevin Duvall from Perley Isaac Reed School of Journalism at West Virginia University. I understand that the project is designed to gather information about influences in my use of Kickstarter and my decision to financially support Kickstarter campaigns. I will be one of approximately four people being interviewed for this research.

1. I understand that my participation in this project is voluntary and that I will not be paid for my participation. I may decline to participate, and my decision to decline will be kept confidential.

2. I understand that I may withdraw and discontinue participation at any time without penalty and that my decision to withdraw will be kept confidential.

3. I understand that I have the right to decline to answer any question that may make me feel uncomfortable in any way.

4. I understand that participation involves being interviewed by a master's student from Perley Isaac Reed School of Journalism at West Virginia University. The interview will last approximately 1 hour. Notes will be taken during the interview.

5. I understand that the interview will be recorded. If I do not want to be recorded, I understand that I cannot participate. I can choose to not be recorded at any time during the interview. 
6. I understand that my name will be used in the resulting thesis. I understand that the full transcript of my interview will be included in the thesis as an appendix.

7. I understand that this research study has been approved by the Institutional Review Board (IRB).

8. I have read and understand the explanation provided to me. I have had all my questions answered to my satisfaction and voluntarily agree to participate in this study.

9. I have been given a copy of this consent form.

My signature

Date

My printed name 


\section{APPENDIX D: INTERVIEWER'S GUIDE}

$\underline{\text { Introduction }}$

- Interviewer introduces himself and explains the purpose of the interview (i.e. discussing why the participant backed the campaign and what the research hopes to accomplish).

- Interviewer explains that the interview will be recorded but kept confidential, and that it will be used only for this study.

- Participant completes information/consent form.

$\underline{\text { Background Questions }}$

- How many Kickstarter campaigns have you backed?

- How did you like the final results of these campaigns? Any favorites or least favorites?

- What was your most important reason for pledging money to the project? Why did you find this reason important? (probe-Make sure the participant goes into depth about this importance.)

Localism Questions

- How did you find out about the campaigns? Did you know any of the project creators personally?

- How important was it for you to support a local creator when choosing to back the project? (probe-Why is localism important to the participant?)

$\underline{\text { Reward Questions }}$

- What exclusive rewards did you get for your contributions, if any? 
- Did these rewards play a role in your decision to pledge? Did you have any favorite or least favorite rewards? (probe-Why did the participant choose these as favorites?)

- What other kinds of incentives and rewards would you like to see in future campaigns?

\section{Participation Questions}

- Did you feel your contributions were important in launching the project?

- Did you feel like you were a part of the creative process?

- If needed, interviewer will explain theoretical background of this idea.

- Did you spread the word about the campaign to your friends, family members, or others in your social network? If so, what methods did you use (social media, personto-person communication, etc.)?

\section{Accountability Questions}

- Interviewer will explain Kickstarter's accountability policies and the crowdfunding provision of the JOBS Act.

- Were you aware of these policies? Did you take the policies into account when choosing to back any campaigns?

- If needed, interviewer will explain the arguments for and against the policies discussed in the literature to ensure the participant understands the issue.

- Would the policies affect your decision to back future campaigns? (probe-How would it affect the participant's decision? Would he or she be more inclined to contribute small amount of money? Would he or she be less inclined to contribute at all?) 
- Would you like to see any changes in the site's accountability rules? (probe-Why, in particular, would the participant want these changes to be made?)

\section{Final Questions}

- Do you have final thoughts to share about any of the topics discussed today?

- Interviewer will thank the participant for his or her participation and emphasize the importance of the interview. 


\section{APPENDIX E: SAMPLE COMMUNICATIONS}

\section{Sample Facebook Post}

Facebook Sample 1: Hey guys. I'm doing a survey for my master's thesis about Kickstarter use, so if you have ever backed a Kickstarter campaign, please take it. And if you wouldn't mind, please share this post or send the survey link to other Kickstarter backers you know. Thank you so much for participating. [link]

Facebook Sample 2: My master's research is coming along well, but I'm still looking for more participants in this survey about Kickstarter use, so if you've ever backed a Kickstarter campaign and haven't taken it yet, please do so. I'd also be most appreciative if you would share this post or send the survey link to other Kickstarter backers you know. Thanks for taking the time to participate. [link]

Facebook Sample 3: My thesis research is coming to a close, but there is still time for anyone has ever backed a Kickstarter campaign to take this survey about Kickstarter use. And it's not too late to share this post or send the survey link to other Kickstarter backers you know. Thanks again for making this study a success. [link]

\section{Sample Twitter Posts}

Twitter Sample 1: Kickstarter backers: take and share this survey for my master's research. Thanks so much. [link]

Twitter Sample 2: Help Kickstarter with my master's research survey. And tell your friends to take it too. Thanks. [link]

Twitter Sample 3: How do you use Kickstarter? Tell me in this survey for my master's research. And share it too. Thanks. [link]

Twitter Sample 4: Master's research is going well, but I could use more Kickstarter backers to take this survey and spread it around. Thanks. [link]

Twitter Sample 5: Master's research is winding down, but you can still take this Kickstarter survey. Thank you for your help. [link] 


\section{Sample Project Creator Email}

Hi [creator name],

Thank you for reading my blog and letting me know about [project title]. It sounds like a great project.

I'm a graduate student in the school of journalism at West Virginia University doing my master's thesis about Kickstarter. Part of my study is conducting an online survey. The goal of my research is to find out whether various factors of Kickstarter campaigns, such as receiving exclusive rewards and supporting local project creators, influence backers to contribute. I am only seeking responses from people who have backed Kickstarter campaigns.

The survey will take 10 to 15 minutes. It is completely voluntary and you are not required to answer every question. Your name will not be attached to your reponse. More information is explained at the beginning of the survey.

Would you take the survey at the link below and share it with backers and other people you know who have supported Kickstarter? Thank you very much for helping me.

http://wvu.qualtrics...1G2Lh7eWaVJSt4V

Sincerely,

Kevin Duvall

Graduate Assistant

P.I. Reed School of Journalism

West Virginia University 


\section{Sample Forum Post}

Hi everyone,

I'm a graduate student in the school of journalism at West Virginia University doing my master's thesis about Kickstarter. Part of my study is conducting an online survey. The goal of my research is to find out whether various factors of Kickstarter campaigns, such as receiving exclusive rewards and supporting local project creators, influence backers to contribute. I am only seeking responses from people who have backed Kickstarter campaigns.

The survey will take 10 to 15 minutes. It is completely voluntary and you are not required to answer every question. Your name will not be attached to your response. More information is explained at the beginning of the survey.

Would you take the survey at the link below and share it with other people you know who have supported Kickstarter? Thank you very much for helping me.

http://wvu.qualtrics...1G2Lh7eWaVJSt4V

\section{Amazon Mechanical Turk Message}

I'm a graduate student at West Virginia University working on my thesis about Kickstarter. If you have ever backed a Kickstarter project, please take this survey. It's completely voluntary and you don't have to answer every question. Thanks! 


\section{APPENDIX F: SURVEY DEMOGRAPHIC INFORMATION}

\section{State or Country of Residence}

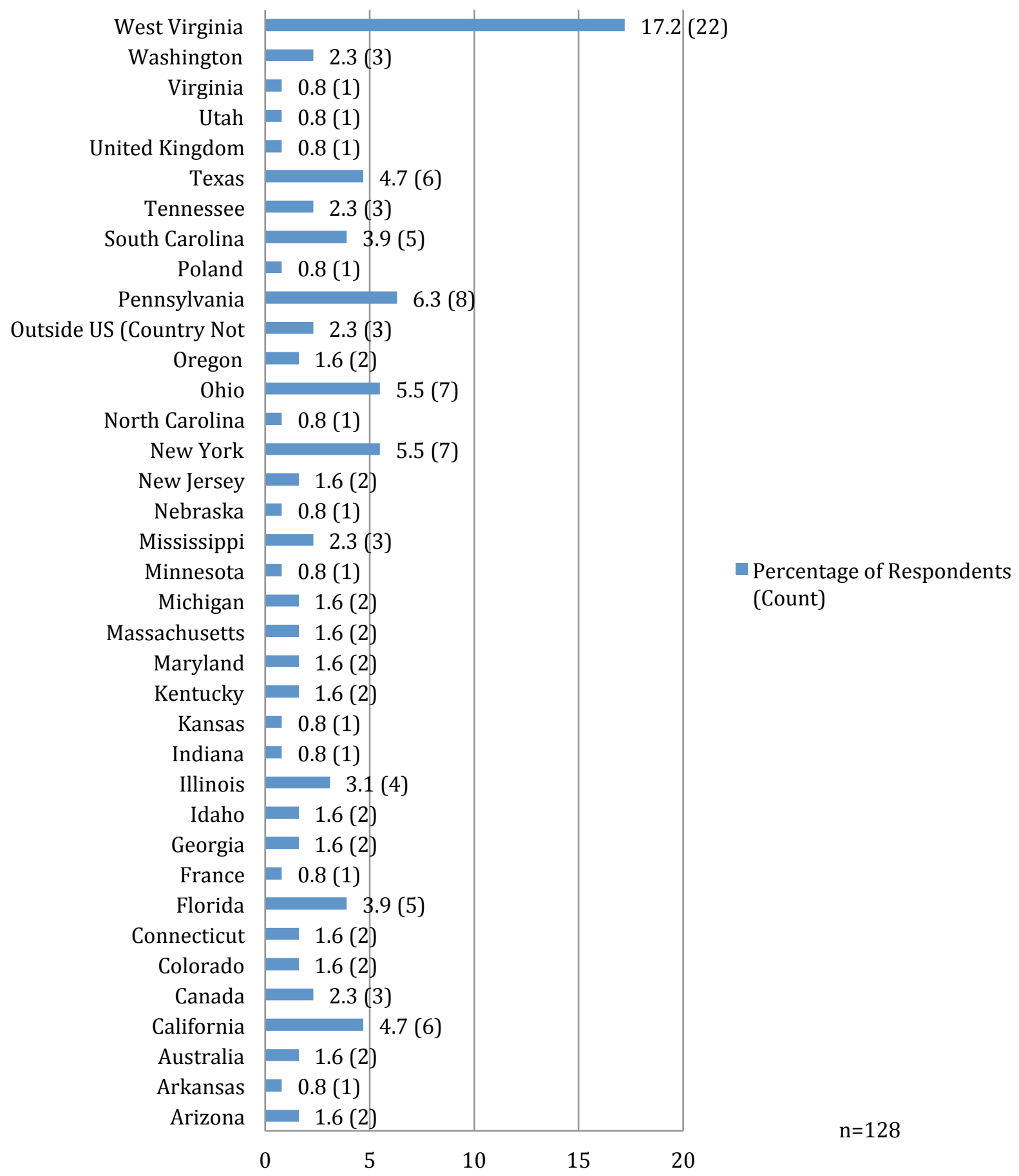


Age

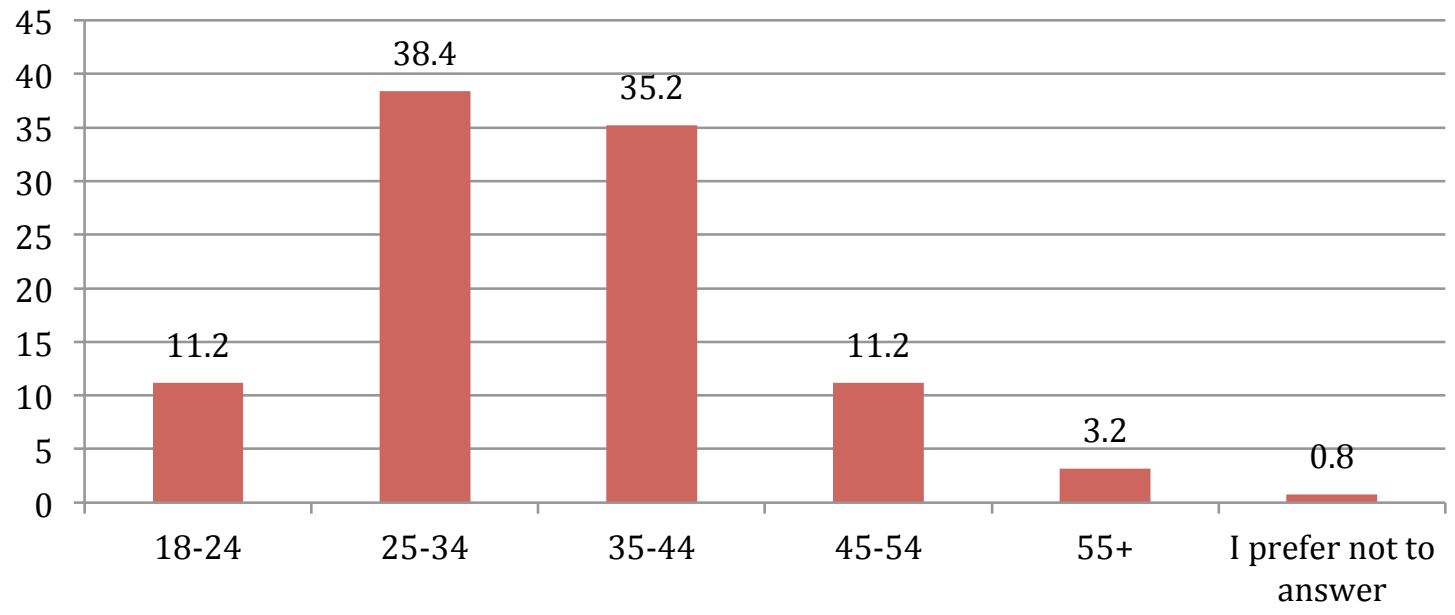

Percentage of Respondents (Count) n=125

\section{Gender}

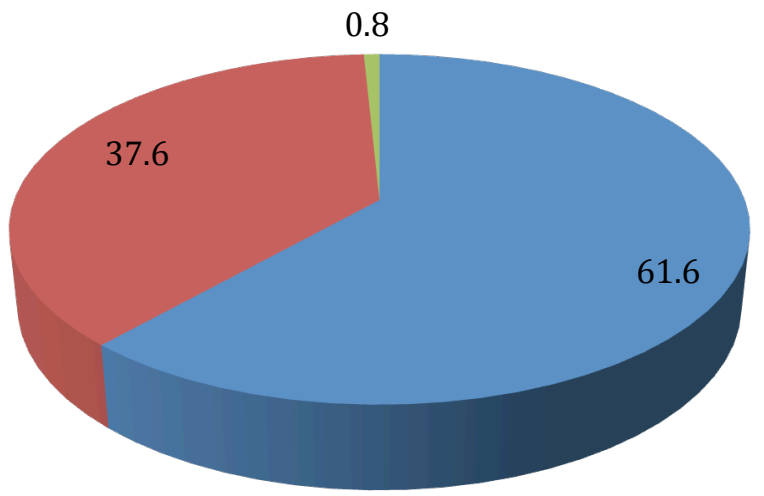

Male

Percentage of Respondents (Count)

$n=125$ 


\section{Annual Household Income}

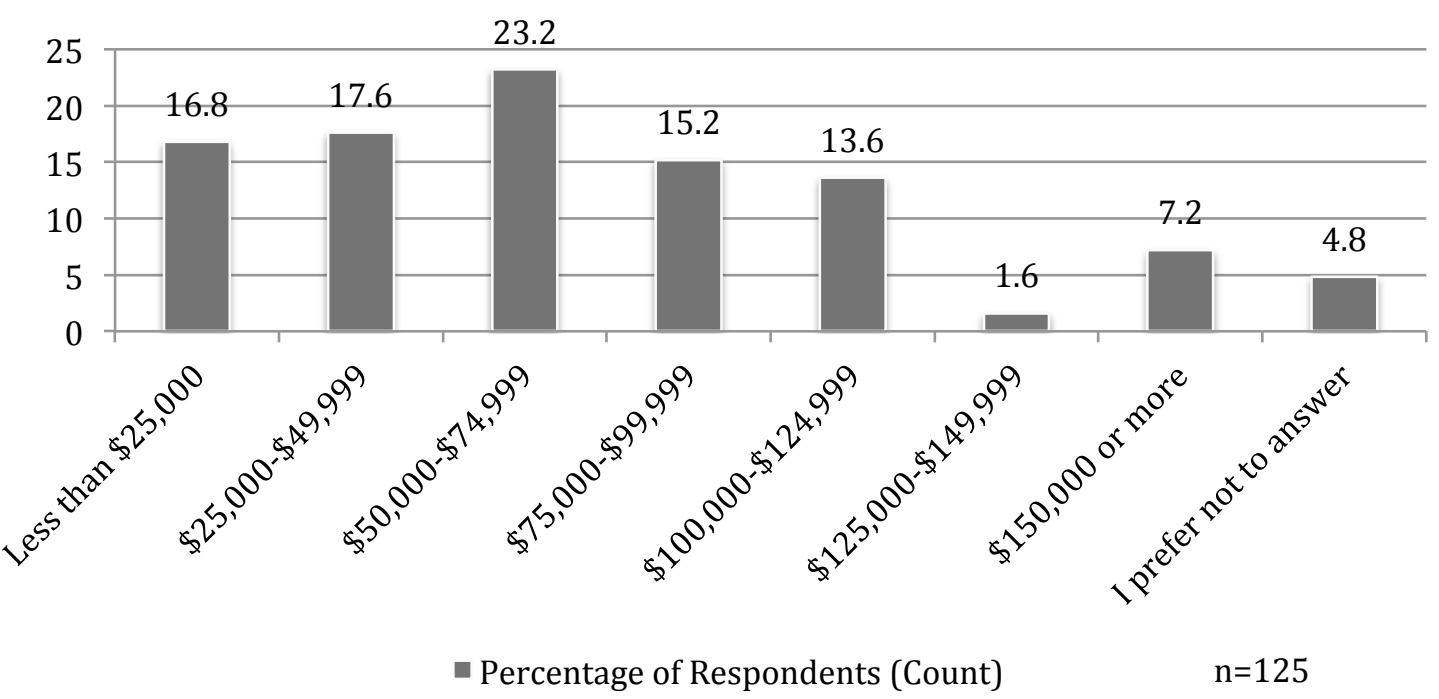

\section{Education Level Completed}

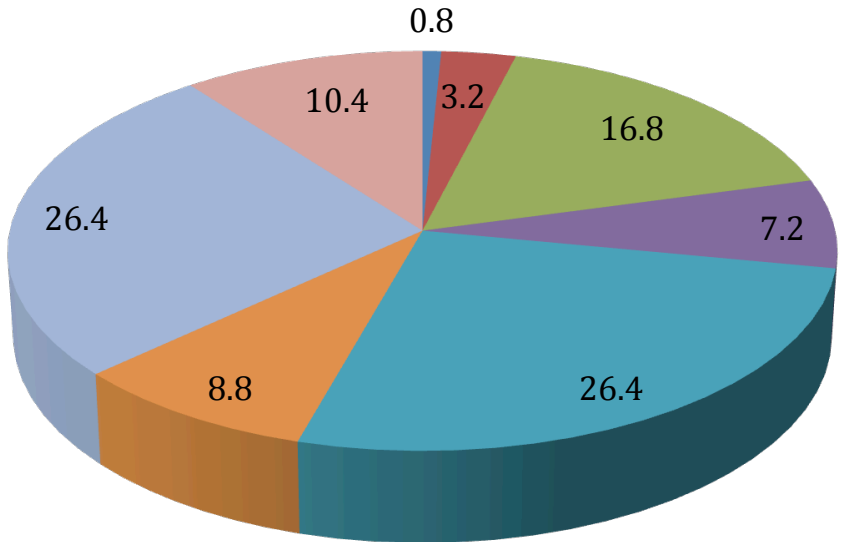

Percentage of Respondents (Count)
- Less than a high school degree

- High school degree or GED

- Some college (no degree; may be currently enrolled)

- Vocational certificate or associate's degree

College graduate (bachelor's degree)

Some graduate work (no degree; may be currently enrolled)

Master's or other graduate professional degree

Doctoral degree

$\mathrm{n}=125$ 
Number of Projects Backed

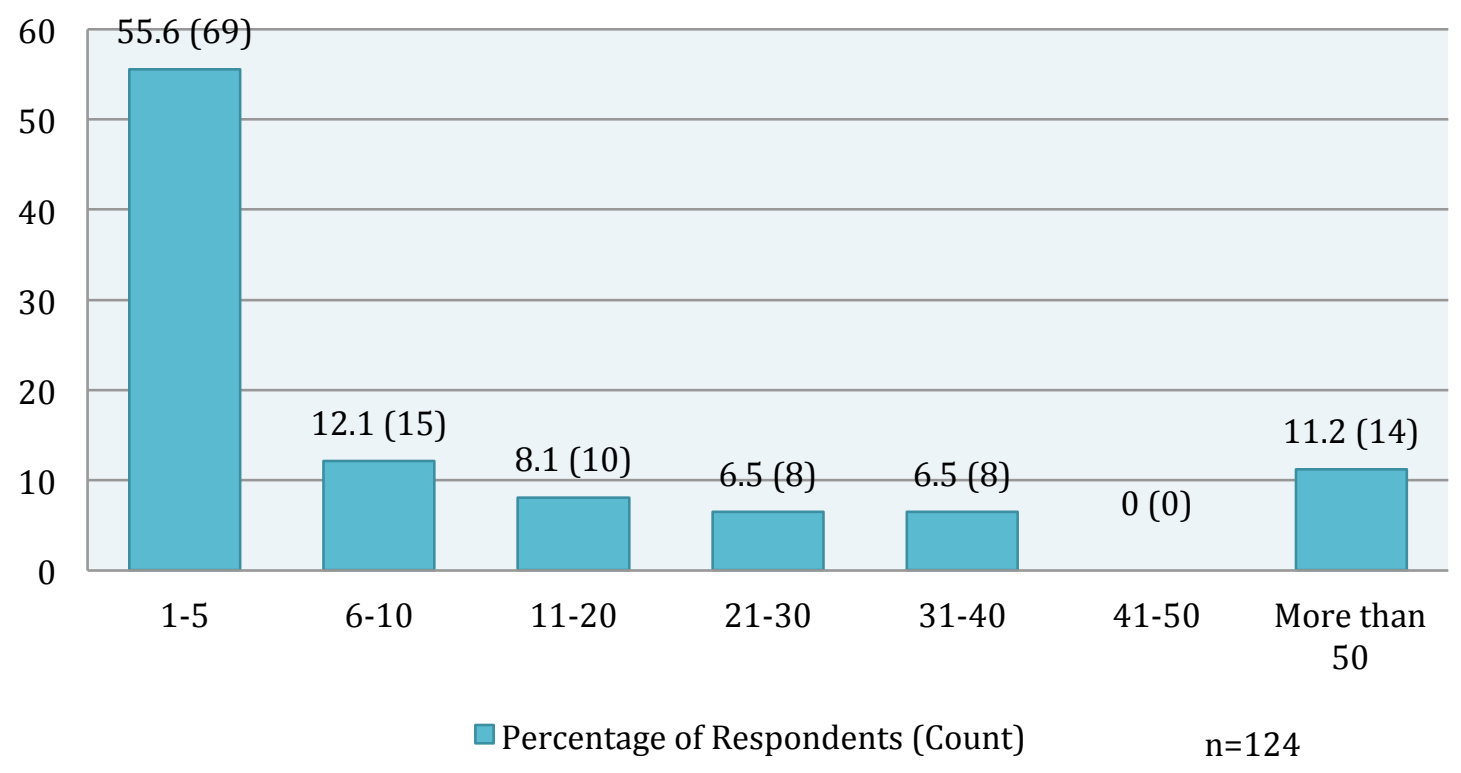

How Long Ago Respondents First Heard of Kickstarter

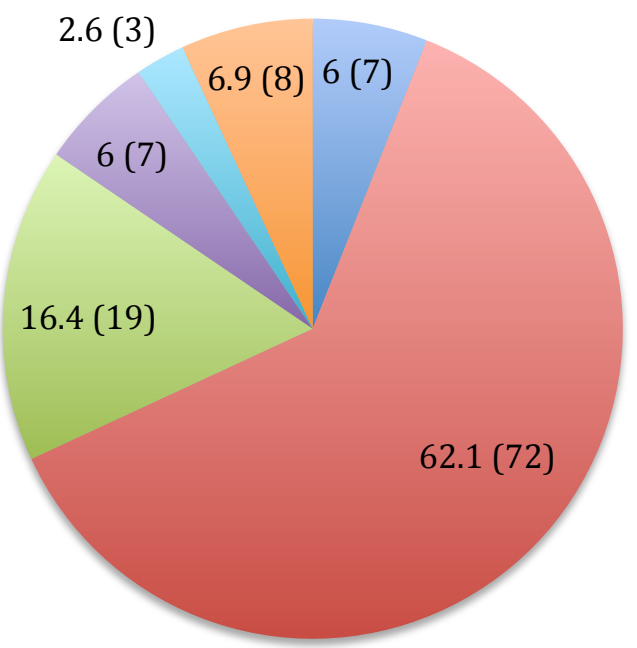

- Less than 1 year

- Between 1 and 2 years

Between 2 and 3 years

Between 3 and 4 years

More than 4 years

$\square$ Not Sure

Percentage of Respondents (Count)

$\mathrm{n}=116$ 


\section{Largest Amount Contributed}

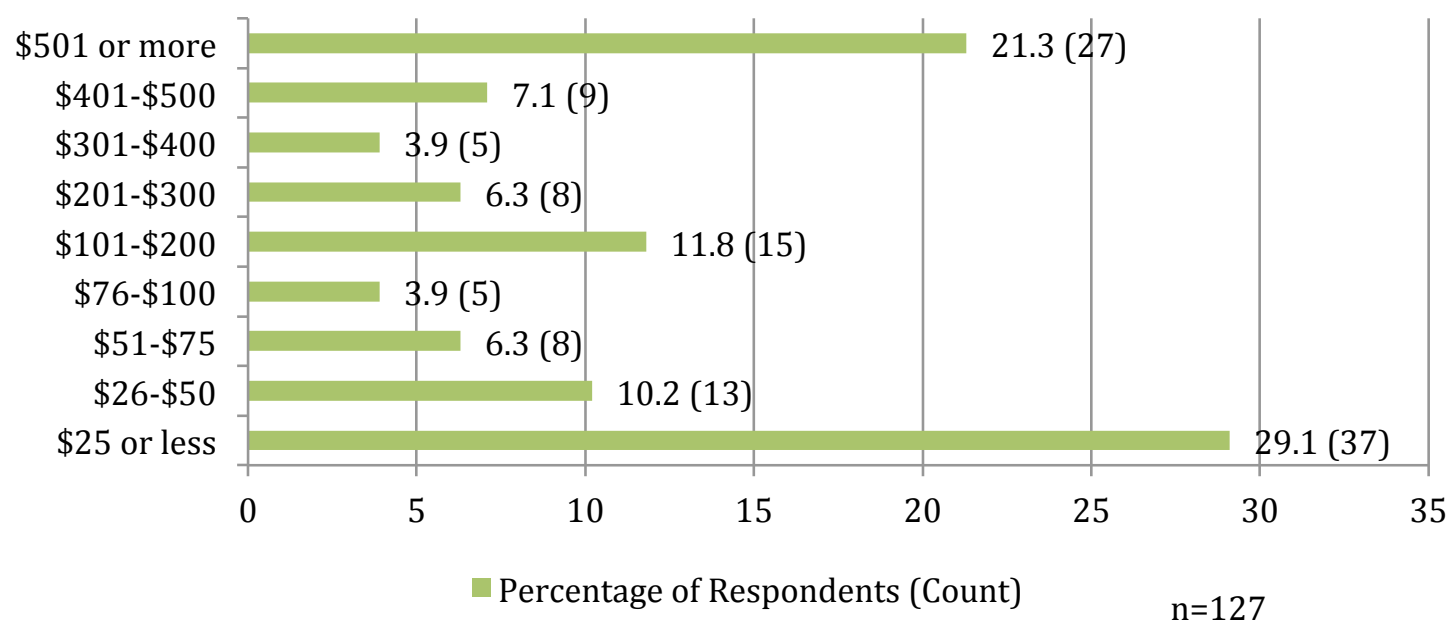

Typical Amount Contributed

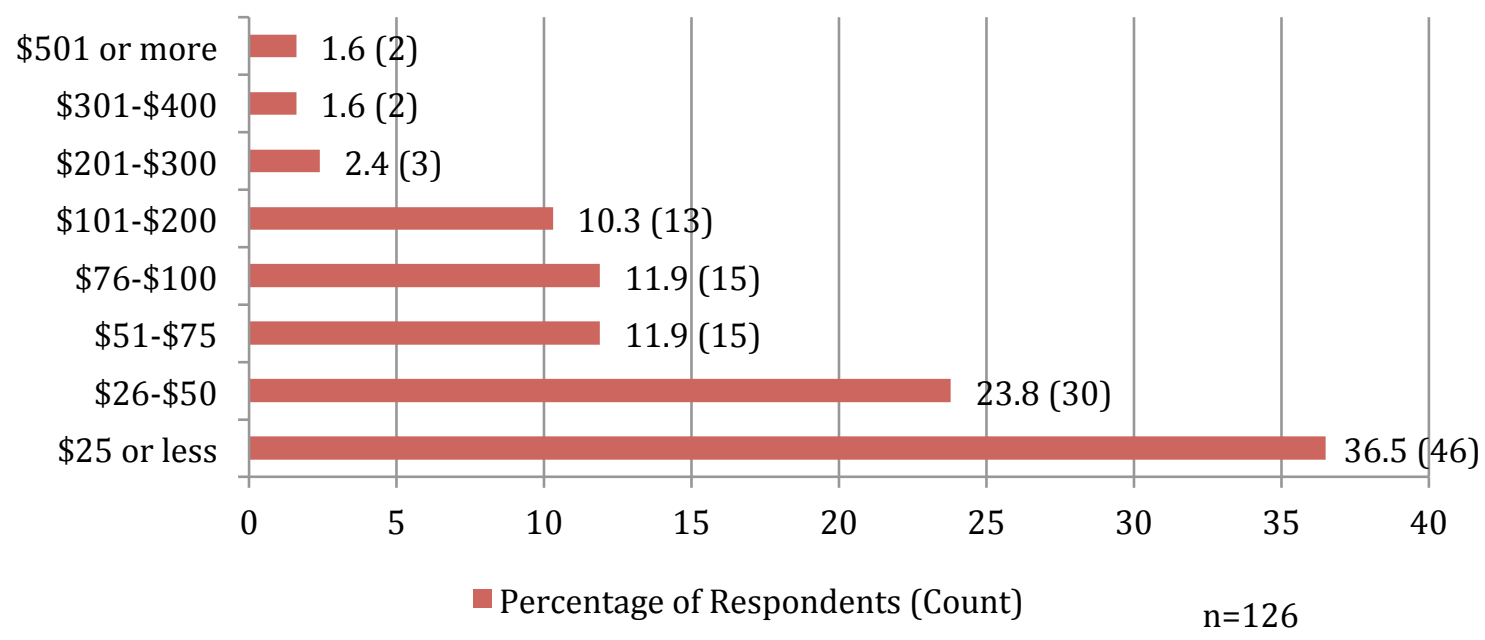




\section{Respondents' Satisfaction With Kickstarter Projects}

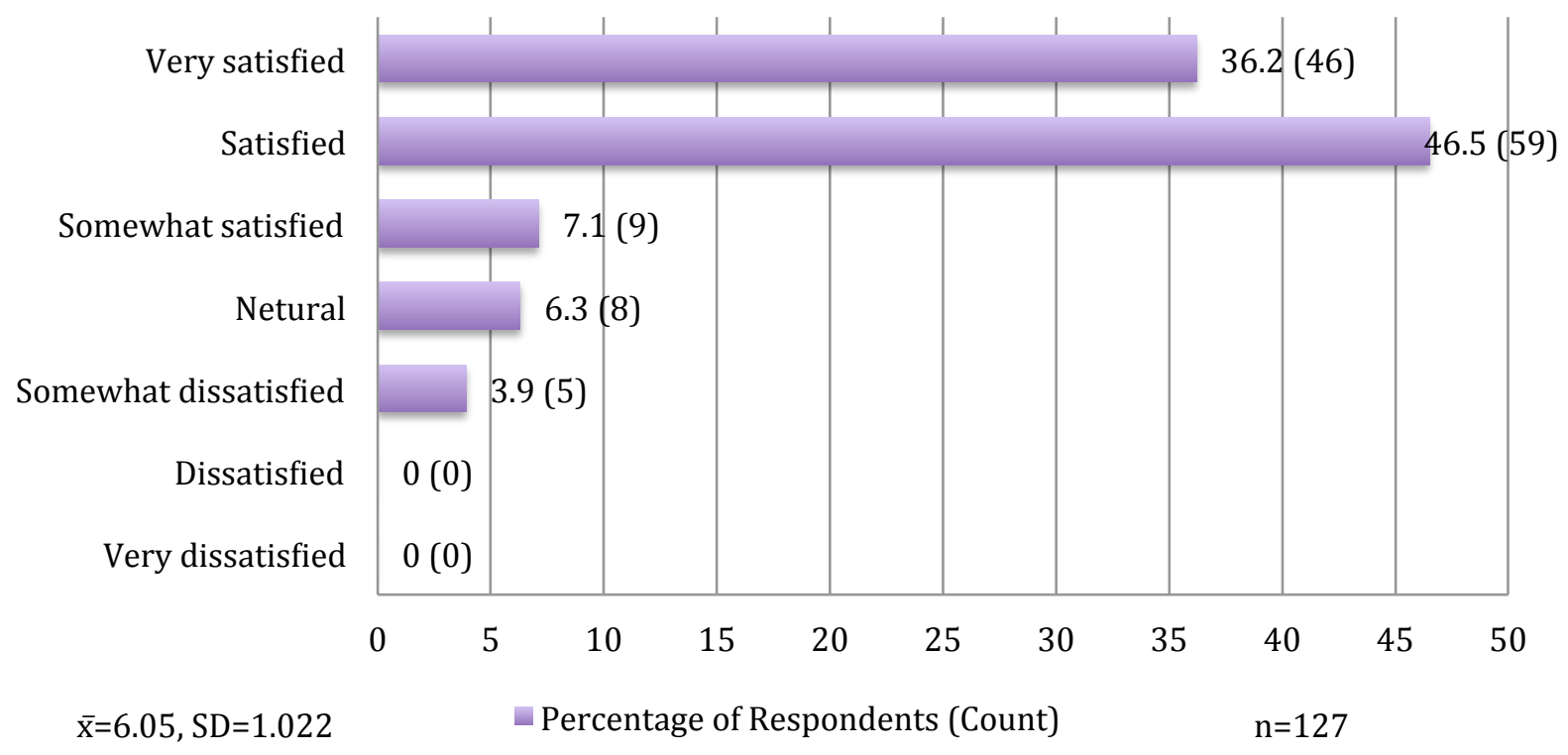

\section{Amount Pledged to Favorite Project}

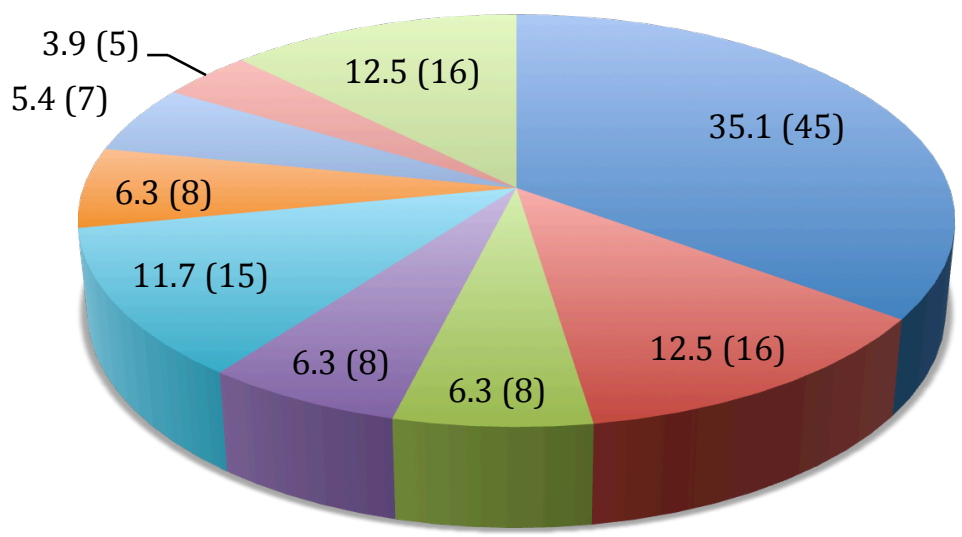

$$
\begin{aligned}
& \text { \$25 or less } \\
& \text { - } \$ 26-\$ 50 \\
& \text { \$51-\$75 } \\
& \text { \$76-\$100 } \\
& \text { \$101-\$200 } \\
& \text { —201-\$300 } \\
& \text { \$301-\$400 } \\
& \text { \$401-\$500 }
\end{aligned}
$$




\section{Respondents' Satisfaction with Favorite Project}

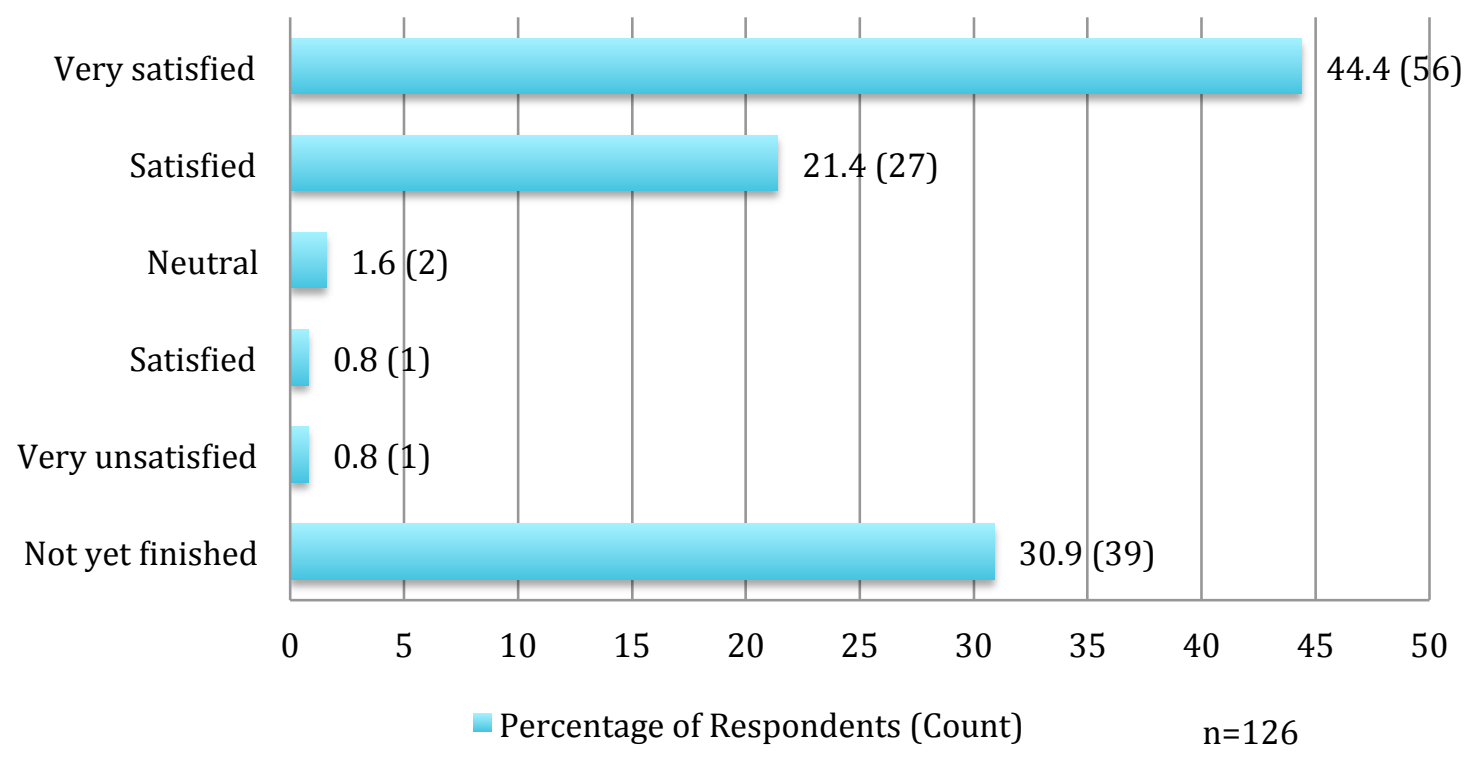


APPENDIX G: QUALITATIVE ANSWERS TO SURVEY QUESTIONS

How did you first learn about Kickstarter ("other" answers)?

Not sure

Not sure

Google news

I honestly don't remember. Probably social media and/or word of mouth.

a media conference

Games forums discussing projects

Web forum.

through indiegogo

Internet Forums (likely WorldWorksGames.com)

A small company I follow held a kickstarter

forum activity

Website forums

A company whose games I was interested in had their first Kickstarter and I found out from their website.

A website that I frequent announced that it would be running a Kickstarter to fund a project, and I joined in.

Mentioned on a company's website following a successful Kickstarter project.

Slashdot 


\section{What else have you done to promote Kickstarter projects ("other" answers)?}

Completed my own successful kickstarter project for my own work

Started my own campaigns

I've helped prepare manuscripts for self-publication.

Bring it up on appropriate forums when appropriate.

Email

Actively helped the project starter with programming, setting up surveys, etc. contributed materials to the KS (either media or products)

Changed my avatar on website forums, discussed the project merits in forums

Maintained active forum threads about KS projects, helped answer questions on KS comments, allowed others to 'piggyback' on my pledge where people wanted to back a project but the shipping for what they were after didn't make sense

I have shared the project with friends on various forums (I don't think forums are generally considered "social media"). 


\section{Why did you decide to support this [your favorite] campaign? Please enter your response in the space provided below.}

For a few different reasons. 1) The project was local, 2) because I felt the story in the play needed to be heard, 3) several of my friends know the person, and I thought maybe I knew this person in passing, too.

I believed in the project.

I knew he person and believed in the final product!

Liked the project, high quality "reward"

It was my favorite band.

A friend's project. I felt it was important for his story to be told.

It was the singer of The Spill Canvas pursuing a solo record, and I really wanted to contribute to the process.

The creator of the comic is brilliant, his work is thoughtful and engaging. I knew that I would likely buy the book if it were published, so I thought that it would be good to give the money directly to him. For the amount that I pledged, I will receive a fantastic perk.

Wanted the book being produced

It was a board game that a good friend of mine was the game designer on.

Local band was raising funds to produce an album.

I really liked the band and wanted them to be able to produce an album.

Was for the Name of the Wind card deck. Big fan of Patrick Rothfuss (the author of the series) and the charity Worldbuilders (which was to receive part of the proceeds)

The topic of the film hit close to home.

It was a film by a favorite actor. He's let his backers make a lot of decisions about the movie. We will also get to attend private screenings virtually and around the world (multiple countries are involved). It's a neat process to be involved in.

Friend and fan of the artist.

Looked like a game I wanted to play 
knew the Kickstarter

The amazing quality of the art, the concept of the game, and the author's page. Also free stuff if I backed.

Help a local young mother start her own business.

The campaign was for a former neighbor and friend of mine and her product is delicious! Plus I like supporting local businesses.

Knew the artist and supported his work

Knew the photographer and believed in his vision for the project.

The writer is a friend of mine and I wanted him to publish his book, hoping that it would get some positive attention.

I knew the musician and wanted to support his work

I wanted the book being produced

Because the product seemed interesting and sponsors for a product

I was unhappy with the way this particular TV show ended abruptly and wanted resolution in the form of a movie.

It was being pitched and developed by a group of proven game developers who have made classic games in the past. They had a solid description and plan for what they wanted to accomplish and what to expect from the final game.

A friend was trying to get a children's book she wrote and illustrated published. I wanted to help her out, but I also thought it was a neat book!

I wanted to see the veronica mars movie made.

wanted to see the project happen

Sounded like a cool idea. The other 2 projects were for friends.

It was for an artist I wanted to support. She was paying for everything out of pocket up until that point, but was brave enough to ask for help. She gives a lot back to her community and fans so I felt my money was going to a good place. I still feel as though it was worth it.

Love of the source material and promising previews. 
I liked the ideas and philosophy behind the project and I collect game consoles

It was the campaign of a talented friend and I wanted to support him

I found the product idea to be of interest and unique and I wanted to receive one of the products.

The company running the Kickstarter was known to me, was a very reliable company and was offering a great deal of rewards for helping them increase their product line.

Favorite author and had a lot of bonus

Reputable company creating a product that looked like it could be a boon to the relevant gaming communities as a whole, while offering attractive backer rewards.

The game contained miniatures most of which were exclusive. I planned to paint the miniatures and sell some or all of them for decent profit.

Company I trusted, excellent concept, quality material.

Print edition, in limited-edition format, of a webcomic I've followed for some time.

I loved the IP they were resurrecting, and I trusted the creators.

It looked to offer a product I enjoy for a very good price

There was a great value for the quality of the design and sculpts. Literally pennies in the dollar price wise for the some of the highest quality materials.

Huge value for amount of money, great selection of miniatures

I don't have a favorite. Each was for a different reason. Puzzles because it was novel, technology because it looked fun, game because I wanted to see how he did it

Large reward, exciting stretch goals, and trustworthy company.

I have always loved fractals and the options available were wonderful applications. Also the project offered the option for different medium options.

Desire to support creator/company, interest in product being created.

The deal was incredible. It was such a good deal that it got me to join a hobby for the first time.

Reliable company, good value 
The book was a unique pictorial perspective of WWI

The project was created by a group who had made games in the past that I absolutely loved so the question was not will I support them but what is the maximum I can afford to pledge

I trusted the company and I wanted the product

Good value, great company that I trust, excellent product that I can always use more of...

I'd been a fan of theirs for years and wanted to support them in their expansion, plus I wanted the rewards.

The product that was offered was something I wanted, and would buy anyways once released for retail. The company that offered it was reputable, and had a decent track record of non-Kickstarter business. The price was below the retail price. Stretch goals provided additional value, although they were not the primary reason for backing the project.

The campaign was Kingdom Death. The individual running the campaign demonstrated that he was capable of producing fantastic and creative miniatures. He is passionate, has an amazing sense of design, and interacts well with his fans/customers. His product fills a niche that isn't well represented, and I felt like a part of something special by helping him fund his dream.

Long-time fan of project creator, and his enthusiasm was infectious.

Support of a company I'm loyal to In return for a substantial amount of product

Long association with project creator.

My husband and I play tabletop role-playing games, using a map and cardboard squares to represent characters and monsters. When a friend introduced us to this campaign, we decided that it would be an affordable way to get a lot of figurines to replace the cardboard squares, and make the games a little more fun. Previously, we had decided not to buy figurines due to their high cost.

Good company history, great effort before the KS.

I had always liked the products this particular company produced, but couldn't buy them as they were only available in very limited quantities. / Backing their Kickstarter not only allowed me to finally buy some of their items, but also helped them to start a new production line that will, in future, make their products more available.

The stretch goals that had unlocked and the overall value of the pledge level as a result, was too good to pass up. 
The company (Reaper Miniatures) has consistently produced good product and had good customer service. They were expanding into an entirely new product line and were creating opportunity for jobs moving to the US from Asia. I wanted both the new product at a lower price plus also wanted to support a company that had earned my respect.

I am an active participant in the creator's online community. I have met the creators, and I both like them, and believe in their work. The offered value for each pledge was also amazingly high.

An excellent bargain over retail.

I was very interested in the high quality resin miniatures (for painting/gaming) the campaign was intended to produce. I knew the company had a lot of experience in that area and had produced really high quality stuff in the past. They offered significant discounts to the estimated MRSP.

It was a unique idea from a small developer. After investigating the project I thought it was worthwhile and the creators were genuine.

I had a working relationship with the company running the campaign, but I was also interested and excited about the product.

Innovative thought/design. Attention to detail and thought about creating the object.

Concern for the esthetic as well as the utile aspect of it.

Awesome models and great value

I liked the product being offered and it was at a price and with perks that were better than would have been available at regular retail later on.

Band that I have followed for years, like to support them as much as possible.

I believed in its purpose.

Extremely positive experience with project creators' previous Kickstarter project, and this project was of an item I was also interested in.

Extremely good monetary deal. Product that filled a niche that was not really available in the same scale before. Was from a company I had bought from in the past.

Kingdom Death: Monster was the campaign. Adam Poots, the owner and designer has a stunning record for high quality art and miniature production.

I liked the concept, and the creator demonstrated that they had most of the work done and just needed a push, so I felt I could rely on them to finish. 
Interesting sounding BBQ sauce - Honey Habanero.

Lots on offer, good discount over buying retail.

I liked the product that was going to be developed. I liked their previous work and had high expectations. And got caught up in the need to have all of the stretch goals and options. Plus there was a significant discount based on what it would be at retail.

Excellent value: the rewards were massively less expensive than retail.

I liked the product and the company.

Original game with cool miniatures

The value and breath of the gaming miniatures offered was a great deal

Great value for money and great to support the creator in their business endeavors

I wanted to see the game made.

Big fan of the publishing studio.

It was a Rifftrax Kickstarter. I was more than familiar with the products that they produce and felt that it was a good use of my $\$ 5$.

This was a game being made by Keji Inafune called Mighty No.9. I decided to back it because I am a huge fan of the Mega Man franchise and it seems like this is the closest thing we'll see to a real Mega Man game for some time.

Because it was a great idea and I wanted to help make it happen.

A friend of mine put up a Kickstarter campaign to get a cd made that could be shared at their show. Since I was friends with the singer I decided to donate \$10 so I would feel like I had contributed, and that seemed to be what our other friends were donating.

I love Photography

I believe that it is smart to support young people who are interested in a performance career but who would otherwise not have the chance to be involved so I gravitated toward this project.

I supported this campaign because I really wanted the game to get made and by giving this amount I could help that happen. The game developers are experienced and I knew I could trust them to make a great game based on their history. I felt like there was very little risk in my backing this project. This amount also got me a digital copy of the game on its release, which I would expect to cost near 20 anyway. 
The person who started the campaign was a alumnus of my school and he made a personal appeal to everyone on the alumni list

The person had shown clips of the work in progress on a film related site, which we both belonged to. I had spoken to him on a number of occasions, liked his taste in film and his ideas, and based on what he'd been able to do so far thought that he might be able to make something pretty good.

It was for a band that I am a big fan of.

I supported the game that was being made and wanted to contribute.

Because I've been a huge fan of Veronica Mars for many years. I believe in the show and I missed it, so I donated to [the biggest] Kickstarter.

Because $\mathrm{i}$ enjoyed the game and wanted to play the sequel

It was for a good cause.

I really like the band that was running the Kickstarter and I wanted to help them get it funded.

Because I was friends with the guy who started it

It was a movie that I really wanted to see made because it is a sequel to a movie that I really like.

Because it was for a local venue trying to earn enough money to open and I plan to be a patron there once they open.

I wanted to get the Kickstarter version and I knew it wouldn't go for less in stores. It looked like a fun game to play.

The Kickstarter that I backed was "Torment: Tides of Numenera" video game. It looks really cool and the developers are awesome people. So I decided I would support them.

I supported it because I liked some of the previous work this person has put out before. I always looked up to the creator of the Kickstarter.

To have fun in life and enjoyment

A friend of mine was having a kid, so I backed a project called "The Bear," which was an artistic children's book written by one of my favorite webcomic authors.

My friend was leading it and I wanted to help out. 
Veronica Mars movie -- interested in seeing the movie made

I have been following someone on YouTube for years and enjoyed the videos he put out. He wanted to make a movie so he started a Kickstarter. I thought it was a great idea so I donated some money at the time.

The person was someone local I'd heard a lot about. I checked them out, and really liked what they had to offer.

A friend was doing the movie.

To make sure it met its goal so it could be finished

I liked older games the same people had made

I am a fan of the creator and liked the project she was starting.

I knew the artist's work in theatre and wanted to support his aspirations as a singer.

I am a huge music addict. I love playing instruments and singing songs. I had a band when I was at college. Even today I encourage my kids to get involved in music as much as they can. This passion for music was the factor that made me support this campaign.

A high school friend of mine was trying to self publish a book he's been working on as long as I've known him.

The game looked interesting and the rewards were solid

I had been a fan of the artist for several years, so I was excited he was making a new album. The \$20 pledge level came with a download of the album and a t-shirt, which I thought was a good amount of stuff for the money, so I backed it.

It was for my cousin 


\section{How do you feel about the final results of the project? Briefly describe in the space provided below.}

I was very pleased. He's in the process of shortening the play, so it's still a work in

progress. The reading was an excellent start, though, and I attended it here in town.

It was successful; well executed, well received, and provoked discussion.

Absolute success.

Well worth the money donated.

Awesome. Feel part of their success.

Very good.

The campaign was funded, but the recording was severely delayed and it has been more than a year (past specified date of getting rewards) and rewards still haven't been distributed. It's mildly frustrating, but he is still promising to distribute the rewards, so I'm not upset.

I have not received it yet, but I am optimistic that it will be fantastic.

Don't have it yet

Haven't received yet. It's in production.

Loved it. Great album. Also, they included a personal letter of thanks and a "newspaper" with articles about the band and their adventures. Really cool!

The final results were great! The band I supported ended up raising so much money that they were able to not only release a new album, but also go on tour!

Haven't received product/rewards yet, but very pleased. Project did so well that Worldbuilders received part ownership in the company designing the game.

Exceeded my expectations.

The film hasn't been released yet, but it was a hit at Sundance. I'm excited to see the final results.

Impressed and felt good about helping

Don't know the final results 
It's not delivered yet; it was scheduled to be delivered in Dec 2013, but has yet to ship. Regardless, I'm still excited.

Fine - hopeful that she will succeed.

Her shop was funded but has not yet opened; the campaign just closed at the beginning of March. I am very excited for her and hope she has great success!

OUTSTANDING.....best work the artist had produced to date

Amazing work.

I liked the book. I don't see why he had a double finding a publisher.

It was great

Haven't seen it yet. Expect it to be good

Great

I enjoyed the movie, but felt there was a lot of pandering to the fans (which was to be expected since it was a movie for the fans and funded by the fans).

This particular project is not final yet, but I can describe how I felt about another project that did finish.

The results were fantastic and I would gladly back them again if they pitch something I am interested in.

I backed the 10-year hoodie and it has basically become my favorite, which is saying something because I have many hoodies. I also love that they guarantee it for 10 years and they will fix it if anything happens to it. Part of the draw, but the hoodie itself is superbly made with quality material. It's also made in the US, which is a great bonus.

The project was fully funded so I was thrilled!

I was very happy with the final film that was made.

It was a good, worthwhile project

Feel satisfied

Awful. Put money in, they never manufactured the product and I was not refunded the money. 
I feel pretty good about it. The quality and effort she put into the album were in no way diminished because she decided to crowd spires the album rather than using a studio to foot the bill.

Highly satisfied. My only gripe is that the delivery of teh product was delayed from initial target date.

The results were about on par with my expectations

I feel good about it. He does good work. Although, honestly, I never saw it, only heard about it.

It is an interesting design and functions well.

Satisfied. There were some bumps, but communication was good and in the end everything delivered.

Great project overall.

Fine as is, though technical quality presumably can and will still be improved.

The project is still underway, I have not yet received it. I have been very satisfied with the other Kickstarter projects I have backed and received.

So far, so good. I'm still waiting on delivery but the creator sends regular updates and I am fully confident that the final product will be worth the wait.

Very pleased

Have yet to receive the rewards from the project but they are tracking to be finished early.

Very pleased.

It took quite some time to deliver, due to the success of the project, with the final items coming in about 4-5 months after the KS said, but that's find as the quality was top notch as was the communication.

The best value for the money of any Kickstarter I have ever supported.

2 complete 2 in progress. Fine.

I was initially disappointed in a 3 month delay, however ultimately I was very happy I backed. I wished that I had contributed more. I have since backed a second kickstarter and purchased additional products from the company directly. 
I think it turned out great, and if I had at that time the additional funds I would have wanted to upgrade to a larger size. [The results were that good.]

Very pleased with those completed. Still waiting on others.

While the product was late (as is just about every project I have backed), I am VERY happy with the end result. It has encouraged me to look elsewhere for more was to build on my skill in the hobby. It was well worth the money and the wait for the product.

Quality was slightly below expected, but value was very high.

The final product was excellent

While the project is over and was successfully funded there are no results yet. As with most large production games, this one was over 1.2 million USD, there is a long waiting period between end of successful campaign and delivery of the game, in this instance the expected delivery is about December of 2015.

Great. I love my Reaper Bones, which arrived last year

Very satisfied; things are on track and updates have been consistent.

Fantastic. The product is great and I went on to back their next KS.

The rewards were delivered in a timely manner (I believe 1 month late), and I am very happy with the products.

Have no shipped yet, but his regular updates leave me confident that we will see a product and that it will be great.

Fantastic project -- creator kept everyone involved through the project, sharing both the highs and lows.

So far so good, the delivery date is not for a few more months at least

Happy with the results even if they came a little late.

I feel the final results were above expectations. The company did well communicating with backers throughout the campaign, rewards were as described, and the way the campaign was run did well in building excitement and enthusiasm in the community. The company did have some communication issues regarding some delays in the fulfillment of rewards, though these were eventually resolved.

Very happy; I would definitely support the company again. They never sacrificed quality and worked hard to fulfill their campaign as promised. Top-notch production rivaling any mainstream product. 
I'm still waiting to receive my items, but their updates make me very pleased I backed their project.

It was exciting to see progress, fulfillment took a bit longer than was originally publicized but this was due to the project being wildly more popular than the owners realized, and there were some delays caused by the transport of the product from China. This plus the delays in communication around the issues caused some concern but once that was all resolved and deliveries started happening, the backer community excitement grew again. The final products were as advertised and this was (for me) a great induction into how Kickstarter can work, and gave me the confidence to back other projects.

The product and service were both great. Everything was delivered within the normal, expected Kickstarter timelines (a little, but not massively, late). Reaper provided good communication throughout the project and excellent follow-up for the few errors I found in my shipment.

The campaign itself was tremendous fun, and the rewards, once shipped, were exactly what they were claimed to be.

I was very happy with both the value I received and the delivery even though it was 'late'

I'm very happy with the way the campaign went. The project funded after a positive campaign with an entertaining and interesting community building up in the KS comments. As the miniatures were sculpted and rewards were eventually dispatched we were given weekly updates on the latest progress on the project in the form of KS updates, we also maintained an active KS comments section, which the project creator continues to use to chat to us. I have received several shipments of miniatures now (almost everything I pledged for) and am extremely happy with the quality.

The project failed to fund, but the developers are still working on it and have migrated the community from Kickstarter to their forum.

Very satisfied with the end result. The product quality was what I expected, and it has ended up being more useful than I expected.

Succeeded. Well designed and the manufacturing was well executed. Result is a novel, original, unique object that works well.

So far I have received half on my pledge and they are excellent!

I was satisfied. The product was reasonably on time and quality was as promised.

very happy with the final outcome of the project and looking forward to further releases by this band.

I believe that progress is made. 
Very happy with it! :) I only wish I could have afforded a higher pledge level to get all the goodies I wanted!

Quality mostly better than expected. Great variety available.

Due later this year, but the released pictures, updates and production samples (I bought some at retail) have been really high quality and I have no concerns about the final product's quality.

I am very excited to receive my rewards

Bit late, but the end product was totally worth it. It is my go-to BBQ sauce now, and I will continue to buy from them aslong as they are in business.

Super happy, delivered a bit late, but nothing major. Everything was as described.

I am quite pleased in the results.

Very happy. It felt like a steal, but I also felt like I was watching history in the making.

The project is on schedule but has not yet reached fulfillment. Based on previous products, I have positive expectations.

Fun game, some weird rules, lots of cool miniatures, especially the Kickstarter exclusives Loved it. Would do it again (and did with their 2nd Kickstarter)

Slight shipping delay but overall a great success

The project is still not complete, however from what has been shown, it looks awesome.

Very pleased, although complete final product has not yet been delivered. Just happy with what I've gotten so far.

It was a positive experience. Though they were not able to riff Twilight in theaters (though they were very open about the process and why the studio declines their offer), they were able to riff Starship Troopers instead.

The final game has not been released but I am more than satisfied with the updates and information given so far. Concept has done a great job of keeping supporters up to date on the project.

I'm very pleased. I've been receiving updates weekly on the project.

I felt like they did a pretty good job. They didn't raise tons of money but were able to get a decent amount of CDs made to sell at their shows in the bars in the area. 
I was very happy about the final result and I am satisfied.

The results were fine. A nonprofit for teens who wanted to learn performance skills was begun and continues to do well as far as I know.

The project has not been finalized yet.

If felt that the money was well spent, the budget listed for the project costs made the Kickstarter founder accountable for his project, and I thought the benefits for supporting the project were comparable to the money donated.

I

t hasn't been finished yet. He is still providing relatively frequent updates with samples of the progress he's made, so I'm still fairly optimistic it will be completed.

I feel really good. The album was made and I already bought it and it is amazing.

It still has not been released but it looks like it's coming along nicely.

I could not be more proud of everything they've accomplished, to be honest. Not only did I get more of one of my all-time favorite television shows, but I was a part of TV/film history.

It was good I got access to the game once it came out

I felt very happy and proud of my contribution.

I was happy because the project was completely funded and the album was released a few months later. I feel like I actually made a difference.

Ultimately the finished product wasn't all that great and my friend gave up

I haven't seen the movie yet, but from the previews I have seen, I'm happy and excited about the results.

I'm very excited. They doubled their original goal and reached a couple of stretch goals so I think the place will be amazing.

I feel just fine about it. It was a great little game I can carry around with me and teach on the fly.

The funding ended about a year ago but the game is still in development. So I have not had a chance to see the final results of the project.

The final results were great. I was very happy with the final result, it was the Ouya system that I backed which I thought had a slim design and the functionality was just great. 
I really enjoyed and the result of the project is vey interesting

I received 2 hard copy books, and could not have been more impressed. It turned out fantastically.

I felt good about being a part of it.

Pleased.

The campaign made the money it was asking for. The project is still moving along slowly. I am happy with it because I get updates every once in awhile. I am sure it will get done when it's the right time.

Everything went really well. I'm super excited to see what the future holds for her.

It happened and it was awesome!

The game isn't out yet, but from what has been shown, $\mathrm{i}$ like what the result is, and glad $\mathrm{i}$ gave them money to finish it

I haven't seen results yet because it has not been completed yet.

Very satisfied

Loved being part of the project and seeing my name on his CD cover. He wrote the name of all his sponsors on his bare back, since we were his "backers" and used that as his cover art for the CD.

It was such a huge success. The people loved it. The kids performed some songs on a stage. They were wonderful. It was huge break for them as people wanted them to sing at their functions. I was very happy.

He got the first book published, and is working on publishing his second. Very excited for him, and glad I could be a part of it.

It is not yet completed

I thought the album was great and the shirt was good quality.

It seems to be progressing well. They're not yet finished with the game. 


\section{Why did you ultimately decide to contribute to one or more Kickstarter campaigns? (Please write your answer in the space below.)}

Because I really felt that the story in the play that I backed needed to be heard.

I have strong beliefs about the importance of the arts, social commentary, and preservation of the performing arts.

Better way to fund things. People power!

Support project, artist, friend, and for the reward.

To assist and be part of the dreams of artists and creators I value

I wanted to do what I could to ensure the project's success

More than the rewards, I wanted to help contribute to a campaign that I thought sincerely needed a community's help in funding.

They seemed like cool projects (usually comics, books or special events). Half of the campaigns (four) have involved people I know personally, so there is another connection. The perks are also usually appealing.

Wanted the rewards

Either to support a project of a friend or a project that I was involved in.

I wanted to lend my support to local artists trying to make something happen in the community.

I was very interested in the product that would be produced by the Kickstarter campaign.

Because I felt the project was worthwhile.

Dreams should be supported. This is what Kickstarter provides, the chance for someone's dream to come true.

It was a project that I felt warranted the help from a person who I felt deserved it.

I want to make peoples dreams come true

Because I knew the person Kickstarting and liked what he was doing (metal art)

It ends up being a better deal, as long as you can wait. 
The product was good and it helped a woman

Ultimately, because her incentives were great! The product I get in return for my contribution would have cost me an additional $\$ 2$ to buy from her later and I'd be buying it anyway.

Strong feelings about supporting local music

Believed in the project and the artist.

Because I thought the projects were good and should be seen by the public, and they were friends.

Supporting work I like or am interested in.

Wanted the rewards.

It is something I enjoy

The incentives to donate (digital copy of the film, $t$ shirt, copy of the script, etc.) made it worth my while.

They pitched items that are not currently available and that I am interested in. Game publishers dominate the market, so most games are pretty similar. Kickstarter gives games a chance to either make older style games that the mass market may not support, but a niche group loves and other innovative games can find a place to get made.

Once I contributed because ultimately I wanted to help a friend. Another time I contributed to a project for a documentary I about a subject I really care about, and I wanted it to be made.

I wanted the film to be made.

Both times I knew a person involved

Help a friend or sounded like a novel idea.

Because it was a project I believed in, created by someone I felt had a great idea.

Reports of positive experiences from friends who have used Kickstarter, and I really like the idea that smaller companies with great ideas and products can use Kickstarter to fund things that might not have been funded the traditional way; it is a more accurate indicator of interest in the product.

It's fun to be involved with the development of an interesting project 
A friend's project

I liked the idea of the product and wanted to back it so I could receive and use it.

Many are a great opportunity to functionally pre-purchase new goods at a significant discount, though with some risk.

I ultimately decide based on what the project is, how much, if I really want it, and if it looks like it is going to be funded or not.

Interesting products I like to see made and subsequently own.

I liked the product(s) being offered. Some I saw potential for making a profit off myself later. I liked being able to get a product for much less than I could in retail.

Interesting projects that I wanted to see succeed. Discount from eventual retail.

Value, inability to acquire Kickstarted project in other fashion, desire to support the project

I back projects that interest me and I want to see succeed. More so than the rewards I love to see someone create something that has been their dream or idea. I've met with four of the creators of the projects I've backed and it's always great to see that joy in their faces.

In many cases it is because I believed in the vision or they offered something I wanted to see produced. Occasionally it's because they offer something at a lower price point than retail.

At first it was for a friends business, this was years before the site because trendy. I thought it was rather quaint and decided to do so. Then, about a year and a half later, games started appearing and I started backing for a few reasons: 1) I wanted these items made, so I was willing to risk some money to do so. 2) I felt like I was helping someone live out their dream. Now I pretty much only do \#1 as there's too many of \#2 to even try to back and most KS in the game area (tabletop) are very well established companies using KS to basically see if there's enough interest in a product.

To fund the production of miniatures that I want to own

Already answered

I have mostly contributed to projects that I wished to own. Almost all have offered direct, tangible rewards similar to a pre-order. 
Sometimes it's the ideas and basis for the project. Often it's the body of work that the launcher can show, whether it is prior successes or existing images or mock-ups.

Desire to help them succeed, plus interest in the final product.

The answer varies depending on the project, but it is typically some combination of perceived value and desire to see the small guy (possibly local) succeed.

Primarily because the product being produced was very interesting an unique or expanded on my collection of games and miniatures

Being a part of a process that empowers individual or small groups to keep ownership of the intellectual rights of what they create is in itself a bit exciting. Being in on all the ups and downs and watching a brand being created and grow into something productive is enjoyable.

I wanted the product and I wanted to see it made.

Good products with good people behind them.

Usually, I backed because I want the product being offered. Sometimes I back because i want to support the company running the $\mathrm{KS}$.

The products were something I wanted, and would purchase at retail anyways. The companies were trustworthy (every company I've contributed to has a track record; I avoid new companies). My perceived value of the product far exceeded the monetary cost.

A great product with Kickstarter Exclusive items + a good price + company I want to support.

Generally because it is a product that I think should exist and I am willing to pay a premium to bring that about.

For the love of my hobby, mostly. Sometimes just curiosity of a small investment

Combination of value provided and likelihood that project will successfully deliver.

Either to support a friend, or because I liked the rewards being offered, and trusted the person or people running the campaign to make good on their promises.

I wanted to see something I thought was interesting created, so that I could share that interest with friends.

I was interested in the products they were creating. 
The perceived value of the rewards for the pledge level, coupled with the excitement of feeling that I personally am helping a project succeed.

All choices are made by a rough formula: The reputation of the project creator combined with the attractiveness of the project/product combined with the cost

Discount is first, then if I'm getting something exclusive, then the desire to help a project I'm interested in coming into the world.

I wanted the rewards on offer, and also (in some cases) wanted to support the artist/small business involved.

For smaller companies, I back because they could not produce the game without support and I like the project. Projects from established companies that will fund I often wait until the retail release. If the reward is worth it (a suitable discount vs. buying at retail or nice exclusives that I care about) I also strongly consider backing.

Most of the campaigns I've supported have been for physical or digital games or gamingrelated items. Generally I support these because I am interesting in owning the game/product, so I'm willing to contribute to a campaign so the creators have enough money to get it made in exchange for a copy. There are a few campaigns I have supported because I work with the company or am friends with the creator and I feel I need to be involved for social/professional courtesy. There are also a few campaigns I've supported that are more like charitable organizations working on a cause I consider worthy. Artistic, well designed intro page. The item showed a different take on the usual solution. Creative view, well thought out, appealed to my sense of adventure, design, and interest. Most of what I like are things that are a little out of the ordinary.

Supporting small and/or local business

I liked the product being offered or project being funded. Sometimes I knew the creators and wanted to see them successful with their project.

Because I believed in the product that was being created and wished to help make it a reality

Belief in the work they are doing. Wanting to support the work and for the people to feel supported.

Their project write-up sounded good; they sounded like honest, sincere, reputable people, and their vision sounded like something I was interested in and supported.

Good financial deal. / Product is part of a genre/style that is often deemed not popular enough to get financial backing. / Convenience of mail order for products that will likely be more difficult to get when (if) they go into regular retail distribution. 
To support artists in fulfilling their vision outside the mainstream production channels where they may not normally be able to function or would face publisher interference.

Desire to receive the rewards, although 3 of the 16 projects I backed for no reward, only to help the creator achieve a dream.

Interested in obtaining a new product.

For better prices than retail shopping and the excitement of the campaign. Not to mention the ability to help actually realize something you find to be a good idea.

Depends on the campaign. More often than not it's because I want a backer reward. In some cases I just want to contribute to what they are creating but don't care about the rewards to the backer (this is most often when the final product will be given away for free like podcasts or videos. In a few cases it's because the creators are local to me.

Value. Also, these items (being new) are unavailable for purchase elsewhere.

The primary reason why I contributed to each of the projects I have backed is because I liked what the project was about; most (but not all) are for physical items, which I will receive.

I wanted to help the project.

The majority because I wanted the product they were creating. Rarely because I support their cause.

I have only contributed to one Kickstarter and wanted to see the game made.

Because it was something I thought people needed.

Faith to the brand/knowledge of their abilities.

I had interest in the games and wanted to support the developers. I also wanted the games to come to my platform of choice so I could play them.

Ultimately it was because the idea was so perfect and I could see myself using it daily.

I will be very likely to donate if a friend has a Kickstarter campaign or if a friend suggests one that they are interested in or if they have a friend who is running one. I haven't found one on my own but if it was something I was passionate about I would donate.

I want to help others from this 
Because it is smart to contribute to projects that will allow people to help themselves instead of just giving them charity so that they develop skills and self confidence.

Ultimately I contributed because I wanted to make sure I was able to buy the product that was pitched in the campaign because it looked like a lot of fun.

I thought the personal appeal for support of the project incentivized me to donate.

Again, because I sort of knew the person, had seen some of what he was capable of, liked his approach, and had some faith that he could do something worthwhile.

I wanted to help the band get their new album released.

I supported the project.

Because I believed in the project.

Because it was a game I wanted to play.

I wanted to make a difference.

I decided to help fun their two Kickstarter campaigns because I really wanted to see the projects get funded because I am a big fan of the band I backed and the video game franchise I backed.

Because I wanted to help a friend out

I wanted to be a part of funding the project and get the reward offered

Because they were things I would enjoy that I thought would benefit the most from the crowdfunding model and I had the funds available.

I like getting things early. I think it is fun. I take it how it is, I'm not afraid to lose money on there.

To help support.

I believed the project could change the technology world. I had a lot of faith in the product.

To grab the benefits from the camping projects

I read about and thought the projects were worth financing, and that they otherwise could NOT be completed.

I wanted to help out. 
Wanted to see product made, and value of reward justified cost of donation.

I believed in the project and the person very much. This has always been the reason for each project I backed. I knew someone very well and they wanted to make a video game. I believed in them so I helped out. Someone else wanted to do a live video at a conference but they needed money so I donated some money because I believed in them. Someone else wanted to make a movie I donated because I believed in them. The different pledge levels only play a part in how much I will spend.

Because I really liked the presentation, and the fact that she was local made it even better.

A friend's project

To support projects that seem interesting to me and could use the support

It wasn't very much money and I had seen the same people's work in the past so I thought it would succeed and I would like the game they made.

My contribution was essentially a preorder for a product I would have bought anyway

It's a way to allow lesser known artists the chance to get their work before the public.

Many people today are talented but they do not get the right stage to deliver. Through Kickstarter we can make a change in someone's life. I felt that was worth it.

Interest in the Kickstarter process, and the quality of the products I purchased.

Two reasons: 1) I wanted the final product and didn't think it would be released outside of the Kickstarter campaign, or 2) I wanted a certain reward that came with the project.

I wanted to support my cousin. 


\section{APPENDIX H: INTERVIEW TRANSCRIPTS}

In all transcripts, the investigator's words are in bold, and the participants' words are not.

\section{Interview \#1}

How many Kickstarter campaigns have you backed?

One.

Just the one. And what was the campaign?

The campaign for the Veronica Mars movie.

How did you like the final results of the campaign - the movie itself or any other rewards that you got with it?

Well, let's see here, I received - for my donation-I received a t-shirt, a digital copy of the film the day it was released, the shooting script the day it was released, as well as little cute stickers. I was very happy with all four of those products. The movie itself was fantastic as a fan to see, but here's the problem - it pandered to the fans. I suppose that's kind of in the nature of it, because it was essentially paid for by the fans.

How much did you donate to get those rewards?

I donated $\$ 50$.

How far in advance did you get the shooting script?

The shooting script, along with the digital copy of the film, the day the movie was released.

When was that?

March 14.

Oh, OK. What would you say was your most important reason for contributing to this project?

Because Veronica Mars is one of two shows that ended in such a manner that was so unsatisfactory that it made me legitimately angry when I thought about it. And it wasn't their fault, so I wanted resolution. And if that resolution came in the form a movie, I was going to get it. 
Did you feel like your contribution was an important part of the movie being made? Did you think the movie might not get made if you didn't contribute to it?

No, because even though I donated on the first day, I donated within like an hour or two after the goal had been met.

Ah, OK. Yeah, I remember that campaign met its goal in the first-

In a few hours; it wasn't long at all.

Did you want any particular rewards? What drew you to the donation level you selected?

Well, I was initially going to donate, I think, \$25 and just get the t-shirt, but when I figured out you would also get a digital copy of the movie, I thought, "Well, I would pay $\$ 25$ to buy the Blu-Ray anyway, so what's the point? I might as well get the digital copy." So then I upped it to $\$ 50$.

Did the digital copy of the movie have any DRM restrictions?

Clarify please.

OK. Sometimes, digital media has restrictions that are designed to keep people from sharing or copying it. For example, if you download computer games through a service like Steam, you can only play it through Steam, and you can't download it directly to your hard drive. Did the Veronica Mars movie have any restrictions like that, or was it yours to keep and use how you want?

As far as I know, it can only be played through Flixster. They used Flixster to distribute the movie. So, as far as I know, I can download Flixster as an app, be it on my iPhone, my Kindle, or my Mac. I can download that Flixster app, and because it's uploaded to my account on there, I can download it as many times as I want to whatever device I want. I could not have read the fine print, but to my knowledge, it can be downloaded as many times as I want.

OK. It sounds like it doesn't have much in the way of restrictions.

Right. Exactly.

How did you find out about the Veronica Mars movie project?

Um, I don't live under a rock (laughs). I'm active on social media and a lot of TV blogs because I am an avid fan of television shows, and the moment this hit the news waves it was pandemonium on social media and those blogs. So that was how I found out. 
One of the movie's premiere locations was Columbus, right? (note: participant lives in Columbus, $\mathrm{OH}$ )

Yes.

Did that play into your decision at all?

Uh, we didn't actually know any of the locations when we donated. They didn't release the locations until after the movie had been shot, I believe.

Were you able to go to the premiere?

I did not, but there were extenuating circumstances. I was actually in London at the time of the premiere.

Did admission to the premiere come with a certain donation level, or was it just like a normal movie you would go to?

No, it was not included on any donation level.

You mentioned liking the rewards that you got from this project. Are there any other kinds of rewards you'd like to see in future projects? Any kinds of rewards you can think of that might motivate you to back another campaign?

I'm a fan of t-shirts (laughs). I am. I'm a sucker for those and they're pretty standard. I'm not very imaginative in that way, so I've got nothing else I'd like to see.

I know a lot of the t-shirts given out with campaigns are exclusive to the projects. Does that make a difference?

No. Not at all.

OK, the next set of questions is about your role in the creative process. The theoretical background behind this idea is that on a platform like Kickstarter, because the fans who are funding the project have a financial stake in it, that they have more of a hands-on role in creating the content. They're sort of like producers of a movie, for example. Did you feel like your contributions were important to launching the project? Well, I know you said earlier that by the time you pledged, the project had already met its goal. Did you feel like even though it was past its goal, your contribution made a difference?

Yes, I do, because it was such a small budget. I mean, the budgets movies get made on are, you know $\$ 100$ million plus these days, and this movie had a goal of just $\$ 2$ million. That's it. And whenever they hit the goal within just a few hours, they were making it clear via email and through, again, social media and whatnot, that the more money they got, the better the movie would be, because the bigger budget they would have. That was 
what encouraged me to donate even thought he goal had already been met, was that, "Hey, I'm just gonna help make it better."

Did the campaign use stretch goals? Are you familiar with stretch goals?

I'm not.

OK. Stretch goals are specific additions to the project that creators will say, "If we make a certain amount of money, we'll add this to the project." Just making the movie better is kind of like a stretch goal, but stretch goals are a specific provision of Kickstarter that's used for adding additional elements to a project. Do you know if they used anything like that, or was the idea just, "The more money we can get for this movie, the better?"

I think it was more of the latter. I don't ever remember hearing, you know, "If we get this much money, then this person's gonna come on board," or anything like that. I don't remember hearing anything specific.

OK. Were you able, as a backer, to see the movie, before other people, or was its video release date the same as the digital download that you got?

No, its video release date was the same as the digital download.

So you would say that despite that the availability of the movie would've been the same to you whether you backed the campaign or not, you still felt your contribution was important?

Yes. Yeah, absolutely. It's because of fans like me that had that kind of passion for the show that the movie was even made.

Do you think other shows that had cult fanbases but weren't on the air real long could have success launching a movie through Kickstarter?

I think it depends from fanbase to fanbase to be honest. There are certain cult shows, things like Firefly, things like Veronica Mars, they have these fans that are known for their unique dedication to the show that I think it words from them. Something that actually might be a bit more mainstream, I'm not entirely sure about, just because I feel like the fans aren't quite as unique in their drive.

Like, for more mainstream shows, that the fans might not be into it enough?

Yeah. Like they're more casual observers.

Was Firefly the other show that you were angered by its lack of ending?

No, no. Actually, I loved the ending to Firefly. Angel was the other show. 
Now, you talked about that the more mainstream projects might not make it as Kickstarter projects. There has been some controversy over the film category of Kickstarter because a few filmmakers who are more high-profile, like Zach Braff and Spike Lee, used it to fund movies that they're currently working on. This came into issue because it was often speculated that they could've funded the projects without Kickstarter. What are your thoughts on that issue?

Veronica Mars was a unique situation in that the studio absolutely did not believe it had an audience. There was absolutely no belief and Rob Thomas, who was the creator of Veronica Mars and the one championing to get this movie made, he had tried for multiple years and gone to the studios saying, "Hey, we have people craving this and crying out for this. I promise you we have an audience." And they didn't believe it until the audience funded it. I think people like Zach Braff, and you mentioned Spike Lee-

\section{-Right-}

-I think those two have much, much wider reach as far as fans go, and I think that it's not necessarily as important for them to prove themselves through a medium like Kickstarter because I feel like a studio would be more apt to believe they have an audience for that. So, it's nice, don't get me wrong, but if I were an equal fan of a Zach Braff movie and a Rob Thomas movie, I would be ten times more likely to go for a Rob Thomas movie than a Zach Braff one on Kickstarter.

A similar concern regarding fanbases and movies on Kickstarter is that the studios who own the properties of TV shows and maybe older movies could basically leverage fanbases into covering some of the costs for them. A YouTube series called PBS Idea Channel talked about this, and the way the host explained it was that FOX, or whatever studio it was, could say, “OK, we'll make a Twin Peaks movie, but you have to give us $\$ 3$ million first. Do you see any problems like that happening with Kickstarter-funded movies from things with a cult audience?

I think it could absolutely be a problem. I mean, just think about it. If a studio does issue that kind of ultimatum, it's incentive for them to make even more money. To make the same movie at less cost to them. Plus, you have the same fans who donated, who are going to buy it and see it in theater.

If you saw a project like that —if you thought that sort of thing was happening - do you think you'd be less likely to contribute to it?

Absolutely. Well (laughs), I say that, but I think even if that happened with Veronica Mars, I would have still donated. I think it just depends on how strongly I would feel about the project.

So the reward of having the movie being made might outweigh the motivation behind it. 
Might. I think it would have to fall on that particular end of the spectrum, but yes.

Changing gears a little bit, you mentioned being active on social media and TV blogs. Did you personally promote the project through tour social media, blogs, or anything you might participate in?

I believe I mentioned it on Twitter. Yeah, I believe I did.

Or mentioned it personally?

I definitely did. I especially told people who enjoyed Veronica Mars and were fans. So I definitely talked about in person.

And you talked about it more in person than online?

Yeah.

Do you think telling people that you know personally who liked the show about it was a better way to spread the word about it than posting about it online? Do you think there's a difference?

Well, I think it just depends on your online presence. I believe I tweeted about it, but it's only a handful of people it would've even mattered to - who read that tweet, who followed me. In my particular situation, talking to the people I knew about it in person was better than tweeting or putting it on Facebook or whatever.

The next thing I want to talk about is Kickstarter's accountability policy for project creators. Are you familiar with that?

I think I am. Can you refresh me on it?

The policy, as it stands right now, is that when a creator puts up a project-all the projects are screened by Kickstarter first, so they have to be approved-so after they're approved, anyone who backs the project has entered into a legal contract with the creator that the creator has to fulfill. So, if the creator defaults on a project promise, then the backers can take legal action against them, but Kickstarter will not go after project creators directly. They provide a means for backers to contact creators, but they don't take any action against them directly. It all has to be between the backers and the creator. The reason for this policy is that-well, first, Kickstarter does not ever actually possesses the funds that are contributed. When a campaign meets its goal, Kickstarter transfers the money that's' been pledged to the project creator. Their rationale for this is that the site isn't intended to be a store for pre-orders of stuff. It's supposed to be about supporting creative projects that, like this movie, might fall outside of what would get funded through traditional means, and they don't want to impose too harsh a penalty on project creators because they 
don't want to discourage creative projects. The counterpoint to this argument is that if the site doesn't allow for enough backer protection, then when it has projects that people are putting a lot of money into-I know, for example, that this movie was one of its top five or ten highest-funded projects - that when people tie up a lot of money in these things, they may be less likely to use the platform if one highdollar campaign doesn't turn out the way people want. Is that a good background for the accountability issue? (pause) Are you still there?

Yes.

I think my thing cut out for a second. Were you aware of these policies at the time that you contributed to the campaign?

No.

The next question says "Did you take them into account when choosing to back any campaigns?" But I guess not. Would their accountability policies affect your decision to contribute to future campaigns?

Yes, it would.

How so?

More so if it wasn't a campaign that I felt really, really impassionate for. So, let's say I'm going to go out and donate $\$ 20$ to some project that, eh, I'd really like to see done, but it's not absolutely necessary, I probably wouldn't donate it if I thought there was a chance that it really wouldn't actually be created and my money would be just lost.

Knowing that the accountability is what it is, do you think you'd be less inclined to donate a higher amount of money to any project?

Yes, for sure. My ultimate decision to donate a higher amount of money would basically come back on a couple things: 1) how strongly I feel for it, and 2) what I perceive as the likelihood of it actually being created — of actually getting my money's worth.

You donated $\$ 50$ to the Veronica Mars campaign. Would you see yourself pledging more than that to a campaign if you felt strongly enough?

Absolutely. If I had an actual income and weren't a poor student, I would have donated a couple hundred dollars to the Veronica Mars campaign, no question.

OK. Would you like to see any changes to the site's accountability policies?

There's not really much that they can do. Would I like them to say, "Oh yeah, well, this didn't work, so here's your money back?" But, at the same time, there's not really much they can do. I know, as a consumer going into this, that I'm donating money. This doesn't 
guarantee that a project is going to go in, so I take responsibility for that. It's not Kickstarter's fault. So I wouldn't expect that as someone who funds a project. I know what I'm getting into.

How interested would you be in a project that was based in your local area? Would that make you more or less inclined to donate? Would it change anything?

I love the idea of supporting local people trying to create things, so it would probably make me more likely to donate. I'm going to apologize in advance if something happens to our connection because my cat as decide to put his paws on my laptop.

OK, well, we're near the end, so the crisis situation won't have to go on too long. Do you see yourself backing any others campaigns in the future?

To be honest, I'll admit that I've never gone through Kickstarter and just searched for projects, but I feel like if something came across my path and I felt like, "Hmm, this might actually be worthy my money," yeah, sure.

So, was the Veronica Mars movie project the first time you had heard of Kickstarter?

It wasn't the first time I'd heard of Kickstarter, but it was the first time I heard of a specific project on Kickstarter.

Do you remember when you first heard of Kickstarter?

I believe I first heard of Kickstarter maybe a couple months before that - so right around a year ago.

Where did you first hear about it? On one of the blogs you read?

No, I think I heard it from a friend.

Anything else you want to say on any of the topics we talked about today?

No, I feel like you covered it pretty well.

That's all, then. Thanks a lot for doing this interview and for taking the survey too. Yeah, sure. 


\section{Interview \#2}

First, how many Kickstarter campaigns have you backed?

I believe the number I gave you was around 11. I mean, do you want strictly through Kickstarter or all the ones that I have slacker-backed through Kickstarter or not, when I've contributed?

\section{Explain the difference.}

Well, what happened is, initially when I found it -Divinity: Original Sin-it was in an article on IGN. I checked it out; it was Divinity and some things they had put up. I liked what I saw, so I backed it. They said, "Oh, hi, there's this, this, and this going on," and I'm like, "I'll take a look," or they were referencing older things like Pillars of Eternity. It was originally called Project Eternity; it was done by Obsidian.

\section{I think I remember that one.}

It got a couple million dollars in funds. Wastleand 2 was the same developer.

\section{I remember Wasteland 2.}

It got 3 or 4 million. And Shadowrun Returns was another one I backed. That's three, at least, that I backed like that. And basically you contribute the money that's gonna fund the game, but it already has the advantage of this game has been funded through Kickstarter.

\section{So slacker-backing is funding a campaign that's already reached its goal?}

Well, it's already reach the goal that it's gonna be made, and any of the slacker backers generally go toward stretch goals for the final product.

\section{OK. I hadn't heard that term before. That's interesting.}

Yeah, it's usually posted on the site. The first time I saw that was Wasteland 2.

I've slacker-backed a few in that case. I think in that case, most of the ones I backed were slacker-backed.

It's always good to see that, OK, it's gonna get made. It's not like they're just taking money from you.

When you backed these campaigns that had already reached their funding goals, what made you want to back them? That you wanted the games or wanted to contribute to the stretch goals? 
Well, I mean, it's how interested I am in the things. I really like Kickstarter because it's not trying to put out more games that are all the same. They're either for a niche market like old-school RPGs-I wasn't around or didn't have a computer that could play them back in the day, so I couldn't enjoy them. And now they're giving me something I never got to partake in, and it's from the same guys who did Planescape: Torment, one of the most well-known games out there, and you know, all these other teams. Obviously Wasteland was huge, but there's no chance I was playing that; it was made around the time I was born. It was nice to allow them to build a game they really wanted to build for years. You know, I get the game at, usually at as much as I back it, it costs me more to back it than to buy the game after it releases, but that's definitely nice, and they give you little perks like putting your name in the credits and stuff like that.

\section{Have you ever gone to the credits of the games and seen your name in them, by chance?}

You know, I haven't yet. Most of them are still in development. The only one that might — and I can't remember cause I backed Battle Worlds: Kronos or Battle World Kronos, I can't remember-and I haven't gotten to play it yet because my Steam backlog is ridiculous. I need to check that out and see if that was in my tier or not, the credits. I know it is for a couple games but I'm not sure for that one.

\section{You kind of covered some of this already, but just to ask as I wrote it, what was your most important reason for backing a project?}

The most important is probably because I know the games wouldn't get made otherwise. And I like to support different types of thinking within the gaming industry. The publishers - actually it's the anti-publisher types, I think. I'd love to see it become more direct relationship with the developers. "We want this? Would you make this game for us, as opposed to what the publishers say we want?"

\section{For the projects where you have received your final product, how did you like them?}

Well, I'm wearing one of them.

\section{Oh, did you get the 10-year Hoodie?}

I did get the 10-year Hoodie. It's awesome. It's probably my favorite now. It's extremely well made. It was made in America, and they guarantee it if anything happens to it. Um, Battle World: Kronos, like I said, I haven't played it, but I did get the collector's edition game in the tin case and everything and that was really well done. I really enjoyed that. And they're really supportive as far as "Well, everything wasn't set in stone when we did the Kickstarter, so some people we promised like a Gog key so there isn't any DRM-not even Steam." Some people want the Steam key, and they have their own, which is, I don't know what they call it. They call it King Arthur Games downloader or whatever, so you can download the game directly to your PC — a little bit old school (laughs), before 
Steam. But they gave people, if you pick one method or another, or if they delivered in one method or another, they really tried to give it to you on Steam or whatever your preferred platform is. They're really flexible, at least the ones I've backed.

\section{So are most of the projects you've backed computer games?}

Yeah, most of them are. That's just because that's where my interests lie, so that's what I'm willing to look at. This is the exception (points to hoodie).

\section{Right. How did you find out about the campaigns that you've backed?}

Well, initially, like I said, I read the article on IGN for Divinity: Original Sin. And then, what they really do, is they call it kicking it forward. I'm not sure who started it. I want to say it was whoever did the Woo-ya [Ouya], or however you say it.

\section{I think it's "ooh-ya."}

Whoever did that and possibly Wasteland 2, whoever did that. I think it's called InXile.

\section{InXile Entertainment, yes.}

They, I believe, probably kind of spearheaded that. So any money they make off the game, they kick it forward to other project, so they give a certain amount-I think it's $5 \%$, to other projects to keep it going. So what they do, in their Kickstarter backer updates - because they try to send you at least once a month it seems like-something saying "hey here's the progress." They'll say, "Here's some other interesting projects you might like." I'm like, “OK, well I'll check it out.” They usually give you a little pitch saying, "This guy has done this game and this game," or whatever, so you know their pedigree. I don't back games that aren't from established names. Like, it's gotta be a really impressive presentation on their video to even consider it if it's not someone like Brian Fargo or Chris Avellone or all the other big names.

So you found out about Kickstarter initially from online news media. Do you now check Kickstarter regularly for new projects, or do you mostly get your information about new projects form the backer emails?

It's a combination of three of them, really. Because, you know, I can't always see it, so I have to check IGN or Game Informer. Sometimes I'll find out about them from a backer update. And sometimes I'll just go in and peruse because I can really drill down on things I'll like when I do that.

\section{Have you ever known any project creators personally that you've backed?}

No, I have not. 
Have you ever backed any campaigns that were based in your local area-either Morgantown or where you're from originally?

No, sadly, not a lot of game development going on in West Virginia.

So, what do you think about supporting a local project? Would you be inclined to support one because it was local?

Well, that would definitely help because I might feel more connected to it. It really depends what they're doing, though, and their pitch.

So you would prioritize what kind it was and then maybe you'd be more inclined to back it if it were local?

Yeah, I would feel a certain sympathy towards anything that were local, if it's not a project I'm interested in, I'm not going to give it my money just because.

You've mentioned some of them already, but what kind of Kickstarter-exclusive rewards have you gotten for the projects you've backed?

Usually, the one that's always in there if you're above a certain level, which I usually am, is they put your name in the credits, and they'll, like, tier the levels. Divinity: Original Sin, I think they have-Torment might be easier. Torment has these crazy levels like Cypher level, and crazy stuff within the lore, so people who played the game will appreciate how high, however much you how much you contributed to the game. So it'll kind of rank them based on where you were able to fund.

So, for most game projects you've funded, I assume you backed enough to get a copy of the game. Did you get any other rewards, other than the names in the credits? I know some games have exclusive in-game characters and stuff.

Yeah, that was the next thing I was going to say.

Have you ever backed any of those?

Yeah, I have backed that level, where they're going to put items in the game that are tailored to whatever I want them to do - within the mythos, as long as it fits - but those games haven't been released yet. The only things I've backed that have been released are the hoodie and Kronos so far. Divinity is close, so I'll be able to tell you more in a couple months whenever it releases, but it's still a ways off. Wasteland is probably close as well.

Did the rewards play into the decisions to back the campaigns?

To back them in general? No. They influenced my decision to back more. 
Any kinds of rewards you'd want to see in future games? Any kind of thing you haven't seen so far that you'd want to see?

Actually, I saw a fairly awesome reward for a game I recently backed. It's called Deliverance: Kingdom Come. And they are actually having people forge legitimate swords as a backer reward.

How much to you have to pay to get a forged sword?

I can't recall exactly, but it's definitely over $\$ 500$. I'd say it's over $\$ 1,000$, probably. I think it probably affects the quality of it. They really went all out on this. They did a backer update just to tell you what the sword would be and whoever they were getting to do it and why they're known in that field. It was really cool. That kind of stuff was awesome - not necessarily the game itself, but it's almost like if Zelda were funded, you could get a copy of the Master Sword or the Hyrulean Shield. That would be awesome. That would definitely make me consider backing it more.

The craziest one I ever saw was a band. For $\$ \mathbf{1 0 , 0 0 0}$, in addition to the other rewards, they would give you their touring van. They would drive to your house, sign over the title to you, and fly home. I don't think anyone did the van.

That's awesome.

That still stands, although the swords are gonna come close to the craziest Kickstarter reward I've seen.

It is awesome. That game, if you're at all interested in swordfighting in games, it's not gonna have dragons in it or anything. It's gonna be more medieval history type, so historical fiction to an extent, but it's awesome. It's first-person like Skyrim, but it's got a lot of complexity going with its combat system and a ton of customization options.

The next set of questions is going to be about the backer's role in the creative participation of making the game. We've talked about some of those ideas already. You mentioned earlier that you like that Kickstarter gives you more direct engagement with the project creator. So, do you feel like you are a part of the creative process in making the project?

As much as I can ever be as a fan and not a developer, yes, because that's what they're doing. The product hasn't been funded yet, so they, during the Kickstarter phase, they are extremely reactive to anything that's brought up and it's actually changed some of the development processes for them, as far as the game and what they want to do on different systems. Once it is funded and they're releasing videos and things of their ideas, like, I know specifically for different games, they get really particular about the user interface, especially for games like Eternity. Torment, not so much, because it's still deep in the pre-development stage, but Wasteland as well. They say "Hey guys, what do you think of this? What do you like? What do you not like? What could we do to make it better? What 
types of fonts would you like to see?" So it's ridiculous really, that they want input back on some of these things.

\section{So creators have asked you and other backers some pretty detailed, specific questions about what you want in the game?}

Yeah, absolutely. For Torment, actually, one of the things they did was, there was a big debate about what the combat system would be, whether they were going to go real-time with pause, turn-based, or another hybrid, I think it's phase-based, which is a hybrid of turn-based. They had two or three weeks where you could put all your arguments together on the forums - backer-only forums, so you had to have been a proven backer to participate - and then they said, "OK, once all your arguments have been fairly represented, we're going to hold a vote." They held the vote and then they made a decision. They took their own thoughts into account, but it ended up being that the fans voted for what they were leaning towards anyway, because they presented the case for each of the different combat types themselves and let the fans battle it out.

Did you spread the word about the projects on social media or by telling people about them?

I think you know I did (laughs).

I know that you did (laughs). I'm asking the question the way that I'm going to ask in general, but $I$ know that you have shared all of them on Facebook.

Yes, I do share them. I share them all because they were appealing to me and I think I know at least a couple people who would be interested if they are able to fund.

\section{I looked at them.}

Yeah, exactly. They're fun things, and if it helps the game get made, or at least helps someone be exposed to a company, because Obsidian's got other things going on.

\section{So, you would say that sharing by Kickstarter backers is an important part of building an audience for a project creator's other works.}

Oh, absolutely, yes. I think some of the developers might be more likely to continue with Kickstarter, especially if they want to make games like Wasteland and Torment. We'1l see what the publishers think about it, whether they're critically successful and financially for them. Because it's hard to tell at this point whether most of the fans who were gonna buy it backed it or not and whether it will catch on with everyone else. At the very least, it would keep them working on the stuff they wanted to work on, but we'll see whether the publishers want to pick it up. And I do know other games use this-I know Divinity: Original Sin's a good example-was kind of a package deal. If you backed enough, you got a copy of a game they were releasing in a more traditional method: 
Dragon Commander. So if you backed enough you got a copy of that, but they were also using to it to spread the word about that other product as well.

OK, the next set of questions is about Kickstarter's accountability policies, and we're gonna tie that into some of the things you mentioned earlier.

OK.

\section{How familiar are you with Kickstarter's project creator accountability policy?}

You know, honestly, when I got into it at least, I didn't really think twice about it because Kickstarter is a trusted name. I didn't realize until I read that that if they don't make the product then they're not liable. I'm like, well, I wouldn't back a project by someone I didn't trust anyway, so it's been moot for me, but I can see some issues with that policy.

It isn't that the creator's not liable; it's that Kickstarter as an entity will not be the one to take action against them. They only provide the means for backers to do so.

Yeah. Well, I mean, that is what it is. They're a platform, so they're acting as such. They're excluding them from being associated with people as much as they can, except when they're successful.

So, you mentioned that when you got into Kickstarter, it was pretty well established. Would you be more likely to trust that a Kickstarter project was going to get made than you would another crowdfunding site?

Yeah, because there are a couple. I know, Zachary Levi, for instance is using a different website, and just because I trust his name, I'd probably feel comfortable that site, but in general, I'd probably stick with Kickstarter, and I would do some more research on other ones before then. Did you get what you needed? You can follow up; it won't bother me. It's your project.

Yeah, I'm just seeing where I am on my list of topics, because I think we covered it. (pause) Would you like to see any changes in the accountability rules?

Well, I think Kickstarter probably should have more accountability for that, but I think it would negatively impact what they're able to do, as far as giving people a space to promote their efforts. If they had to go to court every time someone didn't follow through, they might not be in existence.

OK. You talked earlier about how you were more inclined to back a project creator that you were already familiar with. Is your familiarity based on past Kickstarter projects or games they made before they ever used Kickstarter?

It's usually games they made before. I've only, within the past year and a half or so, gotten into it, so a lot of them haven't cycled back through to using it again. I know there 
are some developers that do that. I think KING Art Games is a big one for that. They made Battleworld: Kronos and that was successful for them, so they came back and wanted to make, I think it's Critter Chronicles or The Book of Unwritten Tales 2, which I think they released more traditionally with publishers before, but maybe they just liked the experience so much they came back to it.

Yeah, I think InXile has-

-Yeah, they did that.

\section{I think they have two of the top ten highest-funded campaigns.}

But they haven't produced either product yet, so I didn't want to put them, because you know, I saw it, and both projects interested me, so that's why I backed it, but they're very different.

\section{Do you think Kickstarter is a viable platform for people to conduct regular business through? A company like InXile?}

For InXile, I think it probably will work very well. The only thing I'm concerned about is the viability of the funding they do receive. They show the math from time to time. I think it was Divinity - the Larian Studios - they said the million dollars we got from backing, that's going to allow us to work for three to six months, depending on what they do exactly. So, it allowed them some time to make the game, but it's not going to fund getting an entire development out of it. So, at least based on that, they're going to have to find some other sources for keeping their workers there developing the game. They're gonna have to sell some titles in addition to it. I worry that some of the titles might be so niche, that they're not gonna sell a whole lot outside of what people are backing. It'1l keep them working for the game, but I don't know if it'll keep them going long-term. In a couple years, we'll probably know.

You also mentioned that, for developers you were not familiar with, page videos were really important. What would draw your attention in the videos or the text pitches from a creator you're not familiar with?

There has actually been a couple I backed that I wasn't entirely familiar with. Torment and some of the games that are similar to that like Wasteland and Pillars of Eternity, I've heard of Obsidian, I've heard of Black Ops Studios, which is where InXile basically birthed from with Brian Fargo-I was a fan of their previous work. But for other games, even Deliverance, the reason I backed that one was that they had a great pitch video as far as being able to show me what the product looked like. They were able to show me alpha footage at least, and it looked good, it looked interesting. And then I read through and read what the game was about. They have a great summary about the features they have at the top, I'm more likely to read the rest. 
So would you be more inclined to back if a game that had some footage already of what the final product would look like?

That's usually been my decision as to whether or not I'm willing to back. Some of them, the ideas are so great and they have concepts they want to do, like Satellite Reign, was one that I backed. They didn't have true alpha footage yet, because they didn't even have offices. But they are from the guys who made The Originals, so I though, "OK, I can trust that name. They have a reputation they need to protect." They had a really good concept and they had concept art and things they were showing off that looked good. If it looks like it's high quality and they really know what they're doing, then I'll back.

\section{Were there any game developers you first heard of from Kickstarter that you would now be interested in again?}

Oh, absolutely. The one that comes to mind is Warhorse doing Deliverance: Kingdom Come - so you have the whole title. I'm backing another project - I think it's called Warmachine Tactics, High Moon Studios. I don't think I've really heard of them before. They have a really cool concept, so I'd look at other projects they're doing or other games they're making. And we'll see how it goes with Satellite Reign. They seem like cool guys, so if that goes well for them, maybe they'll be able to make projects not Kickstarter-based. Either way, I'll look at the Kickstarter too if I like the game.

\section{Any other Kickstarter categories you'd be interested in?}

I'd be willing to look at different things, but it's really hard for me to think, you know, how are they going to pitch me on music, necessarily, unless they have a demo? Because I've never backed music before. I'd be willing to look at that if they had demos in their videos or something like that, or just an audio file you could listen to. I don't know how they lock it down.

\section{Usually the pitch videos have the music in them.}

OK.

I've backed a couple music campaigns, but kind of going back to what you talked about, they were bands I was already into.

Yeah, and I know there are a couple different music-specific websites that do that, where you can back it and keep it going. I think 10 Years did something like that. They're a band I'm familiar with.

\section{I think PledgeMusic is the big one for that.}

Yeah, that's it. Obviously, I did clothing as well, mainly because I'm a big hoodie fan (laughs). I saw that and thought, "OK, that's me." 


\section{That was one of those campaigns I unfortunately didn't see until after it finished.}

They sell them online now. They do sell them online, I believe.

\section{I'll have to look that up.}

Flint and Tinder. Which actually, I didn't know, they're more known for their underwear. I don't know if they're going to sell me on the underwear. They make jeans and stuff too.

\section{Is it ten-year underwear (laughs)?}

(Laughs) I didn't look closely enough. I don't think so. That was mainly for this (points to hoodie). I think it was just kind of, you know, what are you going to say, hoodie? And, oh, you want to back a hoodie? No, we're going to say in the title so people aren't misunderstanding what we're trying to sell here - the product is going to be backed for ten years. If anything happens to it, send it to us, we repair it and send it back. You can actually choose whether it's a contrasting thread or if it matches the color. They also did a cool one for the hoodie. They did patches. If you want to, as the years roll by, you have a new patch you can put on for each year you've had it. They give you explicit instructions on how you can best do it too. I'm like, wow, that's really neat, because I had no idea.

To the extent you can tell-since most of the projects you've backed haven't come out yet-have you seen other long-term customization or stuff that they keep giving you?

Well, the ones that are the games, that's what I mostly back, obviously. Theirs is really frontloaded, I think, as far as customization goes, because they want you on the forums. They want you talking about the game - what you like, what you want to see in there, what you're excited about, what you don't want to see (laughs). So, if you want to spend the time and effort, you can really affect it there if you're building a good case. And I don't know, long term, how they're going to affect, you know, if they do patches, if they do additional expansions and things like that, how it's going to work. I would assume it's going to be similar. I do know that Battleworld: Kronos, which I backed, recently did a trains DLC. It's a turn-based strategy game, so somehow they put trains in there because the backers thought it would be a cool idea. So they did it and released it, and said "Oh, here you go." Cool.

\section{Any final thoughts you want to say on anything we talked about today?}

I think Kickstarter's great. I hope more developers at least give it a try.

All right, well, thank you for doing this interview. You taught me a lot of stuff I didn't know about computer games on Kickstarter, and I think we got some really great stuff. 


\section{Interview \#3}

OK. I've explained what the interview is about. I've explained the consent. So we'll start with how many Kickstarter campaigns have you backed?

I think it is actually around 23. Let me - actually I'm not sure. It's up there. I just

Kickstarted a new one just, like, a couple weeks ago. Like a week or so ago. Sorry. One second. Yeah, it's around 20.21.21 projects.

\section{All right. Of those projects, how many of them have you received the final product for? Approximately.}

Approximately all of them except for one, two, three, four, five, six. Six of them. And that's because they're the most recent six of them. So they're still in the-a couple of them are things that I would - well now that I think about it, a couple of them are things that are like more long-term goals, and a some of them are things that I will not actually receive things for. So, for example, this one is about the L.A. Game Space and I-you know, it's in Los Angeles. I won't be able to go there. But I thought it was a really cool thing to Kickstart so I did.

\section{Yeah. Well, for the ones where you have received the final products, how did you like them? How satisfied were you with the results?}

Honestly, out of all of the ones that I've gotten, that I've received-sorry, all the ones that I've received - I've been pretty happy with almost all of them. I don't think I've been bummed. I don't think I've been bummed out. The one that I got was a little bit not great and they are kind of trying to redo it over anyway. So it was a video game that's supposed to teach you how to make - to go through some programming language. And they had a lot of problems in it. So they were about the one that's an older one that hasn't delivered. And I played the beta version and it wasn't very good. But everything elsealmost everything's been pretty cool. It's been an almost completely positive experience.

\section{What were some of your favorites?}

Ok, well, there's this guy. I will actually tell you this story about the most rewarding Kickstarter campaign I've ever been a part of. There's a guy. His name is Jamie Stegmaier and he runs this board gaming company called Stonemaier Games. And I was, you know, I had Kickstarted a couple things before and it hadn't really-I'd only gotten like two of them at this point. This was probably the seventh or eighth thing I'd Kickstarted. And he ran the campaign so well and did everything just so perfectly that I got, I found myself - I'd already put the money in. I had no interest in putting more money into this game and getting the extra stuff or anything else. But he just ran the campaign so well that every day I logged into the Kickstarter to check out, like, what was new. If he had had any new news about the game, what was going in it. He always had news. It was just so cool. So that, this Euphoria game, even though I've only played the game one time, the actual product was - the product's great. Like, it's a really cool game. 
And I actually had a problem with it. It didn't come with something it was supposed to, and he said, "Hey, yeah, no problem. We can send that out to you. That's not a problem. That was our fault." The experience of the Kickstarter campaign completely changed the way that I looked at it, and it made me-I was more interested in doing it in the future after that. But this - so there was that guy. And that game is great. And, let me see.

\section{What was that game?}

That game is called Euphoria. It's Euphoria: Build a Better Dystopia.

OK.

And he has another Kickstarter campaign; I think it's ending soon. But if I had enough disposable income to pay for it I would because I completely trust that guy. Like he earned my trust very well. He did. He was great.

\section{Great. So what would you say was your most important reason for backing a campaign? Any campaign.}

Any campaign. Ok, well, I will say this. When I first got into Kickstarter, it was something that I thought was like, "Oh man. Board games!" Like, I love board games, and this is a really good platform to release these things - board games and comic books. And so, I Kickstarted a couple things. I was like, "Wow. This is really great." And then I started realizing that the things I was getting, the money that I was putting into it, I was maybe not getting anything extra out of it. Right? Like, if I would have waited to just buy the game when it came out in stores, I would actually know what other people thought about it, I would have other reviews to go on about it, and I would have-I probably would make a more informed purchase and have zero risk. I wouldn't have anyone just stealing my money and running away. But now, and this is the way that I think about it now, if it's a really good cause; if it's something that I think, "Yeah. I would like to see that accomplished." Even if I don't get anything-and I don't even make that much money-I just love helping this person do this thing they say they're going to, right? Like that is a really — that's one of my big reasons for doing it. But my other reason for doing it, and this - and I mostly back board games and comics - is if I can get things from it that will only be Kickstarter-exclusive. That Euphoria game that I Kickstarted, the one I was talking about a moment ago, he - there's a bunch of stuff that came with that game that you cannot get in the retail copy of it. All the resources, like the little tiles and stuff, they're made of like metal and clay as opposed to just, like, plastic - like little crappy pieces of plastic. They're actually made of metal and steel. It's such a cool thing, and he said, you know, you're going to be paying retail price for it, but you're going to get all this other great stuff. And when they kind of put it to me that way, I was like, "Wow. That's a, that's a cool way to do it." So I don't often Kickstart things that - lot of people use Kickstarter as a store in a way, and I, I'm not super keen on just doing it that way. Only if they offer me something that's like a Kickstarter exclusive, and it has to be cool. So, that's my main. I'm a little bit like, I've Kickstarted a ton of stuff, but it still has to be 
something that I think is a very interesting idea or something that I really think deserves money for me to do it.

\section{When did you first hear of Kickstarter? I feel like I remember you posting stuff about it online not long after it was made.}

Yeah. I remember hearing about this. The first time that I did it, let's see. The first thing I Kickstarted was the Double Fine Adventure Game. I had heard about it a little bit before that, so I had pledged the first date that I had pledged anything — and I held out for a long time on this - was February 9, 2012 is what this says. So I had heard about it a little bit before that, but this was the first thing, the first time that it had ever been anything with, like, brought to my attention, and I was like, "Whoa. This is something that I would like to do." I actually signed up and made an account because this was finally something that I was interested in.

\section{What was that project about?}

Well the guy, Tim Schaffer: he is a really famous video game creator. He made a lot of amazing old point-and-click adventures like Monkey Island and Grim Fandango and all of these. Full Throttle was another one I think. And he made all of these really great point-and-click adventures, and they decided to - they tried to go to publishers to try to make a new one and nobody would make it. Everyone's like, "No. That's too risky. No one will give us money because they don't think they'll get a return because they don't think people would want to play a point-and-click adventure in this day of Call of Duty and, you know, World of Warcraft or League of Legends." Like, it's just something that they thought would be too boring or something. And they created this game called Broken Age. It didn't have a name at the time. But they ended up getting like some crazy amount of money for this game. Their goal was $\$ 400,000$ to make this game, and they ended up getting $\$ 3,336,000$. So, that's just a crazy amount of money. And I think this was the first campaign that really elevated this to the public eye. It was just huge. It blew up all over the Internet, and this is when I finally got on board with this; when I finally figured out about this thing.

\section{A little more about the rewards. What were some of your favorite rewards other than the ones you mentioned about the game earlier?}

Well, there was a-I really like this genre of music called chiptune where people make music with video games and Game Boys and Nintendos and things like that. And I found this, like, collective that was trying to be able to put out - they were trying to start, basically, a chiptune record label but in Detroit, and they had all of these artists who were trying to put out albums and stuff but they needed help. And they wanted to raise awareness for it, so they said, "Hey, just send us money, and we'll send you our album. Or you can send us money, and we'll send you a t-shirt." And I think that t-shirt is so cool. It's just like a black T-shirt, but it's pink. And it has a panda bear on it, and it's just adorable. And I love it. I think it's really, really cool. 


\section{Cool. Did you do the Anamanaguchi one?}

Yes, I did. Mmhmm. I sure did. That one, I will say, there were-I like those guys. I like their music and stuff a lot, but I think the problem with Kickstarter sometimes is that people kind of get in over their heads, and they don't really understand what they're getting into. Because they promised on their Kickstarter they were going to have this little acrylic-looking USB that was going to be all wavy and colorful like the cube album thing that they were doing, but they ended up just sending this metal and plastic thing with it engraved on it. And I think-

Yeah, I have that USB, too.

Yeah, that was it. So I got the USB and I was, like, bummed out. Cause I was like, this was not at all what I thought it was getting at. But I was expecting this, like, really cool USB.

Yeah. It looked different from the-it was more of just like a normal drive.

Right.

Like, the professor I work for has the same flash drive, but it says University of South Carolina instead.

Right. Yeah, yeah. Exactly. Exactly. I think that they just got in over their head on that one, and, but that one, it bummed me out a little bit. That one bummed me out, cause I expected so much more out of it, and that was one of the times when I realized that maybe I should have held out and then just bought the album later or just bought it on iTunes or something. Like, I don't know.

I kind of thought so, too. Cause I saw them in Morgantown a few months after, over the summer. And they were selling the flash drives already at their shows, but I hadn't gotten mine from the Kickstarter yet.

Yeah. See, that's a huge bummer. (laughs)

I liked the album a lot. I just, I think that was one for me, too, where I probably could have just waited and got the album.

Yeah. I think you're right. I had a couple friends, my friend Matt here actually, has - he bought the vinyl version of it. It's on his wall here, and it's cool. Yeah, it's cool. And the album's alright, and it just, I kind of felt like I got burnt on that one a little bit.

\section{Any other kinds of rewards that you would like to see in future campaigns?}

You know, that's - my favorite part about Kickstarter is that people come up with, like, really crazy stuff to give you. And when you hear about, like that Jamie Stegmaier guy 
that I mentioned. You should actually look him up. The reason I mentioned him is because he has blog about how to run a perfect Kickstarter campaign in, like, his opinion. Cause he's run like three of them now, and they've all been like really successful. But, anyway, that's the thing I like, particularly from him, is that he listens to the people and, when people are like, "Hey, wouldn't this be cool if this is what we could have?" And he goes, "That's a really good idea! Like, wow!" And hearing these, like, really ingenious things come out of campaigns. I think the things that get me is just, like, really unique items that come out of it. For instance, there was that game. I keep talking about this Euphoria campaign, but it's honestly because it was the best thing that's happened to me on Kickstarter. But it was, like, the box itself. At first it started out and it was just these three factions that fought against each other, right? But then he's like, "Hey. If you guys get to this stretch goal, I'm going to add a whole new faction. And then I'm going to give you all this information about it." And I was like, well that sounds awesome. Like, I want to see that. So he basically pushed the idea like, "Hey guys. I want to do this cool stuff, but I need you to get us there." And it is weird because a lot of times people are, like, begging for money instead. Like, "Alright, guys. Let's get those wooden tokens." Or, like, get those whatever. And this guy was like, "Man, you guys must want to see some cool stuff because if we get here, we're going to see some cool stuff." And I'm like, "Yeah I wanna see some cool stuff! Let's do it!" And so I just got really, really excited. The board game that I have-so there's a whole other faction. All of the stuff inside of it is, like, really unique looking resources. And then he also has - the whole game has a sleeve. Like the box itself comes in a sleeve, and if you put it on your shelf, it looks like a book. It's like silly stuff like that. And I was just like, "This is amazing." And all of those things together make it a whole, like, a really unique package. It's way cool. And people got on and said, like, cause if you bought a retail version of it, it's not; it's cool, but it's not nearly as cool as my Kickstarter version of it. Let's see. What else? What kind of stuff would I like to see again? I really like just art. Like when people come up with art for stuff, sometimes they give you like weird tokens or weird little prints and stuff. And I don't really care about that. I don't really care about that kind of stuff unless it's for like a comic or like an art, you know, like, this board game here actually. This is perfect. I got this Perfect Heist game. It came with this piece of art on the front of it, which was like the cover art, but the guy had signed and stuff. And he had written this, like, big message and stuff on the back of it. And it was cool, but I'm just going to lose it. Like, I'm not gonna put it in a frame or anything like that. It wasn't anything that was like unique enough that I was like, "Wow. That was really neat." So nothing. I think that when people do like little prints and cards like that, it's like man, you're kinda just tossin'; you're just throwin' money away. But I think anything that makes the game feel unique or better but not game-changing. Like, if you bought the retail version of it and I bought the Kickstarter version of it, I want us both to have fun playing this game, but I want you to kind of envy my package-like my Kickstarter package. You know what I mean?

\section{Yeah.}

Yeah. So, that's pretty much it. Like, making it cool enough that I also want to Kickstart it because otherwise I can just buy it in stores later. 
Moving on, you started to talk about participation and communication with creators. Did you feel like your contributions to Kickstarter were important to launching the project?

I've never been a part of something that only had, like, had a really low goal. Well, that's not true. I've Kickstarted something for, one time, at least one time, there was one for this group of people, this girl that I kind of know; we're friends, I kind of know her peripherally. It's called the 219 Project, and it's all about the Seneca Trail in West Virginia. And, let's see. The goal for the project was only $\$ 3,000$, but I gave $\$ 25$, and they-maybe because this was a more local-grouped project and I felt a better connection to these things that I did feel like a really helped it. But there were only 75 people -75 backers for this one. So I kind of feel like out of all of them, that's the one that I helped the most. Yeah, I think that's it. I never felt-it is definitely, you know, it's called crowdfunding for a reason. You're definitely in a crowd of people. I've never felt that my contribution individually was, like, important. But, you know, everyone doing that makes it pretty strong.

OK. Now, you talked about how in one of the projects that you backed that the project creator wanted to hear from you and the other backers for things that were in the game. Did you feel like you were a part of the creative process in doing that?

Yeah, actually. Which was cool. Yeah, with that Euphoria game, the one I keep mentioning, he-I would post stuff, and I never really comment on these things. Like, every once in a while I will if I feel that something is not-I'll read through the comments and if something's not being said then, yeah, I'll say it. But this guy, Jamie, was like, "Hey. Do you have any ideas of what should we put up? Like, what kind of things do we need to- - what would you like to see?" And I suggested something one time, and he actually, like, messaged me. Like sent me things like, "Hey. That's a really good idea. I don't know if we can do that because," and he gave me a whole reason about, like, that the appropriation of Kickstarter funds, you can only use it for certain things, and he didn't want to get too far away from the use of the product. But he, you know, he acknowledged me. And that was even a really big campaign. And he acknowledged what I had to say, and that was pretty cool. Even though I was just like, "Oh, wow. That's nuts." And, you know, that goes both ways, and I don't know if you were going to talk about this later, but there's one Kickstarter campaign that I've had the absolute worst experience with. I would never - no matter what project this company was doing - I would probably never give them money again. They were just - it was the opposite. Like, where that guy acknowledged us, these people just didn't. And it just kind of sucked.

\section{What was that project?}

There was this - this is another board game. This board game called Mister Card Game. It was, I don't know if you're familiar with the old browser-based RPG Kingdom of Loathing. 


\section{No, I don't know that one.}

It's a really, very, kind of - it's a very, very silly game and browser-based RPG, and they decided to make a card game. This company, I think, called Evertide Games decided to approach the browser-based people and they were like, "Wow. That would be great. Let's do it." And this company had only made one other game before, or no. They had not made anything before, but they got this, I think they only asked for, like, $\$ 15,000$, and they got $\$ 142,000$. And they were so bad, man. They were awful. They just-OK. I Kickstarted this game, let's see. It finished on-what does that say? This project was funded October 16, 2012. I got this package, I finally got rewards for this, maybe two weeks ago.

\section{Wow.}

And I Kickstarted a lot of other things since then and gotten all of those things. I lived in Washington, D.C. when I Kickstarted that game. I went to-I lived in China for an entire year and came home, and it still wasn't here. And, yeah, it was crazy. So that was a really bad campaign. But a lot of it had to do with it didn't really - they didn't show us anything. They didn't tell us what was going on. They didn't — it really kind of, like, people were getting angry. They were talking about, like, "I want my money back." And they tried to, like, kind of take it away from Kickstarter and kind of try to like Kickstart their business by using the money from the game. And it was really weird and really bad and I would never. They brought on a new Kickstarter halfway through the game they were planning for us and it was like, "What are you doing? You're not even done. You haven't shown us anything from the other game." And then I got it and some of the things in the game are cool. Like, they had these little tokens that are, like, really nice. But some of the design, they didn't even - they didn't show us the designs for anything. And the Euphoria campaign, the one that was really well run, he was showing us art from the games and backers were saying, "Hey. This art looks really weird." Like, I don't like it. And a lot of people didn't like it. And he said, "Well, what don't you like about it?" And people, you know, they weren't angry when they said they didn't like it. They were explaining what they didn't like about it. And he was like, "You know, you're right." And then he went back, and he changed all the art for the stuff, like had the artist go work this whole new thing around for it. And everyone was like super happy that he even listened, you know? And these guys just didn't care. And we all got-everyone was really, really upset. And only, only in like, I think we got in the end of February or something. And we were just like, "What the heck?" First week of March, I think, is when I got it. And we were like, "What?"

\section{I'm gonna go back to something you said earlier about supporting a campaign from West Virginia. You knew the project creator personally for that one?}

I did. I did know her. But it wasn't - the reason I Kickstarted this campaign, I will say, was not just because it was her project. Because I knew a couple of the people who were doing it; one of the guys who's doing the art for it, he as the one who told me about the project in the first place. He said, hey, she's doing a Kickstarter for that, and I was like, 
"Really?" But then, the rewards they were giving us, let's see here- the whole premise of the project, I'll just explain it really quickly. It's called Travelling 219: The Seneca Trail. They wanted to go up this highway 219 in West Virginia, which goes all the way through the mountains, right into the panhandle of West Virginia, and they were just walking up and collecting stories. It was basically folklore, and I love West Virginia, number one, and number two, folklore; I just love folklore so much. And when my friend said, hey we're doing this stuff, collecting stories and oral histories from people around US 219, I was like, that sounds awesome, let's do it. And as soon as I heard about it, I, um, I sent, um, I got a package, I got a CD with these stories of people talking and it came with some stickers and stuff from it. So yeah, I did know the person, but it wasn't like a charity thing, like "Oh hey, you're working on this, let me give you money for it." It was, "Wow, what you're doing is really cool. I would so give them money for it."

\section{So do you think you'd be more inclined to back projects that were West Virginia- based?}

I think I would, yeah. I think if anybody would try to do something in West Virginia that I thought was a good idea, um, yeah, more than other places, for sure. Yeah. Like, for instance, if someone did a Kickstarter campaign to open a-if they destroyed the Warner, or they to put the Warner back together and had a Kickstarter campaign to renovate or put it all back together, I would totally donate to that, you know?

\section{Yeah.}

Or really just any project, I think. It wouldn't even have to be something I would see. I don't know if I've even driven on the 219 highway in West Virginia, but just because it's folklore in West Virginia and something that promotes our culture as a state, I was really interested in it.

\section{You mentioned earlier that you backed one that was in, Los Angeles, was it?}

Yeah.

\section{What was that one about?}

It was called L.A. Game Space, and basically, all of these indie game developers that I like kept tweeting about it all the time, and I was like, "What the heck is this thing?" So I finally looked it up and basically, what they want to be able to do is, uh, they wanted to create like a big warehouse, and they wanted to be able to take those people and be able to train; you could go there on, like, an artist retreat and stay there and learn how to make games or have people teach you how to make your games better. So if you kind of had an idea, you go there and stay, and you would be able to stay there for some nominal fee, and you would be able to-yeah, it says here: "A nonprofit center of video game art, design, and research, where people of all backgrounds can discover the potential of games together." They want you to be able to have exhibitions, talks and workshops, an artists' residency, and research lab, and anyone in the world can participate in the events, 
you know, via live streaming or private recordings of stuff. They kind of just wanted to create this community for creating video games and be able to foster a more independent developer-minded community. So, this one, I think they were saying, yeah, the reward I got for this one is at the location, my name is on the wall on a plaque there. There was one cheaper than it where you could get all these video games, but I didn't even get that one. I was like, "Wow, this is such a cool thing. I completely stand for this idea." It's like a school for people to get better at games, and independent games are, you know, those are the only games I'm interested in 90 percent of the time, so if I can help get people better at it - and they were having people that made Katamari Damacy and Hotline Miami, Pendleton Ward, the guy that makes Adventure Time; all of these big creative minds were going to be there helping people with storytelling and helping people with game development and I was just like, this just sounds awesome. This is an investment in the future of video games and that's something I want to be a part of, so that's why I gave to that one. And even if I never go to L.A. to see it, like, that to me is totally worth it. They post enough pictures and enough stuff about what the studio looks like that I'm completely happy with the donation I gave to them.

Great. OK, we're going to move on to something you started to talk a little bit on accountability. You mentioned that people on the campaign you said was the worst wanted their money back. How familiar are you with Kickstarter's policy on that kind of thing?

Um, I will say, I'm not the most familiar with it, but I have a general idea, and it's that when you give your money to this person, it's as if you are actually giving them your money, and when you pledge the money to them, otherwise, what's the point? You're giving these guys money to do what they say they're going to do. There is, from the way that I understand it, is that Kickstarter absolves itself form all accountability, so it's like, "Hey, we're just a channel. We're just the dude who takes the money from you and gives it to them, and we kind of step back."

\section{That is pretty much how it is.}

Um, and you need to research it and check it out to make sure what you're investing in is actually worth it. Have these guys done anything? Do they deserve your money? Does it seem well put together? Someone could have the best idea in the world but have the most terribly run campaign. Should you give them money? Will they manage it well? The thing I always pay attention to is the very bottom of the Kickstarter page because it says "Risks and Rewards," and they say what the risks are. For instance, if I would've really been on top of it, I probably would not have Kickstarted the one, even though it was a game I was really interested in - the Kingdom of Loathing game, the one that was the worst one I had-I don't think I would've done it again, because I realized they had: 1) never had any experience doing this before; 2 ) hadn't started; they had an idea of what they were gonna to do, but they were just like, "Hey, wouldn't it be cool for this game? Give us money," and people were like, "Yeah, OK." I mean, that was me. And so, yeah, the accountability thing is a big deal, but that's why you gotta pay attention. You really have to look at who you're giving your money to. I think getting upset about it is a valid 
thing. I think being like, "Hey man, you said you were going to do this, and now you're not doing it. I am angry about it," I totally get it. I totally get being angry.

Legally, the backers entered into a contract with the creator that they're required to fulfill, though Kickstarter, as an entity, doesn't take action against creators who default on projects. Backers have to do that themselves.

Yeah, and so there's an extra level of, "Well, do you know a lawyer? Who are we going to talk to to send them a letter?" You have to, I guess, want to pursue it. I guess maybe if you're one of those super backers who gave a project $\$ 1,000$ or $\$ 5,000$ or something, then maybe it would be worth it. But when you have 1,000 people and all of them give like 10 bucks, then that sucks, because you want your project. "You said you were going to do this and you didn't do it." And I'm even OK with a project that's not working out and they're saying, "Hey, look, we completely mismanaged the money and this sucks," as long as they're keeping me in the know about what's happening and not just being crappy about it and just leaving. I feel for them, right? Bad things happen. I get it. But when they just bail on you, or like that one famous Kickstarter story that came out where that lady — was it a lady? - just started burning those comics, like, "Any time anybody asks me about it I burn one of the comics." And then she went on to say it was a performance piece and went on this weird rant about capitalism or something. Man, just own it, that you had, like, a breakdown. But yeah, as far as that goes, I think that it really just comes down to you need to pay attention to what you're giving money to, because if you're not, that's like a guy on the street promises you something and you're like, "Yeah, alright, let's do it. Why did I do that?"

\section{Would you like to see any changes in the accountability policy from Kickstarter?}

You know, I think having something, and maybe not necessarily-because I understand that from Kickstarter's standpoint, that staying out of it is probably in their best interestbut I think having something where they can provide you a legal service after so much time passes or having some more accountability would be awesome. Like having a Kickstarter legal team, you having that extra security would be nice. I think that would be great, but I feel like that would be so hard to facilitate, like, to get that to come together for something. They would have to write something into the terms of service for the creators.

OK, we're winding down here. There are a couple small things I haven't touched on yet. How did you hear about most of the campaigns you backed?

Well, Twitter is my big one because I follow loads of people - a lot of, like, "creative minds," I guess, on Twitter-just comic book people and various dorky people from things. But then also, I have a good group of friends on Facebook who have similar interests, and when they Kickstart something on there, no matter who it is, if they're friends with me and they Kickstart something on there, they thought it was a good enough thing to give their money to, I always look at it and say, "Is this worth it?" Sometimes it is and sometimes it's not, but I always look at it that way. And then I also 
just get into a black hole of looking at Kickstarter Discover and just going through, like, "Oh, this is cool. This seems neat." Uh, and just finding a bunch of them that the Kickstarter team recommends, or board games people recommend, or if there's a comic strip or something that people recommend. And the other way that I do it is, I'm part of the Reddit community for board gaming, and they have a Kickstarter roundup every week. That's probably where I see the most of them. But between that and getting sucked into the Kickstarter black hole, that's most of it.

The other thing was, what do you do to share the campaigns yourself? Social media? Just telling people about them?

Well, social media. I have a couple friends, the guys I mentioned earlier, they "like" stuff on there. If anybody thought it was interesting, I'd show it to them, probably on social media - almost 100 percent of the time, I would say. I would send it to them through that. I have a couple friends from D.C. I would play board game with all the time. I would always show him stuff on Kickstarter and he always sends me stuff too. Some word of mouth, for sure, but it would be, "Man, you gotta check out this Kickstarter campaign," but then I would send it to him on Facebook, you know, afterwards, to make sure he knew what I was talking about. But yeah, almost always through social media channels. So, they have the option while you're Kickstarting it, or a project that you find, to share it when you find it, but then after you send money, it says, "Hey, I just backed whatever," and you can tweet or Facebook that also, you know? Those two are the mostly the way that I do it.

\section{OK. Any final thoughts you want to share?}

I think it's a really great system. I haven't even actually checked out many of the other things like Indiegogo - there's a couple programs that are similar - but I would totally be open to them. I think it's a really great way to get a lot of really new and inventive products out, but as with anything, you need to be careful with what you're throwing money it. It's still your money, and you need to know what you're getting into. But for the system as a whole, not so much.

\section{Alright. Thanks for doing this interview for me. I got a lot of really good stuff here.}

Cool, man. Glad to hear that.

I'm turning the recording off now. 


\section{Interview \#4}

First, did you get a chance to look over the consent form I sent you?

Yeah.

OK. So, you're on board with that this is recorded and that I'll be the only person who listens to the recordings, but the transcript will be in the thesis-but without your name on it?

Sure. No problem.

Alright. Since you've looked that over, let's get started on the questions. First, how many Kickstarter campaigns have you backed?

48.

48. Wow. Well, overall, how did you like the final results of the campaigns? And did you have any favorites or least favorites?

Um, well, it looks like one of my campaigns is not ever going to go through, and that was just to get a couple miniature figurines. As far as the other ones go-I'm trying to think if I have a favorite - it's be hard for me to pick, so no, I guess, is the answer right now.

OK. What kinds of projects have you donated to?

The vast majority have either been role-playing games or board games.

Oh, cool.

I've done two art projects and I have a couple of, like, kind of electrical-type projects.

What was your most important reason for pledging to these projects?

Well, initially, it was things that weren't out on the market yet, but over time, I would say the reason I keep pledging to stuff is that satisfaction-anticipation is a large part of satisfaction. Does that make sense?

Yeah.

So, a lot of these projects take six months to a year to fulfill. I kinda get to enjoy the fact that I own them but don't have to put them somewhere.

That sounds nice. You mentioned initially it was projects that weren't on the market yet. Have many of the projects that you've backed gone on sale to people beyond the 
Kickstarter campaign, or did more of them only get distributed through Kickstarter?

Um, I would say that a decent amount of them have gone on sale. However, there are at least a lot of them-like, I've backed some miniature games - that offer some exclusives for backing through Kickstarter that aren't available in stores.

Were those exclusive rewards important to you in your decision to pledge?

Actually, usually, yes. It's probably one of the more important things I look at when I pledge, especially for a game. Yeah, if you pledge to Kickstarter - the game that I just received is a good example - you get about 41 miniature figurines with the board game if you were to buy it in the store. But if you pledged on Kickstarter, you get an extra 90, so it's a pretty good deal.

\section{What was that campaign called?}

That was called Myth. M-Y-T-H.

OK. Do you have any favorite or least favorite kinds of rewards you've gotten in addition to the final products of these campaigns?

Um, yeah, actually, in a lot of role-playing game books, you'll have your name in the credits, which is kind of cool.

So, for those kind of rewards, how much of a draw would that be your decision to contribute?

I would say that it's not enough of a draw for me to contribute to something I'm not interested in already. It's just a nice little bonus.

Any kinds of rewards you'd like to see in future projects?

Hmm. Um, I really do like some type of exclusivity as a reward for being a financial backer. Just because there's no guarantee for delivery, so I feel like they have to offer something extra, whether that's a significant discount on the product or extra add-ons or exclusives not available elsewhere.

Have you got many projects where you got a discount on the product?

I'll say over half, just off the top of my head.

OK. I know a lot of them are about the same or a little bit more, but I've seen ones that are at a discount. 
Yeah, I guess for games, usually, one of the things, especially for miniature figurines, one of the things they're looking for is an initial amount to go ahead and get their molds made. And they need a certain amount to justify that cost for a production run, so, generally, they'll offer things at a discount because after they get that amount of money and have those molds made, it's much cheaper to continue in the future.

I'm going to change gears a little bit and ask a couple of questions about sharing the projects and local interests. First, how did you find out about these campaigns you've backed, for the most part?

For the most part, I just go on Kickstarter and check the top favorites and most popular projects.

\section{OK. When did you first hear about Kickstarter?}

I guess it was about two years ago, right when it was first coming out. I backed a roleplaying game by one of my favorite authors.

How did you find out about that game?

My brother mentioned it to me.

Have you ever backed a project where you knew the creator personally?

Yes, I have.

What project was that?

It was as comic book. A very small graphic novel by a guy in Columbia I know.

What was the project called?

Princess Calabretta.

Have you backed any campaigns that were based in your local area?

That is the only one.

That's the only one?

Yeah.

In that case, how important was it for you to support a local creator, or in your case, someone you knew? 
Well, it's a friend of mine, so I would say that would be very important, but as far as supporting local people in general, that's not important at all.

When you've backed campaigns, have you then shared them, either through social or just by telling people about them?

Yes. I would say only sometimes. I generally run it by the group I play games with, if they would be interested in playing some of the games I'm thinking about backing. And then, I'm part of a group on Facebook - a couple of groups on Facebook - that are either board or role-playing game people, and if I thought it would be interesting to them.

Within the group, is there a lot of Kickstarter sharing? I'm in a comic book group on Facebook, and we share Kickstarter projects on it with some frequency.

I'll say once every month or two, if there's something really cool. I try not to be very spammy about it.

Right. OK, some more questions about participation, but we're moving in the direction of your participation in the process of creating the project. Did you feel like your contributions were important in launching a project?

Hmm. I would say except for one or two, probably not.

Why not?

Just because of the number of backers. Whether I backed or not would be inconsequential.

Have most of the campaigns that you've backed already met their goals when you backed them?

No, I think a decent amount haven't. One thing I should mention is that I've backed 48, but I've pulled out of 25 .

"Pulled out of," as in you-

--cancelled a pledge.

Cancelled a pledge?

That's correct.

Why did you end up pulling out of them?

For a couple, I did a little bit of research, and I wasn't convinced of the viability of the project and their ability to deliver it. A few were because you can't control when the 
project ends. I would probably say five or six; I just had other things to do with the money at the time. Um, and then some I just kind of lost interest. It seemed like an exciting idea at first, but as I thought about it for longer, it was not as exciting.

For the 48 that you have completed, did you feel like you were part of the creative process?

Certainly, that was an offer for a lot of them. You could do things like get invited to beta test the game and comment on the rules. I didn't participate in anything like that.

Some of the other people I've interviewed, the project creators asked them about things that they would want in games and asked for feedback about concept art throughout the process? Did campaigns you've backed do that?

Yes. I mean, some have and some have not. That's one interesting thing, because some creators will provide you with very regular updates as to what's going on with the creative process, during the Kickstarter sales and afterwards. Some are less forthcoming.

Have you ever directly communicated with any of the project creators?

Yes. Only a very few times.

What were the reasons you were talking to them?

One of the reasons - I backed a combination role-playing game and graphic novel by someone named Michael Desing called Army Ants - and it turned out he had a misprint in his book. He basically double-printed one page, as opposed to printing two separate pages, so he asked people what they would like as compensation - another graphic novel or something else. Once or twice I just had a couple questions on technical specifications. The only time I've communicated and been disappointed was when I was talking to, actually, that Myth Kickstarter. When I got it, the font on the cards was very, very small, and there's a guy in my group who has vision impairment, so I was trying to get them to maybe see if they could give me PDFs I could print off in a larger scale, and they never really got back to me on that.

You mentioned a minute ago that there were campaigns you backed out of because you didn't think there was enough viability — was it that they wouldn't get released?

Well, I was pretty sure they'd get released. Several of the campaigns, actually, had already met their goals. But, I just wasn't enthused by their level of experience and overall professionalism.

When you're looking at a Kickstarter page or at communications with the project creators, what are you looking for that would give you confidence that they had the proper level of experience and professionalism? 
Well, the first thing I do is - if they have a web page listed-I'll take a look at that. If they've done other projects before, that's of interest to me. You know, I like to see those projects, and you can go read the commentary from backers and see if the project got fulfilled, done on time or not, etc., etc.

Kind of in the same vein, the next set of questions is about Kickstarter's accountability policy. Are you familiar with the site's accountability policy?

Um, it's that there pretty much is none.

Kind of. There's not much accountability from Kickstarter itself. Creators are legally required to fulfill their campaign promises because they've entered into a contract with the backers, but Kickstarter, as an entity, doesn't take any kind of action against creators who have defaulted on projects. They only provide the means for backers to get in touch with the creators.

Correct.

Did you take these policies into account when choosing to back campaigns or choosing to withdraw from them?

I do, because there's very little recourse, especially with the amount involved in most of my projects. I mean, when you're talking about $\$ 50$, it's not really worth going after if you feel like your pledge has been unfulfilled. Like I mentioned, there was one I don't think I'm ever going to get, but that was only a \$10 pledge.

Would accountability issue keep you from pledging higher amounts of money?

Um, I think probably, depending on how much money we're talking about. Probably, yeah, it would.

Would the policy affect your decision to back future campaigns?

You know, although my backing is probably going to slow down quite a bit just because I've kind of reached a critical mass in terms of games, so now something is going to have to be really amazing for me to back it. And I've also received some stuff that I backed that I thought was going to be pretty great but ended up being average at best.

So, have the campaigns that you've backed that turned out to just be OK, have those had a negative effect on whether or not you would pledge to future ones?

Not really. A lot of it, at least in terms of board games, comes down to rules that are not written very well, but that's kind of what I might think of as an early adopter fee. If you wait for it to come to mass market and you wait a year to buy it, then it will just end up being a lot more polished. What you're seeing is kind of a first working draft. 
Do you think, in general, you'd rather have the rougher version, if it meant you got to play it earlier, than wait for it to go on the mass market?

Sure. I would like the polished version, but the other side of that coin is that the rewards you can get for backing are often pretty substantial.

So they would outweigh the desire for the more polished version sometimes?

Correct. Yeah, I mean, the point where you have it, you know, you can always wait for the next generation of the rulebook to come out or the FAQ or errata to come out. But it does also mean that when I get something, I can't-like the Myth board game, I've got so many questions about it and the rulebook is not super, so they're going to be releasing a new version of the rulebook for free in a month or two.

OK. Have you had other projects where they released revised rules or other updates after they had sent you the games?

Yes. Almost all of them.

How long, on average or in examples you can think, have project creators kept up communications about the project after you had received it?

Generally, once you receive the project, communication trails off completely.

Is it only when people have a lot of questions about the rulebook that you get these kinds of communications? Are the communications usually done in response to emails from backers?

They are, but after release, usually, stuff like that is handled through these companies' websites and not through direct Kickstarter emails.

OK, so they're largely taken off of Kickstarter and moved onto other platforms after they're released?

Correct.

Switching back to accountability for a second, would you like to see any changes in their accountability rules?

No. I honestly think that gamble is part of what makes it a little bit fun for me. Usually it's, for me, 50 to 75 bucks, and I can eat that once if I have to.

Are there any other final thoughts you want to share about any of the topics we talked about?

Yes. The only thing I would say is that the one thing I'm super reluctant to back on Kickstarter is video games. 


\section{OK. Why video games?}

Well, a video game - making it from scratch can often be a multi-year endeavor, and a lot of these people are kind of, almost, what I would say, a hobbyist video game maker. For whatever reason, it seems easier to build something like a board game, miniatures, or a piece of electronics than it does a video game because, I guess, the amount of money and the amount of time is pretty rough for video games because a lot of them especially more complex ones will have a multi-year development cycle. And I also think that, at least, amateur video game people don't really know how to budget for that.

\section{For things like tabletop games and miniatures, do you think Kickstarter is a way that upstart companies could break into the industry using it?}

Yes, I do think that. Absolutely, I think the big thing about that is, like I said before, cost to enter a market in that type of field can be pretty prohibitive. That and any kind of electronic thing because you have to meet certain minimum shipping — er, not shippingbut certain minimum gold orders for companies to work with you. So, let's say I have a little doodad that displays laser lights, I probably need 1,000 of those, minimum, for a company to consider working with me, so unless I'm inimitably wealthy, Kickstarter is a way to get that initial capitol.

Well, that's all the questions unless there's anything else you want to add.

No. I think I'm good.

OK. Well, thanks a lot for taking the time to do this interview. I got a lot of good information.

Yeah, no problem. Tell Geah I said hey. 
Interview \#5

Just to go over the consent things real quick. You understand that this is research for my master's thesis and that I'm recording this, although I will be the only person to listen to it.

Sure.

And the transcript from the interview will be in my final thesis but your name will not be on it.

OK.

OK. For starters, how many Kickstarter projects have you backed?

I think the last one was my thirteenth.

Your thirteenth?

Yeah.

OK. And, by and large, how did you like the final results of the campaigns?

Oh, good. It was great.

What kinds of campaigns have you backed?

It's almost always arts oriented; arts-related.

Arts? Like visual art or theater or...?

Everything, yeah. Visual art, theater, music. I've done literary. I'm trying to think. Photography. I've backed a couple films.

Any favorites or least favorites?

Favorites and least favorites. Let me think. You know, I really liked Lola's Prayer. That was, you know, Chris is, you know, this guy's one of my best friends, but I think he did a really good job with it so I probably excited. The film, Lola's Prayer, was my favorite. Least favorite - that is really hard. I don't really have a least favorite. Is it OK for me just to not answer?

Yeah. If you don't have a least favorite, that's great.

Yeah. I haven't been unhappy or anything. 
OK, great. What was your most important reason for pledging to the projects?

With a specific project?

Any project.

Oh, any project. Well, I tend to support arts-oriented projects because I'm working very diligently to promote the arts from, you know, a personal way as well as professional way. I have an art magazine.

So were a lot of the campaigns you've backed locally based?

Uh huh.

OK. Why did you feel like it was important to go for locally based projects?

I'm sorry. Would you repeat that?

Why did you feel like it was important to back locally based projects?

Oh. Well, because I live in South Carolina and the arts aren't supported very well by our leadership and our government, so it's something that we have to do from the ground up.

You mentioned a friend of yours started a campaign. Have you known other project creators, too?

Another project that he's done?

Have you known other people who have created the projects?

Oh. Yeah. I've known almost every project that I've supported. I've known the person who started the Kickstarter.

Do you usually find out about the projects from the creators then?

Yeah, yeah. I usually find out via social media usually.

Have you ever just gone on Kickstarter and looked at the projects, or do you wait and find out about them through specific people?

Yeah. I've looked around before but typically, honestly, I think usually from things like on social media, on Facebook, that someone else whose work I respect or who, you know, I respect, has backed something, so I'll see if that's something I'm interested in.

Have you backed multiple projects from the same creators? 
Yeah. I've done that a couple times.

In addition to the final product of the campaigns - the art installations or performances-did you get any other rewards for your pledges?

Oh yeah. Sure, sure.

\section{What kinds of things?}

Let's see. Posters, signed posters, copies of books, a t-shirt one time, paintings. I just did one and got a painting. Post cards, photographs, framed photographs.

OK. Any favorite rewards?

Um, my favorite was probably a friend of mine - a photographer — went to Syria and did photography there, and at the level we supported, he brought back a framed black and white photo from Syria, so I was able to give it to my father-in-law for his birthday, and that made him really happy.

That sounds great. How much did the rewards play into your decision to back the campaigns?

You know, I'm a sucker for rewards. I really am. I'm not saying I wouldn't do it without there being rewards, but I am much more likely to go up a level if I say, "Ooh, I want that." So I think they're important.

Have you been inclined to contribute more because you wanted certain reward? Yeah.

Any kind of rewards you haven't seen so far that you'd like to see in future campaigns?

Um, I can't really think of anything, no.

OK. The next set of questions about your role as a backer in the creative process. OK.

Did you feel like your contributions were important in launching these projects?

Other than financial contributions or financial contributions?

Well, both, actually.

Well, financial contributions, obviously yes, but in terms of the creative process, no. 
So, with the projects you've backed, have you had much communication with the project creators after the funding part of the campaign has finished?

Yeah, I tend to, but I think I'm in a unique situation. I own and edit a local arts magazine, so I tend to support the endeavors that these guys do, and they're all really my friends. You're not from Columbia, are you? The art community in Columbia's a very incestuous community — everybody knows everybody, so you continue to know these people.

I'm from Charleston, West Virginia, but it's another community where a lot of people who participate in local arts know each other.

Mhmm.

After you backed the campaign, did you spread it around to other people?

Yeah. I tend to, if I'm backing something, use social media to promote something.

Have you ever featured the campaigns or their final results in your magazine?

Yeah. For example, the Syria project I was talking about - the photography projecthe's one of our staff photographers, so yeah, we actually did a special thing on that.

The next set of questions has to do with Kickstarter's accountability policy for project creators. Are you familiar with the policy?

I guess so. I can't tell you specifically. No, maybe I'm not. I've read it before but I couldn't tell you, I guess, is what I'm saying.

OK. Just as a refresher, basically, it says that when you back a project and it's successfully funded and money has been transferred to the creators, the creators have entered into a contract with the backers, which they're legally required to fulfill. But if the creator never finishes the project, then Kickstarter as an entity doesn't take any action against the creators. They only provide a way for backers to contact them. It sounds like that's probably less of an issue when you know the project creators personally and have primarily backed locally-based ones, but did that policy play into your decision to contribute at all.

Um, sure. Yeah. I have faith in Kickstarter, I guess, though.

Could you repeat that?

I trust Kickstarter. I have faith that they're going to come through.

Would you trust it more than other crowdfunding sites that maybe aren't as well known? 
I haven't used any other crowdfunding sites, but I do trust it, so I'd say yeah.

Do you think the accountability policy would affect your decisions to back any future campaigns?

Yeah.

How so?

Again, just because I've had good results, so I'm more likely to go ahead and do it again. My experience has been good.

Do you think that kind of policy would affect your contribution level?

No, not really.

Are there any changes you'd like to see in the policy?

No.

Well, we're pretty much at the end of my list of questions. Do you have any final thoughts on the topics we talked about?

Um, no. Is this for your master's?

It is for my master's.

Is it for your thesis? Are you doing all qualitative research?

I'm actually triangulating. I'm doing interviews and I did an online survey, for which I finally reached my participant goal yesterday, so I closed it.

Gotcha. Well, no, I can't think of anything else. Good luck with it.

Thank you for doing the interview.

Yeah, absolutely. Bye.

Bye. 


\section{Interview \#6}

Did you get a chance to look over the consent form that I gave you for the interview?

It's been a few days, but I gave it a glance.

You remember that the interview is recorded, I'll be the only person to listen the recordings, and the transcripts are in the thesis, but your name will not be on it at all?

Yeah, that's fine.

OK. I always have to run through those again at the beginning of the interviews. To really start with the questions, how many Kickstarter projects have you backed?

Have I backed? Um, nine. Nine.

Overall, how did you like the final results of them? Did you have any favorites or least favorites?

I usually do a fair amount of research - not research, but the ones I've donated to, I've known the people personally, so in the end, my expectations were met because I knew their work already, or I knew previous work they'd done if they were matched up with something new, so I can safely say for all of them that I enjoyed all the outcomes. Or they are ones that are still in progress.

Did you say four of them are still in progress?

I think one - two - two of them are still in progress.

Two are still in progress. What categories of projects have you done?

Photography, audio, film, and marketing - or, in the marketing one, they were raising money for packaging and distribution of an audio, um (long pause), yeah. So those are the four.

OK. What would say was your most important reason for pledging to the campaigns?

Supporting the work of an artist or individual that I knew how good their work was-you know, that was enthusiastic about the project they were undertaking.

Have you known any of these creators personally?

Yes. 
Did you find out about most of the campaigns from the creators?

Uh, no, actually. Through, whatever they did, the watch, I received an e-alert or a message through social media.

Oh, OK.

One of them, specifically, I received a personal email about two weeks after it had already launched, and I had not heard about it until then, but the rest of them were either an alert or a Facebook message.

Were a lot of these projects based in your local area?

Half of them were. Four were not local. Five were.

How important was it for you to support a local creator when you chose to back a project?

It wasn't. Local had nothing to do with it. I mean, because I knew them or knew their work, it was important, but I thought they did really good work and I was interested in it. I thought I should support them because they are local, but just because somebody does a Kickstarter and they're local doesn't mean-you know, that's not a really huge weighing factor.

In addition to the final products of the campaigns you've backed, what kinds of other rewards have you gotten among Kickstarter-exclusive rewards that were given for backing?

I'll start from the bottom: personal email thank-you's, video thank-you's, postcards, tshirts, emails about the project in progress, photos of the project in progress, videos of the project in progress, I don't know what to call them - tchotchkes - it was a branding thing. One of the projects was a musician who passed away, and some of it was his actual personal effects or relics, you know. They offered a bunch for different rewards. Like, he was a guitar player, so guitar picks and things like that.

Any favorite rewards you got?

Really, no. I just like the final products, and a thank you is always good.

So, did the rewards play a role in your decision to back the campaigns?

You know, giving a higher dollar amount, yeah. Below 100 bucks, no, the rewards didn't have any factor whatsoever.

Have you given $\$ 100$ or more to a campaign? 
Yeah.

What kind of rewards did you get for that level of contribution?

Well, a lot of times, it's been more when somebody's creating a specific work. A lot of times, between 100 and 500 — between 100 and 200, let's just say that - there's usually micro-levels where there's variations on the final product, maybe, where in addition to the final product, you get a photograph, you get a printed lithograph, composite collection, or if it's, um, one of the pieces I contributed to was a composition. They were performing live this original composition along with a poetry reading, so I got the booka hand-printed book of the poetry.

\section{That sounds nice.}

Yeah. And there was this level that was $\$ 125$, and there were four of them. One of them, you got puppetry or marionettes created for the show. Another level, you got the handprinted book, so that weighs into the factor. The main reason I give it a higher dollar amount is how much I believe in the work.

\section{Any kinds of rewards you'd like to see in future campaigns?}

Good question. I guess I'd like to see more that attract me; the ones that are personally associated with the project. I'd like to see that more. For example, if somebody writes a book, you know, maybe they give away pages of notes or a pen they used if they wrote longhand or something like that. You know what I mean? Not those things specifically, but-

Something that came from the creator and the process rather than something that was produced at large?

Yeah. A photograph is the best example. I've given, I think, to three photography projects, so I get a printed photograph from the work.

OK. The next set of questions has to do with your role as a backer in the process of creating a project.

Yeah.

The first question there is, simply, did you feel like your contributions were important in launching these projects?

Yes.

Had you backed most of these projects before or after they had met their funding goals? Did that change the way you looked at the projects at all? 
The ones I backed?

Yeah.

I usually backed early on.

What usually makes you decide to back early on, as opposed to later in the campaign?

How much I like the concept of the work, and if I know the person or know their worktheir previous work- how much I enjoyed it.

All right. Did you feel like you, as a backer, were part of the creative process?

Yeah, that's - I do my role in supporting it.

How much communication have you usually gotten from creators between the time the campaign had been funded and the time the final product was released? Do you usually receive updates from the creators?

About a third of them do just regular updates for the projects. I mean, just letting them know if anything new has come along or how it's going. I'm trying to think if any of them didn't do anything at all — maybe one. But the vast majority of them do some kind of update on the process. The frequency of those varies greatly.

Have any of the creators of the projects you've backed sought input from backers as to how the final project will be executed or things they want to see in the project? Some of my other interview participants have told me that the creators sought a lot of input from backers, but those were in other project categories, so I wanted to hear your take on that.

No, I haven't received any. I mean, that makes sense. They're mostly categories with preconceived concepts, so they're usually fully conceived by the time they get to the crowdfunding point, so no. I haven't received any requests for creative input.

OK. Did you spread the word about the campaign to friends or family members or other people that you know? And if so, what methods did you use? Did you lean toward social media or just telling them in person?

Yes, I put responsibility on anyone who donates to promote it as much as possible. If I didn't donate but still thought it should be heard about, I would spread the word.

Facebook is the way that is the most effective. I would send emails if asked by the funder [creator]. I think on two occasions, I sent personal emails out about the project. 
OK. The next set of questions is about Kickstarter's accountability policy for project creators. Are you familiar with the policy?

Very much so.

Did you take the policy into account when choosing to back any campaigns?

No, I did not.

I figured, since you knew most of the project creators, that it probably wasn't as much of an issue. Do you think the accountability policy would affect your decision to contribute if you didn't know the creators?

Well, some of the things I've done before, if I don't personally know the people, the one thing I do look up is a kind of history of them. If they post a video and it's not thorough, I usually don't contribute. But if it is, I seek them and see what else they've done and go from there. Also, the other thing is if the friends of mine that I trust their opinion, then information gets out that they've already given — contributed to the campaign — after I take a look and I like it, I don't care about the accountability. I just go with their word about it - my friends' word - about it. They directed it to me.

When you come across a campaign page and you're kind of doing the researchyou're looking at the video or the way they've written their pitch-what kinds of things do you look for that you know would tell you this was a creator that you would trust?

If they explain their concepts clearly to me. I also look for projects that are in some sort of stage of production already - if it's a creative project already. If it's not, then something tangible that's there. For instance, one project was a photographer who was going to Syria to cover the civil war-document it visually - and he had a timeline. He was getting on a plane on this date, so he explained that and showed some of his previous work. In a nutshell, I look for a clear explanation of the concept, some sort of guide to previous work, and that tangible stage where the project has begun. I mean, if it's just an idea and nothing has been done and there's not much supporting material, that doesn't seem as appealing.

Would you like to see any changes in the site's accountability rules?

Um, from a personal standpoint of receiving rewards and things like that or completing the project, I would like Kickstarter to make these more readily accessible to those who are giving. I don't think they should put up a scoring system for people who have started multiple campaigns or anything like that —a rating system or a star system or review system, like if you were reviewing something on Amazon or Yelp or something like that. I don't think that's a good idea, but I think somebody giving money would assume that this is set in stone, that the money's going to go to the project they're giving it to, so for 
the person who's contributing, I think the rules should be - even a general explanationshould be highlighted.

OK. Well, that was the last question. Are there any final thoughts you'd like to share on any of the things we talked about?

Let me think. No, I think we covered it.

All right. Well, thank you very much for doing this interview for me, [name redacted].

You got it. You're welcome.

Have a good evening.

You too. Bye. 


\section{Interview \#7}

Before we get started, I need to go through the consent form.

Yeah, I just sent that over to you.

OK. Let me check that real quick. (pause) OK, thank you.

No problem, man.

So now that we have the form taken care of, we'll just start into the questions. First, how many Kickstarter campaigns have you backed?

I've done three, I think.

OK. How did you like the final results of them?

Of the campaigns or the actual projects?

\section{The projects.}

Two of them were fantastic. Two of the three were music ventures, and they were good. The first one I had done was with Seth Walker, and the album he put out, Time Can Change, was just unbelievable. Just unbelievable.

\section{How about the other one?}

I did another one with Carsie Blanton, and it was fine-it was a great campaign, and then the third one, honestly, I cannot remember. I hate to say this, I didn't back it with a whole lot of money, but it was one of those Kickstarter - the thing I like about Kickstarter is they send you the little listing of, you know, "Here's some things we like. Here's some projects that we really like." And when I get time to go through it and say, "Hey, this is kind of cool, let me see." It was some-honestly, Kevin, I don't remember what it was, but I think I donated like 25 bucks to it.

\section{What was your most important reason for backing those projects?}

I'm a strong believer that Kickstarter is a game changer in the music industry. And I think that one of my big passions in life is to support the arts wherever I can. The first Kickstarter, I knew the performer fairly well, so it was a very easy one for me to jump into, but I really think when I look at Kickstarter, I think the combination of Kickstarter and social media, they're the real game changers for indie music.

What about music in particular do you think lends itself well to Kickstarter? 
Well, I think, for me, as a frustrated musician and an avid supporter of music, I think the big thing that has always baffled me with music is that you have these amazing bands out there that, because they don't hit or resonate with an A\&R guy in Nashville or in L.A., they go unheard. So, you know, you saw in 2008, I believe, when the economy crashed and suddenly it became hard to get into a van and drive from show to show to show to show because gas was 5 bucks a gallon, you saw this massive explosion on social media. Yeah, it started with MySpace, but it really saw this massive explosion. And then Kickstarter suddenly was this opportunity to say, "Hey, if you like what I'm doing, screw the record label. Screw the A\&R guy. If you like what I'm doing, then kick some money towards it, because I have a project that I want to put out - an album or a set of recordings - and I need $\$ 35,000$ to do the post-production work." And it really allows musicians to be heard and otherwise put out work that I don't think would be done commercially.

\section{How did you find out about the campaigns that you've backed?}

The first one, I got an email from the guy, who said, "Hey, I'm doing this Kickstarter campaign," and in all candor, I really didn't know much about Kickstarter before that. The second one, I got a Kickstarter note that said, "Hey, you know this person, Carsie Blanton; she's doing this project," and then I saw it on Facebook as well, on her post. And the third one was getting an email from Kickstarter that said, "Here are five projects," I think it was. "Here are some projects that we like," and I was able to go through and really look at it and say, "This is kind of cool."

\section{Do you know if those projects were picked to email to you based on ones you had backed before, or were they just general staff picks?}

I couldn't tell you that. I really couldn't tell you.

\section{So, the creators that you knew, were they from your local area?}

No. In fact, I was living in New Jersey when I backed the Seth Walker program, and the Seth Walker album was - I believe Seth was either living in Nashville or New Orleans, but he's originally from North Carolina. And I knew somebody who was related to him who turned me onto his music, and then I went and saw him and met him a couple times, so it was very easy for me to donate. It was very much, "Oh, I know this guy. Let me see." And then the second project, because I knew Seth, I went to one of his shows, met Carsie, got on her mailing list, so it was a very easy transition.

\section{How do you feel about backing a campaign from your local area? If you had one in your local area, would you be more inclined to back it?}

I don't think so. I'm not geographically bound. So I don't think geography-let me say this for a second. If there was a project locally that was going to benefit my community that I was behind, and I thought it was a good project on its own merit, I would probably - it would depend on the project. If it was a musical project: no real 
geographical boundaries. If it were a project to help underprivileged children on the North Maine Corridor of Columbia, South Carolina, I would probably stop and look at it, and if it were something that met my criteria of charitable giving, I might be more inclined because I would see a direct impact locally. But I don't necessarily have geographic boundaries that say I would only give in this arena or that arena.

\section{Now, for, say, music projects, looking at a campaign's pitch or video, what kinds of things would draw you to want to contribute to those?}

With music, I think it's kind of a twofold process. I have to think that what the artist is doing is important. Again, if you take Seth Walker, which was by far my biggest backing - I think I gave $\$ 500$ or more to him, I can't remember what I gave - but to me, what Seth is doing from a blues standpoint - again, not commercially viable in the sense of, you know, he's not a John Legend. Hell, he's not even a Harry Connick, Jr., from a selling standpoint, but the work he's doing, in my opinion, is really, really important from the legacy of blues. And, in my opinion, what is being lost through commercialization of music is, again, you've got an A\&R guy, or you've got a label, that kind of looks at it says, "Well, I like it and I can make money off it," not "This is really good work that's really important, and it's following these five attributed of blues progressions." So for me, it's more about what I think is the importance and, candidly, Kevin, it's gotta be a little freaky (laughs). I gotta look at it and say, "You know what? I think it's important." And maybe nobody else is going to, and I want this to live on, so yeah, I'll spend $\$ 500$ or I'll spend $\$ 100$ or I'll drop $\$ 1,000$ to make that happen.

\section{OK. What all did you get, as far as rewards for a donation of that level?}

Well, it was funny. The reason I'm laughing was I got an 8 by 10 glossy of this guy, and I know him, so he sent it to me and I laughed, and I'm like, "Really? I need an 8 by 10 glossy of you?" It wasn't even autographed (laughs). I got an 8 by 10 glossy, I got a tshirt, I got a copy of the album, and then I've got bonus tracks in the studio itself, which I thought was pretty cool. But again, it's kind of like my donations to PBS. I don't do it for the rewards. The rewards are nice, but I do it for a different reason.

\section{What kinds of other rewards have you had from projects?}

T-shirts. Hmm. T-shirts and discs, mostly.

And though you said the rewards were not important in your decision to contribute, did you have any rewards that you liked the best?

I think the bonus tracks and the behind-the-scenes recordings of what was going on in the studio were really cool. I think it made me feel like I was an invested partner in the project.

\section{Any kinds of rewards you would want to see in future campaigns?}


I think any time - again, speaking to music, I think any time you can take the contributor and make them feel special, make them feel like they're really invested in the project, like you want to see the project go on, is a good thing. When I made my investment in the albums, $\$ 500$ in the scheme of $\$ 35,000$ is not huge, but it's sizable for an individual. What was really cool, once I made that commitment and I knew I was making the commitment to it, I then started to spread the work through my social network. "Hey, I just made this - I didn't say how much the dollar amount was-but here's a project these 50 people, you guys really should look at this, because this cat's amazing and you think the same way I do." So I think the more you can make the investor feel invested and committed to the project, the bigger you're gonna go. The higher you're gonna go in terms of your donations.

\section{You mentioned Seth was a blues artist. Is that a favorite kind of music of yours? DO you feel like part of a blues kind of fan community?}

Well, I love all music. I love everything from, you know - if you look at my iPod and my playlists, you would think that I really need psychological help. Clearly I've got the playlist of a psycho killer. I like everything from classical and chamber music all the way up to Biggie Smalls, OK. I've got it all on my playlists. For me, it's about pushing the envelope. It's about coming away from the mainstream a little bit. I would equally back something from Coastwest Unrest, which is a jazz and punk fusion group, as I would a blues group, as I would a really good rock group. I think it's about the energy level, and I think it's about why people are making the music. And yes, I consider myself to be an avid fan of blues, but that's not the only thing I consider myself to be an avid fan of. I would be just as quick to back something from The Mowgli's, who are so anti-blues it's not even funny. I mean, you can't get any more west coast poppy, you know, "Everybody's great. Let's eat granola and hug and make love and do all those things." I would backs something very quickly for them because I like what they're doing. I like the sound they're making. I think it's important to music.

\section{Do you feel like, in the last few years, that Kickstarter has made a noticeable impact on music in terms of what has been funded and what has gotten out there?}

Yeah, I think that's a fair statement. I think that, if you take the case of Seth, if you take the case of Carsie, you take the case of some of the work that Amy Ray's backing, from an indie standpoint-Amy Ray from the Indigo Girls - I think there is absolutely, and I can't measure this; this is not scientific by any stretch of the word, but it definitely feels like - and this is why I said earlier it's a game changer - it definitely feels like this is a real opportunity for new music to be heard and to be funded and get out there. And if you look at the combination of Kickstarter and social together, I think it's revolutionary, and I think we're only starting to scratch the surface on this. There's a young man out of New York who had a company called Subway Records, and he records and signs subway and platform musicians to his label. And that was revolutionary at the time, back in the midto-late 2000s. I think the combination of Kickstarter and social together is a real game changer, and I think you're gonna see a lot more of these amateur musicians who are 
techno-grounded with looping. I think you're gonna see a lot more of those projects get funded, which is cool.

You mentioned having shared campaigns on social media. Have you shared them in other ways like just telling people about them?

Oh yeah, absolutely. I think, though, that for me-I'm in the newspaper business, so I have traveled extensively throughout the country; I've got friends in every major city in America - social is really the way I keep in touch with that community. So for me, just putting it out on social repeatedly, "Hey, we've got five days left and we're this close to the goal," I think that, for me, is even more impactful than telling my close circle of friends.

Have you backed all of the campaigns you've backed before they hit their goals?

I'm sorry, say that again.

For all the campaigns you've backed, did you back them before they reached their funding goals?

Oh God, yeah. Yeah, and I think all three made their funding goals.

It sounds like your sharing on social media was a big part of getting the project out there and attracting more backers. Do you think so?

Yeah, absolutely. Absolutely. And I think that, again, if you look at the evolution of social as it relates to indie music, you know, I'm not inventing anything here, if you go back to the days of MySpace, these kids were putting their stuff out there long before an old guy like me with a checkbook realized that, "Hey, I've got 600 friends and, exponentially, I could get this in front of five or ten thousand people," they were doing it long before that.

As a backer, and earlier you used the word "investor," do you feel like you're a part of the creative process-like creating the project?

I wouldn't necessarily say I'm part of the creative process. No, not at all. I think I have a very realistic and pragmatic approach to it. The reason I hesitated was I actually—Seth and I had a conversation about his last album and what it was going to look like and things like that, and I backed that as well. Actually, I didn't back that one. I didn't. $\mathrm{He}$ didn't do a Kickstarter on that one. But, you know, the interesting thing is that no, I don't feel like I'm invested from a creative process standpoint, I just feel like I'm a fuel in the engine.

OK, that makes sense. How much communication have you had with the project creators between the time that the campaign ended and the final album and other rewards were released? 
One-on-one communication, not much. But again, just being updated on the projects, where they were to goal, primarily through personal one-one-on email or mass email to everyone on their list, as well as Facebook and social updates.

\section{Did you get any updates after the albums were released?}

Yeah, I got that 8 by 10 glossy, man. That was worth everything (laughs). Actually, I did-again, through social. If you go to Carsie Blanton's page on Facebook and go back, I think it was late last year, she was good at updating everyone, contributor or not, "Hey, I've got eight hours left to hit this goal," "We've got five hours left. We're this much away. Who's going to put me over the edge?" These artists are really starting to figure out the telethon PBS model of really getting the dollars behind them, and it's pretty cool.

I've read some research saying people were more likely to back crowdfunding campaigns at the beginning and at the end with kind of a lull in the middle. Since you've been an early backer, have you noticed this trend at all?

Yeah, it seems like - again, equate it back to PBS, the original Kickstarter-if you look at it, it seems like, at least in the art community, you get a rush of the people who are avid fans. "Yes, let's do this." And then, it does feel like there's a lull in between, especially if it's like a four- or five-week window, it does seem like it slows down. And again, I think it depends on the artist and how much they're communicating. I think you've got two very distinct groups of people. I think you've got the people who back it in the beginning and don't care about the investment if they lose it or it doesn't get funded-you know, "I'm not gonna back this because it may not get funded; they may not hit their goal"-I think you have that group of people, which I sit in. But then then I think you have this other group of people that they realize their friends and families have all backed these projects, and they want in on it too. So it goes like this: it peaks, and then it valleys out a little bit, and then it peaks again at the end. But a lot of that depends on the artists. Don't discount the power of the individual marketing that happens from the artist.

You started touching on this in what you just said, and I'm glad you did, because the next set of questions has to do with Kickstarter's accountability policies. How familiar are you with the-

I'm not. In fact, let me pull this up here. I've got my little Kickstarter program here, and it automatically goes to music for me. And right now, there are four projects that are up on Kickstarter right now from my local area. The Post-Timey String Band's new album - great case in point on this. I'll show you exactly what's going to happen on this: They're at 50 percent funding right now, they've got 1,500 [dollars] pledged, there's 20 days to go, I'm actually going to see this band for the first time on Saturday at River Rocks, if I like them, if I think they've got some cool funk to them, if I think it's something that's important, I'll come back on Monday, or even Saturday after the show, I'll go to Kickstarter and I'll drop 100 bucks, 200 bucks, on them. And to me, it's the cost 
of admission, almost. If it gets funded, great. If it doesn't, I don't know what happens to my money (laughs). I've got to be honest.

Oh, well if the projects don't get funded, you get your money back. Or more specifically, the money never gets transferred from you to the project creator. Because Kickstarter, as an entity, only acts as an intermediary, so the funds start to get transferred once they hit the goal. So if you give them $\$ 100$ and they don't meet the goal-

It doesn't get transferred.

- nothing happens. As far as the accountability from the creators if the project gets funded, the policy is that the backers have entered into a legal contract with the creators that the creators have to carry out the project the way that they said.

OK.

But if a creator defaults on a project, then if backers want any kind of restitution, they have to seek action against the creator, and Kickstarter itself will not take action.

And, you know, I have to be really candid with you when I say this, I didn't know that, probably because two of the three projects that I funded were people that I knew or at least knew on some level. I physically met one of them. One of them I trusted. If the project went bad, I was pretty sure I was going to see him at some social event and be like, "Seriously, dude?" But to me, if I donated 100 bucks to this Post-Timey String Band, and the project got funded and they didn't live up to it, I don't think I would seek restitution or remuneration for that project, I just wouldn't back them again. And I think that, yeah, at some point, you can probably make some money off this. You and I could set up a band, we'll and call it the [name redacted] and Kevin Band. We're gonna do this great album. We're gonna try to generate $\$ 5,000$, and we get our five grand and walk away. OK, you're gonna make five grand one time. I don't think that I would ever try to seek restitution for that. And at the same time, but I'm not investing tens of thousands of dollars either. I'm not looking at it from a commercial investment. I'm looking at it as more supporting local music or charitable contribution. I look at this the same way I do making a donation to PBS or the Red Cross.

OK. So you think that the fact that a person's reputation is on the line is a good check for the kind of lax accountability policy?

I do. But again, I haven't gone through Kickstarter and looked at every type of project that's out there. I've primarily looked at only musical projects. And again, I think you really have to look at it and say, "Why am I doing this?" Every year, I join PBS. I write a check, or actually, I get it taken out monthly from my bank account, and let's say it's 50 bucks a month-I don't even know what it is off the top of my head-to become some platinum level sponsor, and I get the great documentaries from, what's his name, you know, the guy who does the baseball thing. 


\section{Uh, Ken Burns.}

Yeah, Ken Burns. I get the Ken Burns video collection, but I have no idea if that money's being used for what they tell me they're gonna use it for. It could be lining the coffee maker at the local PBS station. I have no clue. I don't do it for the accountability. I do it because I think, at that moment, the project or the work that they're doing is important.

\section{Do you think that kind of policy would affect your decision to back future campaigns?}

Not music, no. I think I look at it from the standpoint of, the same way I go, if I were gonna go this weekend and see live music, and I dropped 20 bucks in a cover charge or a ticket price to go see a band, and something happened and that band didn't show up, and someone else showed up, I'm not the type of person that goes, "Well, I want my \$20 back."

\section{OK.}

Now, if I spent $\$ 500$ to see front row for Phish and suddenly they didn't show up, I might be pissed. But I've had shows cancel where I've got the make-good ticket for, like, six months later, and I've used it, so I think I go about it from a different standpoint.

\section{Have you looked into any other project categories besides music? Anything you might contribute to?}

I've looked at some art projects. Hang on a second here. Let's see what I got here. To me, I don't know how to say this nicely, I have a very thin amount of time and resources that I want to donate to, and my passions, while deep, are not very wide. I think art's important, but I would much rather give \$200 to my local art museum to join a contemporaries group to fund bringing in stuff to the local community. When it comes to music, though, my passion is such that, again, if it strikes me and I think the music is important, I look at it, and that's primarily what I look to Kickstarter for.

One last question in the accountability section, and then we're pretty much at the end. Would you like to see any changes to Kickstarter's accountability policy?

Me personally, no. I mean, I can see how if - for me, no. I think you said this earlier, Kickstarter is a facilitator.

\section{Right.}

I look at Kickstarter as just a tool. I look at Kickstarter like PayPal. It's a facilitation tool. If I'm gonna back a project, I'm gonna back a project, and if it's Kickstarter, great. I think the cool part about Kickstarter is it's a community, and it's an easy turnkey way to make money happen and investments happen. I don't know what Kickstarter charges, if 
they charge anything. I don't know what the fees are. I don't know any of that stuff. I just know that it's relatively easy for me to make a donation.

The fee is 5 percent for every successfully funded project.

OK.

So if it doesn't meet the goal, they don't get charged for the listing.

OK. It's only a matter of time before somebody comes in and does it for cheaper.

Do you have any final thoughts on anything we talked about today?

No, sir.

All right, well, thank you very much for doing this interview. I got a lot of really good information here. Thanks.

All right, man. Bye. 


\section{Interview \#8}

Just to go through the consent stuff, this is research for my master's thesis, it is audio-recorded, and the transcript of this recording will appear in my thesis, which will be published in WVU's thesis database, but I'm the only person who will listen to the recordings. Are you OK with that?

I am.

Starting into the questions, then, first is, simply, how many Kickstarter projects have you backed?

Just one.

\section{Just one. What was the project?}

It was a film festival, but sort of a contemporary take on it, where people who work in different video capacities came together, developed teams. They were given the beginning and the end of a plot, and they were to film, edit - all in the course of one day - film, edit, produce a movie that had the same beginning and end as all the other movies but unfolded in different ways, that was then screened at a film festival in Columbia, South Carolina.

OK. That sounds interesting. How did you like the final results of the campaign?

Unfortunately, I wasn't in town when the results were all completed, so I didn't have the opportunity to actually see any of the movies.

So they were not available for you to see anywhere else after that?

I probably could have gone online and found them, but I didn't actually try.

\section{Oh, OK.}

I guess that speaks to the fact that I was not sent a copy of the winning movie or the top three movies, which is fine, because I didn't support it with the intention that I would get anything out of it.

\section{What was your most important reason for supporting it?}

It was a friend of mine who is a very talented business owner who owns a videography company, and I wanted to support his efforts to increase the visibility of video art in a city I used to live in.

OK. 
So friend, primarily, but then, I guess, secondarily, wanting to support arts and culture in a community that I love.

\section{What about the local aspect of it drew you to wanting to back the project? Other than knowing the creator, I mean.}

Right. The Columbia community has a lot of really good things going on, particularly for young professionals on the food scene and the art scene, etc., but it tends to circle around the same group of people who are starting projects or promoting initiatives, and a lot of them get city funding. We have this thing called the hospitality tax, so a percentage of taxes on hospitality-based purchases in the city of Columbia is set aside to fund arts projects such as this, and actually, this project didn't receive any hospitality tax funding, so I thought it was great that he was doing fundraising and engaging more people in the arts community. It was also good that the same sponsors who are always tapped to support everything arts and cultural were not the sponsors of this, so it was sort of giving them a little bit of relief, and it was highlighting new artists in a genre that is not particularly thought of often. So while I believe that movies and these kinds of things are important pieces of the arts community, a lot of the arts and cultural focus is on more traditional painting, ballet, theatre, etc., so it was a way to bring that funky vibe that is starting to emerge in Columbia to another level, engage more people, and was able to be privately funded without drawing from city funds or from the private sector donors who are typically supporting the arts. So it gave us a chance to make something cool and funky happen.

\section{Do you think the final result of the film festival would have been different if it had city or sponsor funding? Like, do you think because it was funded by the audience, that the final result of it might have only been influenced by the audience —or rather, not been influenced by city or private kinds of interests?}

You know, that's an interesting question. I hadn't thought about it. The city funds have to be used - when you get the funds from the city out of this hospitality tax pot, they have to be used to bring in people from outside the city, or they have to show that there's some tourism component. They try to use it as a way to replenish the funds and provide opportunities for business development, economic development, exposure to the city, tourism, etc. That wasn't really the focus of this, so I don't know if they would have gotten the funding; or if they did get the funding, they may have focused more on promoting in a way that would be focused on drawing people in outside of the major metropolitan area zip codes, which wasn't the focus of this. It was something funky and cool for the Columbia community. And from the private sector donation perspective, the private sector anticipates that they'll get something out of it when they make a donation, so, say, the Wakovia Bank or one of the big banks there, if they were to sponsor this, they would expect that there would be ads and posters and things with promotional visibility, and they would have had banners and signage, so I guess it would've maybe changed the vibe of it, so it wasn't local. This was all sort of a grassroots, fun, funky local thing. I kind of talked through that thought. I hope it made sense. 
It made sense. Do you think that having it as a crowdfunded project kind of brought people who backed it together more as, well, a crowd or as a community?

I don't know because I wasn't there, but I would anticipate people who live in the market, who are still in Columbia, would have gone to the festival, so it almost becomes a way to pre-promote and, like you said, build a community or a crowd, but aside from that, I don't know who the other donors were. I'm sure there was a list somewhere, but I never really looked to see who else was funding it. And maybe that was something the promoter should have done, or the person who was developing it, was to recognize who all the contributors were or something to help engage more people, I don't know. I guess that was his choice.

OK.

So no. No, it didn't build a community from my perspective. Maybe for someone else but not for me.

Do you think you'd be likely to use Kickstarter in the future?

Yeah. Actually, I'm trying to figure out ways to use it and work with the event planning class. I think it has a lot of potential to do the things that may or may not have been successfully done in the campaign I was involved in, but it gives folks a chance to make a small contribution and be a part of doing something cool and cultural or whatever in their communities. It engages them and gives them a stake in the success of the project or at least has the potential to, and it gives them a reason to participate in it once it's complete. I've not funded technology-based stuff and all those gizmos and gadgets I know it's capable of. I've only thought about it from a cultural arts perspective.

Do you think in campaigns that you wanted to run or wanted to support that you would lean more toward the cultural and artistic endeavors than the more productbased categories?

Absolutely. However, I will say that if it was one of my friends who had a cool idea for something technology-based, I'd probably donate some small amount-like 20 bucks or something - just to support a friend, but if I was to support something, and I didn't necessarily have a personal relationship with the person who originated the campaign, I would lean more toward cultural and arts stuff, because I think it's a brilliant way to elevate the arts community and engage people in funding something to make their community a better place. You know, Milan Puskar can’t fund everything.

What is it about the less community-based, broader, product-focused categories that makes you less interested in those than the ones that you were more likely to support?

I'm not really sure how this makes me sound, but I'll be honest, that the product-based stuff has a commercial intention; it has a long-term profit-seeking - and there's a lot of 
people out there who have a lot of talent. I know Steve Jobs started in a garage, but Apple is a successful company that's turning out technology gadgets all the time. I guess I'm not sure that's the best use of my time. Because of what I know about marketing and promotion and to make a brand and build a brand and be successful at launching a new product line and how much money that takes, I don't know that I necessarily believe that's going to be successful or as successful or as meaningful as an arts event or an arts opportunity.

Do you think most projects that you would be inclined to back would either be locally focused or made by someone that you know?

Absolutely. If it wasn't locally focused-locally focused meaning in Morgantown, where I live now, or Columbia, where I previously lived — and/or initiated by someone that I have a close relationship with, I'm never going to go to Kickstarter.com and scroll through projects and be like, "Ooh, that looks interesting, I'm going to fund it." I'm never going to do that. There's enough nonprofits asking me for money and that I know have valuable causes and solid people behind them working hard to do good things in the community that I'm never going to look for a way to donate money.

You backed the project and weren't able to attend the film festival. Did you get any other rewards for your contribution?

No, daggone it, and that makes me want to email him and be like, "Hey, what's up? I wanna know who won. I wanna see the movie" (laughs). That was poor follow-up on his part.

If you did back future campaigns, are there any kinds of rewards you'd want to see?

No, just a follow-up to let me know what the success was and what the outcome was. Nothing arduous, just part of a mass email that says, "We had this many teams that competed and this many people came and saw it and it was a cool event. Thanks for supporting," would have been sufficient. But to that same degree, if he asks me to fund the same thing next year, I'm going to give him money again. It's a cool idea.

\section{Do you think a nonprofit organization or an individual could return to Kickstarter and use it as a regular source of funding, in the way some companies have kind of started in their industries originally through Kickstarter?}

I think they could, but I don't think it's wise. I mean, not that it's not wise, but I've already given to this cause. I don't want another Kickstarter request. I want an email from the organizer saying, "We're about to this again this year. Thank you for contributing last year. Would you be willing to do it again?" I want a personal email from them asking me again. But again, like I say, if you post it on Facebook-I guess my point is if I funded it once already, then you already have my email address and contact information. Why would you just use it as a funding-I don't know, maybe for bookkeeping purposes they would. I don't know. I don't have a good opinion on it, I guess. It just doesn't seem very 
sustainable to me. It seems more sustainable to start developing relationships with your funders and then maybe use Kickstarter to get new people engaged.

You might be right. Kickstarter does take a 5 percent cut of all successful projects from the money funded, and Amazon Payments gets a portion too, so it probably would benefit people running nonprofits to just add the people who backed their Kickstarter campaign to their pool of people to contact about new projects they want to do.

Yeah, there's gotta be a more cost effective way to do all that.

How much communication did you get from the project creator from the time you first backed the project to the time when the film festival was over, or even afterwards?

(laughs) Well, he posted it on his Facebook page, I made a donation, he sent me an email that said, "Hey girl, thanks, that's awesome," and that was it.

OK, so he didn't post updates about the project on a regular basis?

Yeah, I guess he did-on Facebook. Nothing to me specifically, but on Facebook, I knew what was going on. So I guess in that sense, I did get follow-up.

OK. In many Kickstarter projects, the creators will post updates on the website or have mass emails to people who backed it kind of going through the process-

- I've got no idea if he did. He didn't send an email.

OK.

I say that all confidently, but maybe he did and I just didn't see it or don't remember it. I'm not traumatized by it. It is what it is. The event was successful.

On that note, how important was it for you to have updates about what was going on in the project?

Not at all until this conversation, and now I'm mad at him (laughs). I really didn't put any thought into it at all. I think I gave like 50 bucks. It wasn't like I made a huge conversation and felt like I deserved something in return, but it would've been nice to get some kind of email that gave me an update, I guess. But like I said, I didn't put any thought into it after it happened. If he asks me again, or if he puts it on Facebook again, I'll probably donate again. After this conversation, he might get less money, though.

Do you know if there were any other rewards besides, I guess, admission to the festival that were offered with different pledge levels? Do you remember? 
You know what, that's right. I did get tickets for the festival, and he did email me about the tickets for the festival, which I gave to another friend that still lives there. So yeah, I just sandbagged him for no reason. I did get something out of it. I take back all those mean things I said. No, to my knowledge - there was probably at a higher giving level, he may have given them something else, but I don't know what he could have given. It wouldn't be very fiscally responsible to take money from a donation pool and buy some kind of reward, I think.

Next, we're going to move on to the category of your role in creative process of the project and your participation as a backer. First, do you feel your contributions were important in launching the project?

It probably would've happened even if I didn't. Somebody would have made donations. It wasn't like he needed millions of dollars. It was a small budget. It was a very fiscally responsible budget just to cover necessities, so no, I don't feel like I changed the world by making a contribution.

Do you remember how much above the goal that it received?

I don't.

Do you remember what the goal was?

I don't.

That's fine. In backing the project, did you feel like you were a part of the creative process?

Nope (laughs). Not at all.

\section{Why not?}

I just made a contribution. I didn't do anything more than that. I didn't even go to the event itself.

It sounds like the project ideas were pretty well set in stone before the funding phase even took place.

Yeah, my anticipation was that using Kickstarter was just in exchange, basically, for PayPal or something - some other way to make a donation. It was just - maybe it was the cool, new, hip way to get donors. It wasn't-I don't know what I'm trying to say - the business plan was thought out, it wasn't a think tank kind of thing, it wasn't a brainstorming or sharing of ideas. It was just a way to collect funds.

A couple of the other people I talked to said the creators for the projects they've backed wanted some input about the project throughout the process, but those 
categories were a lot different. Those were computer games and board games and stuff. It seems like most of the arts-based ones, where the final product is a performance or an art installation of some sort, usually had everything how they wanted it to be before the project started.

That makes sense. It would be cool — not that I would fund a board game or an online video game or something like that - I could see other people in my world that would be interested in it and would be very excited about the opportunity to test beta samples of it.

Did you spread the word about the project, either to people that you know or through your social media network?

Yeah, actually, I did send an email to a couple of our mutual friends, saying, "Hey, did you see this? I made a donation. You probably should to."

OK. Do you think social media makes the potential for sharing projects greater than person-to-person communication?

I'm sorry. Say that again.

Do you think social media allows for greater potential to reach people who are going to donate to these projects than person-to-person communication, like an email?

I think it's beneficial on both sides. If it's somebody you have a personal relationship with, you can connect more directly and send them something more personal, you are more likely to get a donation or response out of a personal communication, like, "Dear [name redacted]," as opposed to something on Facebook. But on the same token, I saw it on Facebook. It would have been easy enough for me to share, because that whole "slacktivism" concept of people wanting to be activists or supporters of something, but they want to do it in the easiest way possible, and the easiest way possible is to hit "share." There's no real challenge in that, and people are willing to do it if something seems cool or if it's an image they want to be associated with, then I think people will share things, so you may reach a wider audience of people you don't know who have similar interests.

Do you think for a nonprofit artistic endeavor, though, that a creator could reach people only through slacktivist sharing, or do you think they need a solid foundation of personal connections and past donors to fully fund their projects?

I guess it depends on the budget. I mean, social media certainly has its place, but I don't think it's wise to rely on a post that is not personalized as a way to develop a relationship with somebody and have the potential for effective future opportunities, particularly with somebody you aren't already friends with or don't already know. Did I answer your question? 
Yeah. I would think that's especially true for locally based projects, where the final result is an event that takes place in one city.

I mean, for one-off events-I don't know. I'm a big fan of personal communication, which is ironic, because I also love social media, but I think social media has a place in fundraising if you're trying just do a quick little one-off event, maybe that's sufficient. I don't know. I go back and forth on it. But why would someone ever want to do an event or something and aspire to only do it once? If it's successful, wouldn't you want to do it every year or quarterly or whatever? If you've created a model that is successful, why wouldn't you want to do it again? And in order to do it again and not-I don't know. Having a relationship with the people who donate, or whatever the case may be, seems like it would be more beneficial to have personal relationships and use social media as a way for those people you have personal relationships with to support you in a way that doesn't tax them. "Support you" meaning, "I'm going to share this with my friends list."

The next set of questions has to do with Kickstarter's accountability policy. How familiar are you with the policy?

I believe I read it when I was reviewing your thesis proposal, but I don't remember it right now.

The policy says that Kickstarter, as an entity, does not take action against project creators who either don't complete their projects or don't complete their projects at the deadline they had set, and that any action the backers want to take, be it a legal action or just a request for their money back or anything like that, they have to communicate directly with the creators. Kickstarter, as a company, won't take action against them.

So, in other words, Kickstarter's saying, “We ain't gettin' involved in your business. If the project works, great. If it doesn't, OK. If you want your money back, that's your issue to have to figure out how to deal with it?"

It's kind of like that, but Kickstarter does stipulate that it is a legal contract between the creator and the backers that the creator does have a legal obligation to fulfill.

But wait, I've understood that if I'm a project leader and I don't get my budget, I don't get the money.

\section{Right.}

But what Kickstarter is saying is if I meet my budget, I get the money, and then I never complete the project - basically, I just rip you off and take the money - that's your problem, not mine? If the project organizer takes the money and never completes, the project, they're not responsible for getting you your money back.

\section{That's right.}


Um, huh. How do I feel about that? I suppose, as someone who is potentially going to fund future projects, that makes me think I'm really sure I'm not ever going to give money to someone I don't know, who I don't know who will finish a project, and I'm certainly never going to fund a tech gadget, because by the time that project is finished, it could be that a newer, greater, version has already come out. So it affects my desire to fund certain types of projects, but I don't know that I would expect Kickstarter to do anything to intervene on my behalf. And honestly, I'm not going to give a sizeable donation over Kickstarter anyway. It'll be maybe 50 bucks at the max of what I'd give. Anything else, I'd write a check and mail it or give it to a nonprofit that I know is already doing good work in the community.

\section{Would you like to see any changes to the accountability policy?}

No. I have no qualms with a business doing business like they want to. I guess knowing it means - I suspect most people don't know the accountability policy when they back a project. And, you know, Kickstarter probably - for all the backers who have backed projects that never came to fruition, if they ended up going after all of those people and trying to get money back, the fees to use Kickstarter would have to increase even more, because that's time, that's money, that's an additional expense for Kickstarter's overhead, which means Kickstarter becomes less effective as a fundraising tool because it becomes more expensive as a fundraising tool. I think it's just a necessity.

\section{Well, that's all the questions I have. Are there any final thoughts you would like to} add?

Finish your thesis.

\section{OK. Thanks for doing the interview.}

You're welcome. Goodbye.

Bye. 